UNIVERSIDADE DE SÃO PAULO

ESCOLA DE ENGENHARIA DE SÃO CARLOS

DEPARTAMENTO DE ENGENHARIA MECÂNICA

\title{
ANÁLISE DINÂMICA TEÓRICA E EXPERIMENTAL DE VIGAS FABRICADAS A PARTIR DE MATERIAIS COMPÓSITOS POLIMÉRICOS REFORÇADOS
}

\author{
Eng $^{\circ}$ Volnei Tita
}

Dissertação apresentada à Escola de Engenharia de São Carlos da Universidade de São Paulo, como parte dos requisitos para obtenção do título de Mestre em Engenharia Mecânica

ORIENTADOR: Prof. Dr. Jonas de Carvalho

São Carlos

1999 
“...Designing with any material is often more art than science...our desire is to use as much science as possible for designing with composites."

(TSAI, 1986) 
Aos meus pais pelo enorme apoio.

À Sandra pelo amor e compreensão. 


\section{AGRADECIMENTOS}

Ao Professor Jonas de Carvalho, por me conceder a possibilidade de desenvolver este trabalho.

Ao Professor João Lirani, pela amizade e constante disponibilidade.

Aos Professores José Marcondes Agnelli e Paulo Sérgio Varoto, pelas grandes contribuições que enriqueceram o trabalho.

Aos colegas e companheiros do grupo CAD/CAE, pelos momentos de diversão e alegria.

À "galera das salinhas" de estudo, pelos momentos de descontração.

Aos graduandos em engenharia mecânica Rafael Ramos e Rafael Zitto, pelo apoio técnico durante o desenvolvimento do trabalho.

Ao Eng. Marcelo Uller, pelo grande apoio dado durante a fabricação das amostras.

Ao Eng. Marcelo Dalla, pelo auxilio durante os ensaios experimentais.

Às secretárias da pós-graduação, Ana Paula e Beth, por auxiliarem nas questões burocráticas.

Aos funcionários da secretária do departamento de Engenharia Mecânica que sempre estiveram dispostos ao atendimento.

Ao CNPq (Conselho Nacional de Desenvolvimento Científico e Tecnológico), pela bolsa de estudo concedida.

A Deus, principalmente, por permitir realizar este trabalho. 


\section{SUMÁRIO}

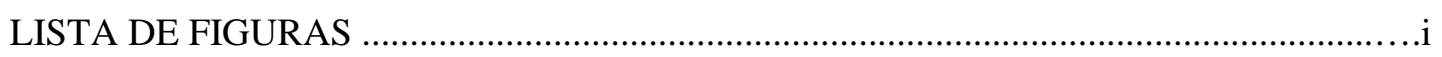

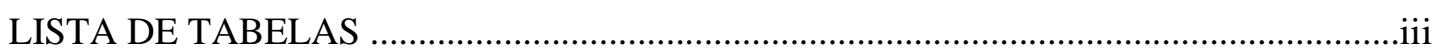

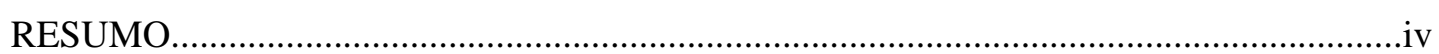

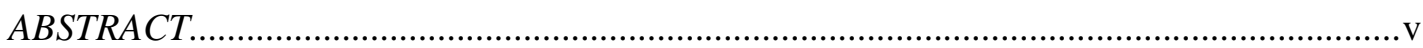

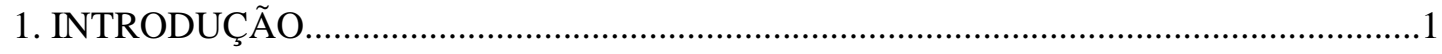

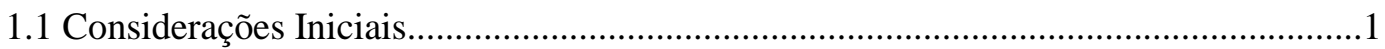

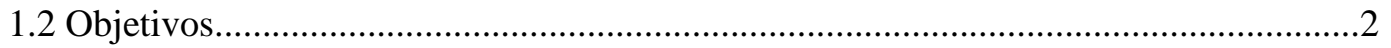

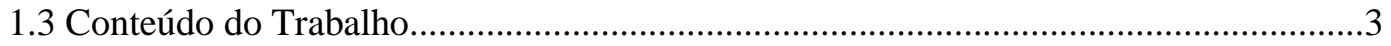

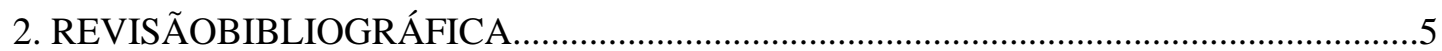

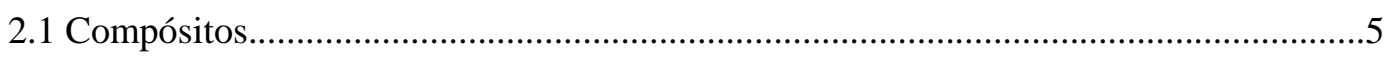

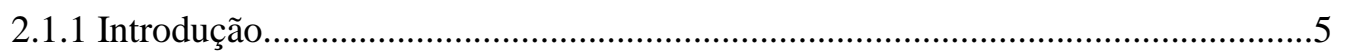

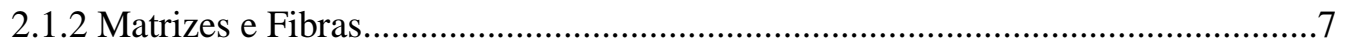

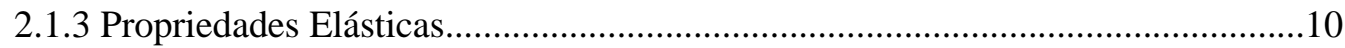

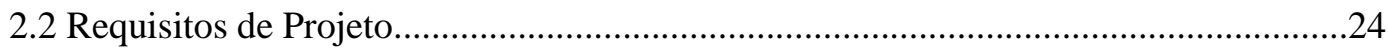

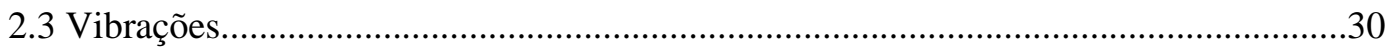

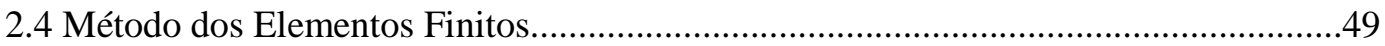

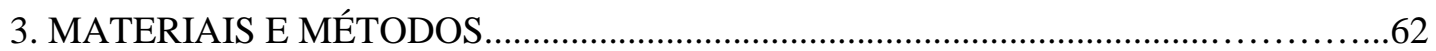

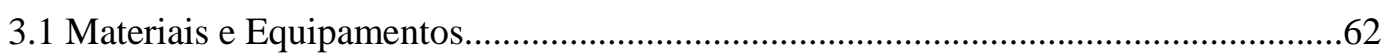

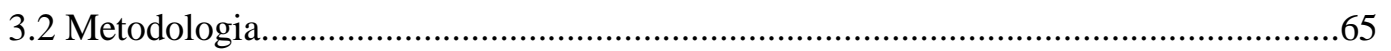

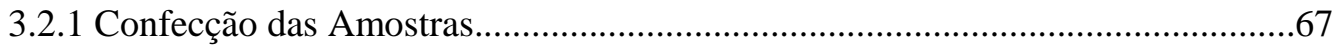

3.2.2 Análise Modal via Método dos Elementos Finitos..............................................72

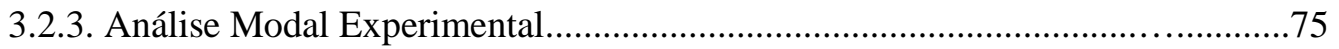


5. PROPOSTA DE CICLO DE PROJETO PARA COMPÓSITOS SOLICITADOS DINAMICAMENTE.

6. CONCLUSÕES E SUGESTÕES

REFERÊNCIAS BIBLIOGRÁFICAS. 114 APÊNDICE A: ANÁLISE DE MATERIAL COMPÓSITO UTILIZANDO ANSYS 5.2 .

APÊNDICE B: ANÁLISE MODAL UTILIZANDO ANSYS 5.2. 124

GLOSSÁRIO 


\section{LISTA DE FIGURAS}

FIGURA (2.1.1-1) - Esquema de classificação para materiais compósitos....................7

FIGURA (2.1.3-1) - Abordagem micromecânica e macromecânica............................11

FIGURA (2.1.3-2) - O laminado e suas direções principais................................12

FIGURA (2.1.3-3) - Lâmina de material compósito..........................................18

FIGURA (2.1.3-4) - Tensões Normais (N), Tensões de Cisalhamento (Q) e Momentos (M)

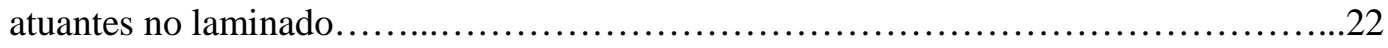

FIGURA (2.2-1) - Ciclo de projeto para compósitos................................27

FIGURA (2.3-1) - Viga engastada-livre de comprimento L...........................31

FIGURA (2.3-2) - Resposta do Sistema Sub-Amortecido............................... 37

FIGURA (2.3-3) - Amplificação da Ressonância...........................................39

FIGURA (2.3-4) - Largura de banda na frequência de ressonância...........................40

FIGURA (2.3-5) - Energia de amortecimento real e equivalente por ciclo.................41

FIGURA (2.3-6) - Força de amortecimento histerético x deslocamento.....................44

FIGURA (2.3-7) - Propriedades do gráfico polar (Círculo Modal).......................45

FIGURA (2.3-8) - Método de KENNEDY \& PANCU para determinação de um sistema

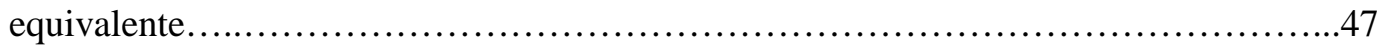

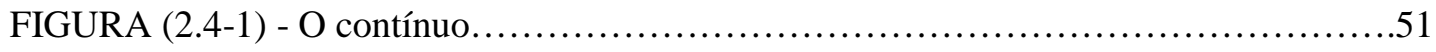

FIGURA (2.4-2) - O contínuo discretizado por inúmeros elementos......................51

FIGURA (2.4-3) - Típico Pós-Processamento de um pacote comercial......................53

FIGURA (3.2-1) - Laminado com os respectivos ângulos de orientação de cada camada....65

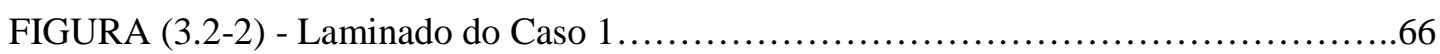

FIGURA (3.2-3) - Laminado do Caso 2 ...............................................66

FIGURA (3.2.1-1) - Máquina de Lay-Up.......................................69

FIGURA (3.2.1-2) - Sequência de Empilhamento (stacking sequence).....................70

FIGURA (3.2.1-3) - Laminado prensado pelos grampos e a madeira......................71

FIGURA (3.2.1-4) - Laminado sofrendo o processo de cura sob pressão....................71

FIGURA (3.2.1-5) - Dimensões da Amostra............................................ 72

FIGURA (3.2.2-1) - Geometria do modelo.............................................. 73 
FIGURA (3.2.2-2) - Modelo discretizado vinculado.................................. 74

FIGURA (3.2.2-3) - Modelo a ser solucionado....................................... 75

FIGURA (3.2.3-1) - Caminhos percorridos para o cálculo da resposta no domínio do tempo

(1- Convolução) e da frequência (2- Multiplicação).....................................78

FIGURA (3.2.3-2) - Ensaio experimental............................................. 79

FIGURA (3.2.3-3) - Pontos de obtenção da FRF (Função de Resposta em Frequência)......79

FIGURA (3.2.3-4) - Método da Amplitude do Pico da Análise Modal.........................80

FIGURA (4-1) - Comparação entre as frequências naturais do Caso 1 e do Caso 2 via

MEF. .84

FIGURA (4-2) - Modos de vibrar da viga engastada.................................. 85

FIGURA (4-3) - Pontos de obtenção da FRF (Função de Resposta em Frequência).........87

FIGURA (4-4) - FRFs (H21) do Caso 1 e do Caso 2 .................................. 88

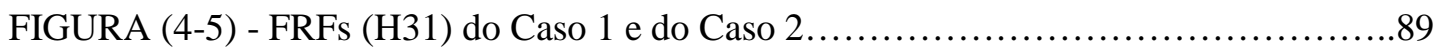

FIGURA (4-6) - FRFs (H21 e H31) do Caso 1........................................... 90

FIGURA (4-7) - FRFs (H21 e H31) do Caso 2 ......................................... 91

FIGURA (4-8) - Comparação entre as frequências naturais do Caso 1 e do Caso 2..........94

FIGURA (4-9a) - Comparação entre as frequências naturais experimentais e via MEF do Caso1.... .97

FIGURA (4-9b) - Comparação entre as frequências naturais experimentais e via MEF do Caso2. .97

FIGURA (4-9c) - Regressões lineares entre as frequências naturais experimentais e via MEF

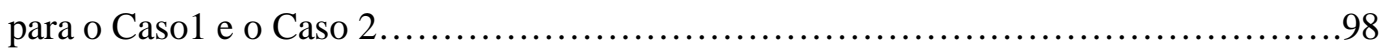

FIGURA (4-10) - Círculo modal ajustado pelo Método de Kennedy e Pancu para estimar o amortecimento à flexão no Caso 1 (sáida do programa freq) 101

FIGURA (4-11) - Círculo modal ajustado pelo Método de Kennedy e Pancu para estimar o amortecimento à flexão no Caso 2 (sáida do programa freq)

FIGURA (4-12) - Círculo modal ajustado pelo Método de Kennedy e Pancu para estimar o amortecimento à torção no Caso 1 (sáida do programa freq) 102

FIGURA (4-13) - Círculo modal ajustado pelo Método de Kennedy e Pancu para estimar o amortecimento à torção no Caso 2 (sáida do programa freq) ...........................103

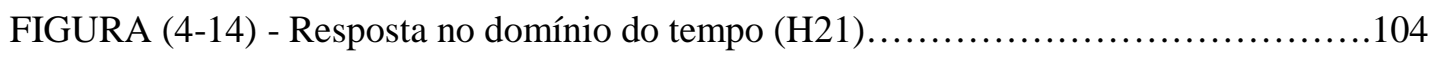

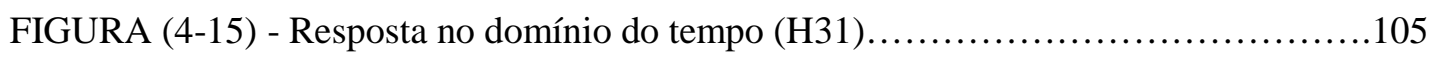

FIGURA (5-1) - Ciclo de projeto para compósitos solicitados dinamicamente..............108 


\section{LISTA DE TABELAS}

TABELA (2.1.2-1) - Propriedades de fibras de reforço para compósitos.................................9

TABELA (2.1.2-2) - Constantes Elásticas............................................................................14

TABELA (3.1-1) - Propriedades da fibra de vidro tipo E (E-glass) ........................62

TABELA (3.1-2) - Propriedades de uma resina epoxi para fins estruturais..................63

TABELA (3.1-3) - Propriedades de uma lâmina de material compósito.....................63

TABELA (3.2.1-1) - Processo de Fabricação de FRP durante 1986-1990..................68

TABELA (3.2.2-1) - Propriedades adotadas na análise ................................73

TABELA (4-1a) - Resultados obtidos via MEF...................................... 84

TABELA (4-1b) - Modos de vibrar e suas correspondentes frequências naturais via MEF..86

TABELA (4-2) - Resultados Experimentais de $\mathrm{H}_{21}$ para o Caso 1 e para o Caso 2...........92

TABELA (4-3) - Resultados Experimentais de $\mathrm{H}_{31}$ para o Caso 1 e para o Caso2 ............93

TABELA (4-4) - Resultados numéricos e experimentais $\left(\mathrm{H}_{21}\right)$ para o Caso 1.................95

TABELA (4-5) - Resultados numéricos e experimentais $\left(\mathrm{H}_{21}\right)$ para o $\underline{\text { Caso } 2 . . . . . . . . . . . . . . . . . .96 ~}$

TABELA (4-6) - Fatores de Amortecimento estimados para o Caso 1 e o Caso 2...........99 


\section{RESUMO}

TITA, V. (1999). Análise dinâmica teórica e experimental de vigas fabricadas a partir de materiais compósitos poliméricos reforçados. São Carlos, 1999. 125p. Dissertação (Mestrado) - Escola de Engenharia de São Carlos, Universidade de São Paulo.

Os materiais compósitos (composites) poliméricos reforçados são bem conhecidos por sua excelente combinação de alta rigidez estrutural e baixo peso. Sua inerente anisotropia permite ao projetista customizar as propriedades do material juntamente com as características geométricas e funcionais da peça de maneira a se obter o desempenho desejado. Desta forma, é de fundamental importância que o projetista disponha de ferramentas de auxílio para análise e otimização que possibilitem dimensionar de modo rápido e seguro a peça a ser fabricada considerando-se os requisitos estruturais, características funcionais e restrições impostas pelo processo de fabricação. Dentre esses requisitos, considera-se o comportamento dinâmico de componentes fabricados a partir destes materiais. Sendo assim, confeccionou-se amostras na forma de vigas através do processo de hand-lay-up (moldagem manual) seguido de uma moldagem sob pressão e aquecimento. Um banco de ensaios foi montado com amostras a base de resina epoxi e fibra de vidro possuindo diferentes sequências de empilhamento de lâminas para a realização de uma análise modal. A partir dos resultados obtidos experimentalmente, buscou-se verificar a influência da sequência de empilhamento das lâminas nas frequências naturais e nos fatores de amortecimento modal. Tais experimentos foram também utilizados para validar os resultados do modelo teórico proveniente de uma análise numérica realizada pelo método dos elementos finitos. Finalizando, o trabalho propõe um ciclo de desenvolvimento de projeto para estes componentes integrando procedimentos de simulação numérica e experimentais visando a otimização do projeto do componente com maior rapidez, confiabilidade e menor custo.

Palavras-chave: compósitos, método dos elementos finitos, vibrações, projeto, análise modal e amortecimento 


\begin{abstract}
TITA, V. (1999). Theoretical and experimental dynamic analysis of beams manufactured from polymer reinforced composites. São Carlos, 1999. 125p. Dissertação (Mestrado) Escola de Engenharia de São Carlos, Universidade de São Paulo.
\end{abstract}

The composite materials are well known by their excellent combination of high structural stiffness and low weight. Their inherent anisotropy allows the designer to tailor the material in order to achieve the desired performance requirements. Thus, it is of fundamental importance to develop tools that allow the designer to obtain optimized designs considering the structural requirements, functional characteristics and restrictions imposed by the production process. Within these requirements, this work considers the dynamic behavior of components manufactured from polymer reinforced materials (epoxy and glass fiber). To this end, some beams were made using the hand-lay-up process followed by a molding under pressure and heating. A set of experimental dynamic tests were carried out using samples with different fiber orientations and stacking sequences. From the results, the influence of the fibers orientations as well as the stacking sequences on the natural frequencies and modal damping were investigate. Also, these experiments were used to validate the theoretical model and the results obtained from the finite element analysis. Finally, it was proposed a design cycle which integrates experimental and theoretical procedures in order to get optimized designs in a faster and reliable way.

Keywords: composites, finite element method, design optimization, modal analysis, vibration. 
“...Designing with any material is often more art than science...our desire is to use as much science as possible for designing with composites."

(TSAI, 1986) 
Aos meus pais pelo enorme apoio.

À Sandra pelo amor e compreensão. 


\section{AGRADECIMENTOS}

Ao Professor Jonas de Carvalho, por me conceder a possibilidade de desenvolver este trabalho.

Ao Professor João Lirani, pela amizade e constante disponibilidade.

Aos Professores José Marcondes Agnelli e Paulo Sérgio Varoto, pelas grandes contribuições que enriqueceram o trabalho.

Aos colegas e companheiros do grupo CAD/CAE, pelos momentos de diversão e alegria.

À "galera das salinhas" de estudo, pelos momentos de descontração.

Aos graduandos em engenharia mecânica Rafael Ramos e Rafael Zitto, pelo apoio técnico durante o desenvolvimento do trabalho.

Ao Eng. Marcelo Uller, pelo grande apoio dado durante a fabricação das amostras.

Ao Eng. Marcelo Dalla, pelo auxilio durante os ensaios experimentais.

Às secretárias da pós-graduação, Ana Paula e Beth, por auxiliarem nas questões burocráticas.

Aos funcionários da secretária do departamento de Engenharia Mecânica que sempre estiveram dispostos ao atendimento.

Ao CNPq (Conselho Nacional de Desenvolvimento Científico e Tecnológico), pela bolsa de estudo concedida.

A Deus, principalmente, por permitir realizar este trabalho. 


\section{SUMÁRIO}

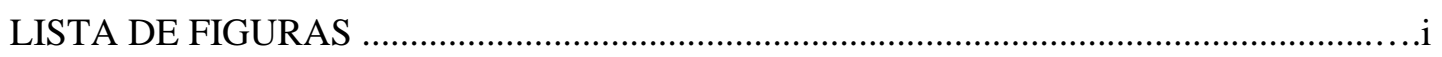

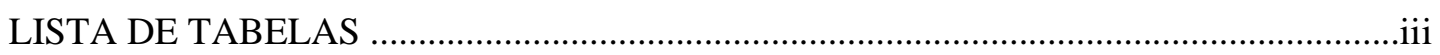

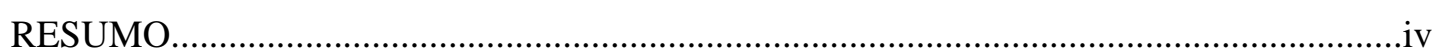

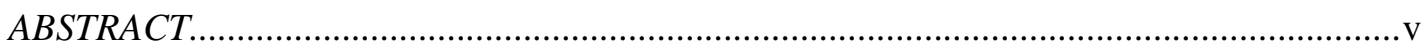

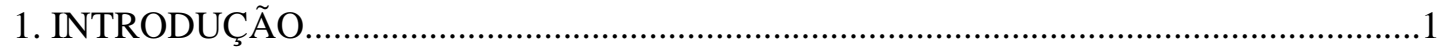

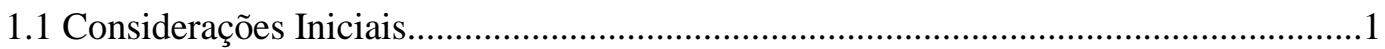

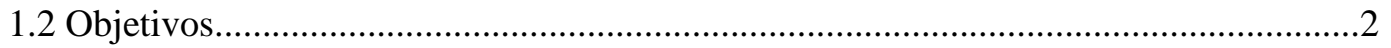

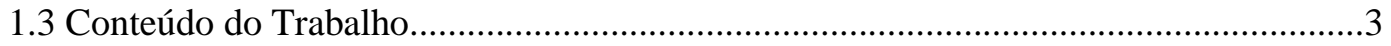

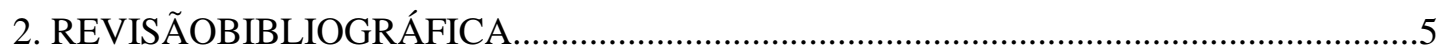

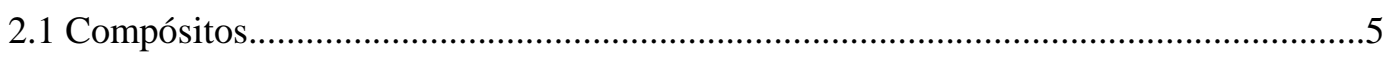

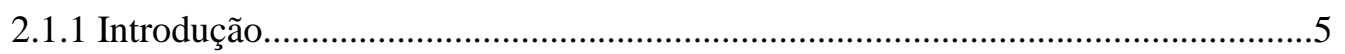

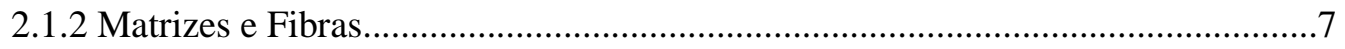

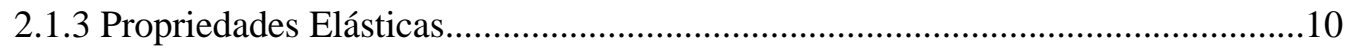

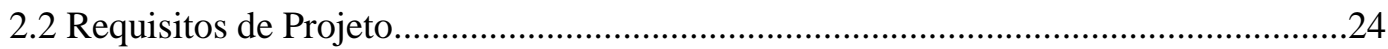

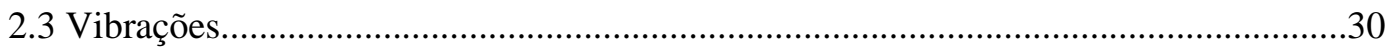

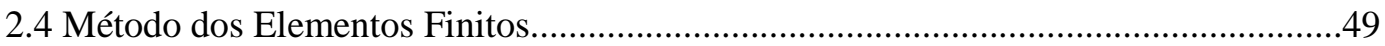

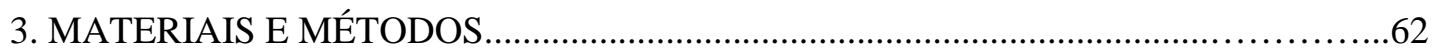

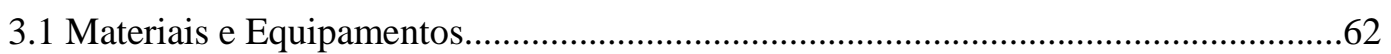

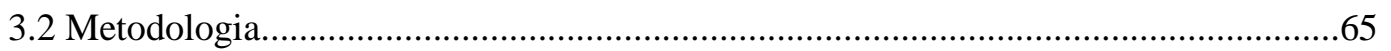

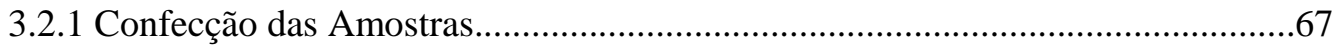

3.2.2 Análise Modal via Método dos Elementos Finitos..............................................72

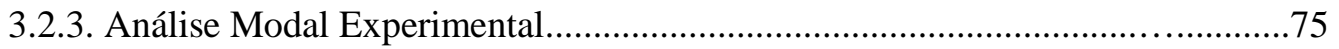


5. PROPOSTA DE CICLO DE PROJETO PARA COMPÓSITOS SOLICITADOS DINAMICAMENTE.

6. CONCLUSÕES E SUGESTÕES

REFERÊNCIAS BIBLIOGRÁFICAS. 114 APÊNDICE A: ANÁLISE DE MATERIAL COMPÓSITO UTILIZANDO ANSYS 5.2 .

APÊNDICE B: ANÁLISE MODAL UTILIZANDO ANSYS 5.2. 124

GLOSSÁRIO 


\section{LISTA DE FIGURAS}

FIGURA (2.1.1-1) - Esquema de classificação para materiais compósitos....................7

FIGURA (2.1.3-1) - Abordagem micromecânica e macromecânica............................11

FIGURA (2.1.3-2) - O laminado e suas direções principais................................12

FIGURA (2.1.3-3) - Lâmina de material compósito..........................................18

FIGURA (2.1.3-4) - Tensões Normais (N), Tensões de Cisalhamento (Q) e Momentos (M)

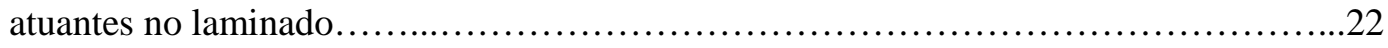

FIGURA (2.2-1) - Ciclo de projeto para compósitos................................27

FIGURA (2.3-1) - Viga engastada-livre de comprimento L...........................31

FIGURA (2.3-2) - Resposta do Sistema Sub-Amortecido............................... 37

FIGURA (2.3-3) - Amplificação da Ressonância...........................................39

FIGURA (2.3-4) - Largura de banda na frequência de ressonância...........................40

FIGURA (2.3-5) - Energia de amortecimento real e equivalente por ciclo.................41

FIGURA (2.3-6) - Força de amortecimento histerético x deslocamento.....................44

FIGURA (2.3-7) - Propriedades do gráfico polar (Círculo Modal).......................45

FIGURA (2.3-8) - Método de KENNEDY \& PANCU para determinação de um sistema

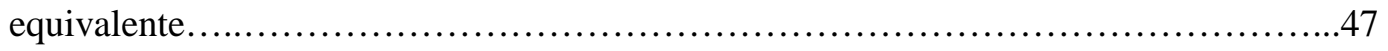

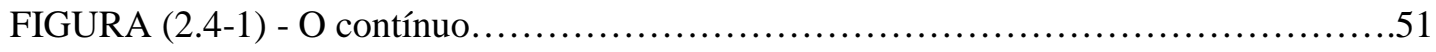

FIGURA (2.4-2) - O contínuo discretizado por inúmeros elementos......................51

FIGURA (2.4-3) - Típico Pós-Processamento de um pacote comercial......................53

FIGURA (3.2-1) - Laminado com os respectivos ângulos de orientação de cada camada....65

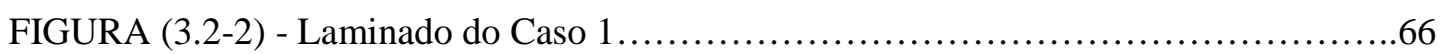

FIGURA (3.2-3) - Laminado do Caso 2 ...............................................66

FIGURA (3.2.1-1) - Máquina de Lay-Up.......................................69

FIGURA (3.2.1-2) - Sequência de Empilhamento (stacking sequence).....................70

FIGURA (3.2.1-3) - Laminado prensado pelos grampos e a madeira......................71

FIGURA (3.2.1-4) - Laminado sofrendo o processo de cura sob pressão....................71

FIGURA (3.2.1-5) - Dimensões da Amostra............................................ 72

FIGURA (3.2.2-1) - Geometria do modelo.............................................. 73 
FIGURA (3.2.2-2) - Modelo discretizado vinculado.................................. 74

FIGURA (3.2.2-3) - Modelo a ser solucionado....................................... 75

FIGURA (3.2.3-1) - Caminhos percorridos para o cálculo da resposta no domínio do tempo

(1- Convolução) e da frequência (2- Multiplicação).....................................78

FIGURA (3.2.3-2) - Ensaio experimental............................................. 79

FIGURA (3.2.3-3) - Pontos de obtenção da FRF (Função de Resposta em Frequência)......79

FIGURA (3.2.3-4) - Método da Amplitude do Pico da Análise Modal.........................80

FIGURA (4-1) - Comparação entre as frequências naturais do Caso 1 e do Caso 2 via

MEF. .84

FIGURA (4-2) - Modos de vibrar da viga engastada.................................. 85

FIGURA (4-3) - Pontos de obtenção da FRF (Função de Resposta em Frequência).........87

FIGURA (4-4) - FRFs (H21) do Caso 1 e do Caso 2 .................................. 88

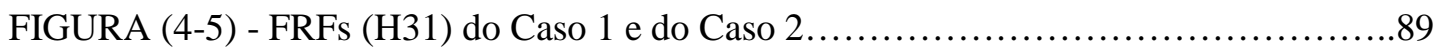

FIGURA (4-6) - FRFs (H21 e H31) do Caso 1........................................... 90

FIGURA (4-7) - FRFs (H21 e H31) do Caso 2 ......................................... 91

FIGURA (4-8) - Comparação entre as frequências naturais do Caso 1 e do Caso 2..........94

FIGURA (4-9a) - Comparação entre as frequências naturais experimentais e via MEF do Caso1.... .97

FIGURA (4-9b) - Comparação entre as frequências naturais experimentais e via MEF do Caso2. .97

FIGURA (4-9c) - Regressões lineares entre as frequências naturais experimentais e via MEF

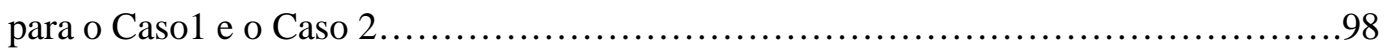

FIGURA (4-10) - Círculo modal ajustado pelo Método de Kennedy e Pancu para estimar o amortecimento à flexão no Caso 1 (sáida do programa freq) 101

FIGURA (4-11) - Círculo modal ajustado pelo Método de Kennedy e Pancu para estimar o amortecimento à flexão no Caso 2 (sáida do programa freq)

FIGURA (4-12) - Círculo modal ajustado pelo Método de Kennedy e Pancu para estimar o amortecimento à torção no Caso 1 (sáida do programa freq) 102

FIGURA (4-13) - Círculo modal ajustado pelo Método de Kennedy e Pancu para estimar o amortecimento à torção no Caso 2 (sáida do programa freq) ...........................103

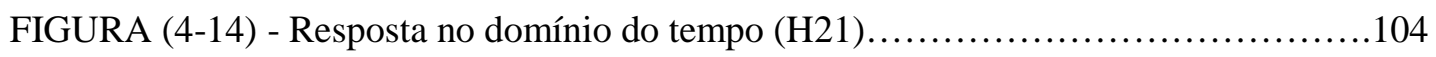

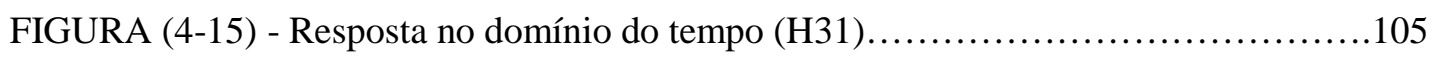

FIGURA (5-1) - Ciclo de projeto para compósitos solicitados dinamicamente..............108 


\section{LISTA DE TABELAS}

TABELA (2.1.2-1) - Propriedades de fibras de reforço para compósitos.................................9

TABELA (2.1.2-2) - Constantes Elásticas............................................................................14

TABELA (3.1-1) - Propriedades da fibra de vidro tipo E (E-glass) ........................62

TABELA (3.1-2) - Propriedades de uma resina epoxi para fins estruturais..................63

TABELA (3.1-3) - Propriedades de uma lâmina de material compósito.....................63

TABELA (3.2.1-1) - Processo de Fabricação de FRP durante 1986-1990..................68

TABELA (3.2.2-1) - Propriedades adotadas na análise ................................73

TABELA (4-1a) - Resultados obtidos via MEF...................................... 84

TABELA (4-1b) - Modos de vibrar e suas correspondentes frequências naturais via MEF..86

TABELA (4-2) - Resultados Experimentais de $\mathrm{H}_{21}$ para o Caso 1 e para o Caso 2...........92

TABELA (4-3) - Resultados Experimentais de $\mathrm{H}_{31}$ para o Caso 1 e para o Caso2 ............93

TABELA (4-4) - Resultados numéricos e experimentais $\left(\mathrm{H}_{21}\right)$ para o Caso 1.................95

TABELA (4-5) - Resultados numéricos e experimentais $\left(\mathrm{H}_{21}\right)$ para o $\underline{\text { Caso } 2 . . . . . . . . . . . . . . . . . .96 ~}$

TABELA (4-6) - Fatores de Amortecimento estimados para o Caso 1 e o Caso 2...........99 


\section{RESUMO}

TITA, V. (1999). Análise dinâmica teórica e experimental de vigas fabricadas a partir de materiais compósitos poliméricos reforçados. São Carlos, 1999. 125p. Dissertação (Mestrado) - Escola de Engenharia de São Carlos, Universidade de São Paulo.

Os materiais compósitos (composites) poliméricos reforçados são bem conhecidos por sua excelente combinação de alta rigidez estrutural e baixo peso. Sua inerente anisotropia permite ao projetista customizar as propriedades do material juntamente com as características geométricas e funcionais da peça de maneira a se obter o desempenho desejado. Desta forma, é de fundamental importância que o projetista disponha de ferramentas de auxílio para análise e otimização que possibilitem dimensionar de modo rápido e seguro a peça a ser fabricada considerando-se os requisitos estruturais, características funcionais e restrições impostas pelo processo de fabricação. Dentre esses requisitos, considera-se o comportamento dinâmico de componentes fabricados a partir destes materiais. Sendo assim, confeccionou-se amostras na forma de vigas através do processo de hand-lay-up (moldagem manual) seguido de uma moldagem sob pressão e aquecimento. Um banco de ensaios foi montado com amostras a base de resina epoxi e fibra de vidro possuindo diferentes sequências de empilhamento de lâminas para a realização de uma análise modal. A partir dos resultados obtidos experimentalmente, buscou-se verificar a influência da sequência de empilhamento das lâminas nas frequências naturais e nos fatores de amortecimento modal. Tais experimentos foram também utilizados para validar os resultados do modelo teórico proveniente de uma análise numérica realizada pelo método dos elementos finitos. Finalizando, o trabalho propõe um ciclo de desenvolvimento de projeto para estes componentes integrando procedimentos de simulação numérica e experimentais visando a otimização do projeto do componente com maior rapidez, confiabilidade e menor custo.

Palavras-chave: compósitos, método dos elementos finitos, vibrações, projeto, análise modal e amortecimento 


\begin{abstract}
TITA, V. (1999). Theoretical and experimental dynamic analysis of beams manufactured from polymer reinforced composites. São Carlos, 1999. 125p. Dissertação (Mestrado) Escola de Engenharia de São Carlos, Universidade de São Paulo.
\end{abstract}

The composite materials are well known by their excellent combination of high structural stiffness and low weight. Their inherent anisotropy allows the designer to tailor the material in order to achieve the desired performance requirements. Thus, it is of fundamental importance to develop tools that allow the designer to obtain optimized designs considering the structural requirements, functional characteristics and restrictions imposed by the production process. Within these requirements, this work considers the dynamic behavior of components manufactured from polymer reinforced materials (epoxy and glass fiber). To this end, some beams were made using the hand-lay-up process followed by a molding under pressure and heating. A set of experimental dynamic tests were carried out using samples with different fiber orientations and stacking sequences. From the results, the influence of the fibers orientations as well as the stacking sequences on the natural frequencies and modal damping were investigate. Also, these experiments were used to validate the theoretical model and the results obtained from the finite element analysis. Finally, it was proposed a design cycle which integrates experimental and theoretical procedures in order to get optimized designs in a faster and reliable way.

Keywords: composites, finite element method, design optimization, modal analysis, vibration. 


\section{CAPÍTULO 1 INTRODUÇÃO}

\subsection{Considerações Iniciais}

Cinqüenta anos já são passados desde que os chamados materiais compósitos (do inglês "Composite materials ") foram empregados pela primeira vez em projetos estruturais, inicialmente na indústria aeronáutica. Atualmente, compósitos têm sido aplicados nos mais diferentes setores produtivos tais como automobilístico, marinha, construções civis, área médica e muitas outras. O motivo principal reside nas muitas vantagens que os compósitos potencialmente oferecem:

- Baixo peso associado com alta rigidez e resistência mecânica, que reflete diretamente na eficiência do componente e da estrutura global;

- Melhor desempenho devido à grande versatilidade de moldar o material de acordo com as necessidades de projeto. Esta versatilidade pode ser obtida através da otimização simultânea das propriedades de material, geometria do componente e processo de fabricação. Por exemplo, compósitos permitem que o material seja reforçado com fibras nas direções mais adequadas e novos processos de fabricação tem permitido que componentes de geometria complexa sejam produzidos em uma única etapa de fabricação;

- Alto potencial para redução de custos que pode ser obtida reduzindo-se o número de peças e sub-montagens, e também o custo inicial e custos associados com manutenção e reparos. Também, certos tipos de produção em grande escala como moldagem por injeção e pultrusão (Pultrusion) permitem que compósitos sejam produzidos a baixos custos e com ciclos de produção curtos.

Contudo, certos obstáculos ainda dificultam a integração dos compósitos entre os materiais estruturais utilizados convencionalmente, como aço ou alumínio. Entre tais dificuldades ressalta-se: 
- A dificuldade de prever o modo de falha exato do material. Isto reflete diretamente na confiabilidade dos componentes fabricados, e torna-se ainda mais sério para componentes de alta responsabilidade, onde a combinação de fadiga, danos por impacto, e efeitos do meio ambiente podem causar falha catastrófica;

- Embora seja amplamente aceito que compósitos apresentem uma boa resistência a corrosão, os projetistas ainda não estão totalmente convencidos sobre sua resistência à ação prolongada de combustíveis, lubrificantes e produtos químicos altamente corrosivos;

- Apesar dos esforços para automatizar processos de manufatura de compósitos, a produção manual (Hand Lay-Up) é ainda amplamente utilizada, o que eleva sobremaneira os custos de fabricação. Também certos processos de manufatura como Spray-Up e enrolamento filamentar (Filament Winding), são muitas vezes excessivamente lentos e envolvem grandes perdas de material;

- Relutância de projetistas e fabricantes habituados ao uso de materiais convencionais. Isto limita o número de informações que se tem a respeito do comportamento de componentes mecânicos que são feitos a partir de materiais compósitos;

Assim, mesmo com a presença de tais dificuldades, mantém-se um foco em projetos de peças em compósitos que possuam uma ótima combinação de desempenho, manufaturabilidade e custos.

\subsection{Objetivos}

Pretende-se contribuir para o desenvolvimento de projetos de componentes mecânicos feitos à base de material compósito polimérico reforçado, investigando o comportamento dinâmico de estruturas como por exemplo vigas através de ensaios experimentais em laboratório bem como cálculos numéricos via Método dos Elementos Finitos. Esta investigação fornecerá subsídios ao projetista permitindo a obtenção de um projeto mais otimizado estruturalmente num tempo menor. Portanto, os objetivos deste trabalho são:

a) avaliar experimentalmente o comportamento dinâmico de vigas feitas de material compósito;

b) estudar a influência da sequência do empilhamento das lâminas (stacking sequence) nas frequências naturais e portanto verificar as alterações provocadas 
nos parâmetros de rigidez e fatores de amortecimento modal da estrutura, fixando a fração volumétrica de fibra;

c) confrontar valores experimentais com valores teóricos obtidos via Método dos Elementos Finitos, buscando a validação de modelos teóricos para futuras utilizações em projetos de componentes mecânicos que necessitam de uma análise mais complexa;

d) demonstrar a versatilidade que os materiais compósitos poliméricos reforçados possuem, quando utilizados em projetos mecânicos que requerem um comportamento dinâmico especificado. E desta maneira, propor um ciclo de projeto para materiais compósitos poliméricos reforçados;

\subsection{Conteúdo do Trabalho}

O trabalho está organizado de tal forma que haja primeiramente um entendimento global sobre materiais compósitos e suas características, destacando os materiais compósitos poliméricos reforçados e sua potencialidade para projetos. Em seguida, discuti-se o ciclo de projeto para este tipo de material. Reflete-se, então, sobre os requisitos de projeto, dentre os quais destacam-se os problemas de vibração. Com o auxílio de técnicas laboratoriais bem como ferramentas computacionais, levantam-se informações, criando assim uma nova proposta de ciclo de projeto. Portanto, tem-se os seguintes capítulos:

\section{- Capítulo 2 - Revisão Bibliográfica}

É constituído por quatro seções: a primeira faz uma abordagem geral sobre materiais compósitos, destacando propriedades e características; a segunda destaca a utilização de materiais compósitos para o desenvolvimento de projetos bem como os requisitos necessários para tal; a terceira discute em específico os problemas de vibração presentes em componentes e para finalizar, a quarta apresenta como a análise numérica via Método dos Elementos Finitos pode auxiliar o desenvolvimento de projetos de materiais compósitos que apresentem problemas de vibração.

\section{- Capítulo 3 - Materiais e Métodos}

É constituído por duas seções: a primeira trata do material compósito analisado e dos equipamentos utilizados durante as análises; a segunda mostra o método de confecção das amostras, os ensaios de vibração realizados e o processo de análise via Método dos Elementos Finitos. 


\section{- Capítulo 4 - Resultados e Discussões}

Apresenta-se os resultados provenientes dos ensaios laboratoriais bem como os provenientes do cálculo computacional. É então feita uma comparação entre tais resultados com a finalidade de se discutir e analisar suas convergências e divergências bem como correlacioná-los com a teoria proposta no Capítulo 2.

\section{- Capítulo 5- Proposta de ciclo de projeto para compósitos}

Propõe-se um ciclo de desenvolvimento de projetos de componentes mecânicos a base de materiais compósitos que sejam solicitados dinamicamente com base nos resultados analisados no Capítulo 4. Um fluxograma é demonstrado seguido de uma descrição de cada etapa do desenvolvimento do projeto bem como estas etapas interagem entre si.

\section{- Capítulo 6- Conclusões e Sugestões}

Demonstra-se a gama de possibilidades que o projetista possui ao projetar um componente a base de materiais compósitos poliméricos reforçados, e como auxiliá-lo para que se obtenha de maneira rápida e eficiente um produto otimizado que atenda aos requisitos exigidos. Por fim destacam-se futuros trabalhos que podem ainda ser desenvolvidos neste âmbito.

\section{Referências Bibliográficas}

Contém as fontes das referências bibliográficas utilizadas para o desenvolvimento do trabalho.

\section{Apêndice A - Análise de material compósito utilizando ANSYS 5.2}

Descreve os tipos de elementos finitos existentes para modelar materiais compósitos, bem como possibilidades de entradas (input), saídas (output) e características fornecidas pelos mesmos.

\section{Apêndice B - Análise Modal utilizando ANSYS 5.2}

Descreve o procedimento pelo qual o pacote computacional obtém as frequências naturais não amortecidas e os modos de vibrar de uma estrutura.

\section{Glossário}

Constitui-se de termos muito utilizados em trabalhos que abordam materiais compósitos. 


\section{CAPÍTULO 2 \\ REVISÃO BIBLIOGRÁFICA}

\subsection{Compósitos}

\subsubsection{Introdução}

Muitas das tecnologias modernas requerem materiais com combinações de propriedades não usualmente satisfeitas pelas ligas de metais convencionais, cerâmicas e materiais poliméricos, especialmente em se tratando da área aeronáutica, onde são necessárias baixa densidade, alta resistência, rigidez e resistência à abrasão e ao impacto. $\mathrm{O}$ acelerado desenvolvimento de materiais compósitos reforçados, ocorrido acentuadamente nos últimos anos, tem propiciado aos projetistas novas alternativas para solucionar tais problemas, fornecendo-lhes um novo leque de possibilidades.

Um material multifase exibindo uma combinação de propriedades que o torna superior a cada fase de sua composição pode ser considerado um compósito.(CALLISTER, 1985). De acordo com esse princípio de ação combinada, procura-se moldar os melhores arranjos de propriedades por uma combinação criteriosa de dois ou mais materiais distintos. Esses materiais que formam o compósito podem ser classificados como aglomerante (fase contínua ou matriz) ou reforçante (fase dispersa). A matriz tem como função manter os reforçantes unidos, transmitindo a estes o carregamento aplicado. Os reforçantes têm como função suportar os carregamentos transmitidos pela matriz. Devido a grande variedade de matrizes (aglomerantes) e reforçantes, CALLISTER (1985) decidiu classificá-los como: compósitos reforçados por partículas, compósitos reforçados por fibras e compósitos estruturais. A FIGURA (2.1.1-1) apresenta uma idéia da gama de materiais compósitos que podem ser obtidos. Dentre os principais fatores que tornam tais materiais tão atraentes está o reduzido peso que se pode obter, sem entretanto pecar no que diz respeito à propriedades mecânicas do produto final.

No caso de componentes que utilizam materiais poliméricos como aglomerante e fibras de vidro como reforçantes (laminados), o baixo peso é garantido pela matriz utilizada, que em geral apresenta baixa densidade. Em MATTHEWS \& RAWLINGS (1994) constata- 
se que a densidade do compósito depende das densidades dos constituintes e das proporções que eles aparecem:

$$
\rho_{\mathrm{c}}=\rho_{\mathrm{f}} \mathrm{V}_{\mathrm{f}}+\rho_{\mathrm{m}} \mathrm{V}_{\mathrm{m}}
$$

onde:

$\rho=$ densidade

$\mathrm{V}=$ fração volumétrica

Subíndice $\mathrm{c}=$ indica o compósito

Subíndice $\mathrm{m}=$ indica a matriz

Subíndice $\mathrm{f}=$ indica a fibra

Outro aspecto interessante é a inerente anisotropia, ou seja, a presença de propriedades mecânicas, físicas, térmicas e elétricas diferenciadas direcionalmente ao longo do material. Isto permite ao projetista desenvolver as propriedades do material juntamente com as características geométricas e funcionais da peça, com o objetivo de se obter a performance desejada.(VINSON \& SIERAKOWSKI, 1986). Segundo CARVALHO (1996) no projeto de um componente feito de material compósito é extremamente necessária a atenção no que se diz respeito às particularidades que ele apresenta, tais como:

1-Diferentes propriedades mecânicas dependendo da orientação da fibra na peça (anisotropia);

2-Escolha apropriada das fases, ou seja, dos reforçantes e aglomerantes e suas proporções a fim de se obter o comportamento desejado;

3-Fatores de processamento que influem nas propriedades do produto obtido.

Adicionalmente, o projetista deve estar atento aos aspectos de segurança no processo, efeitos ambientais e custos associados. 


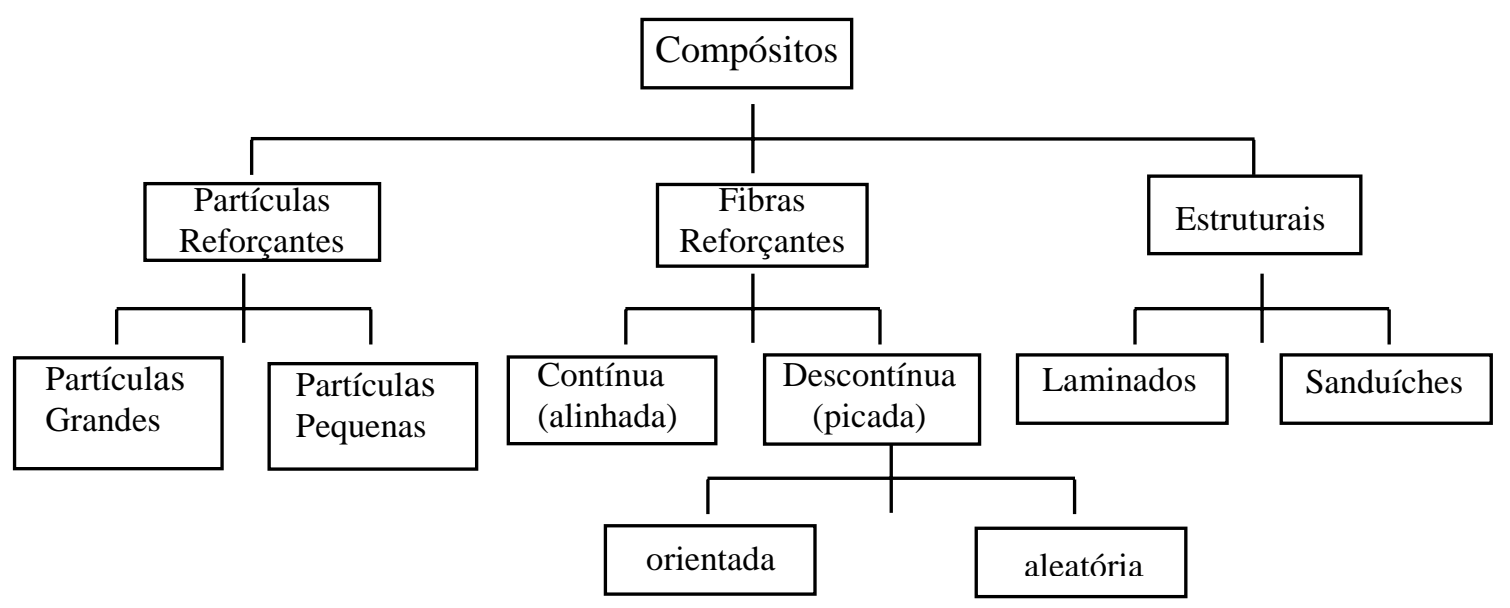

FIGURA (2.1.1-1) - Esquema de classificação para materiais compósitos

CALLISTER (1985)

\subsubsection{Matrizes e Fibras}

\section{Matrizes (Fase Contínua)}

A fase contínua de um compósito é conhecida como matriz. As matrizes podem ser materiais poliméricos, metálicos ou cerâmicos, sendo que os polímeros são os mais utilizados devido ao baixo custo e à facilidade de processamento. Como já foi comentado, uma das funções da matriz é envolver a fibra e assim permitir que os esforços atuantes na peça sejam transmitidos.

No presente trabalho, são utilizadas matrizes poliméricas, as quais podem ser classificadas como resinas termoplásticas e resinas termofixas. As termoplásticas sofrem deformações com o aumento da temperatura e por essa razão são largamente utilizadas em processos de injeção plástica. Já as resinas termofixas entram num regime chamado de cura (endurecimento) quando aquecidas, sendo essa uma reação irreversível. A cura é uma interligação química de cadeias moleculares, formando assim moléculas maiores e mais complexas, tornando o componente mais resistente. A cura ainda é acelerada na presença de catalisadores adequados e na proporção certa para cada tipo de resina. Por ser um processo exotérmico, a temperatura irá influenciar no tempo de cura, sendo portanto realizado dentro de fornos ou estufas com temperatura controlada para cada tipo de matriz. As resinas termofixas são mais comuns para uso estrutural pois apresentam um enorme número de aplicações e suas características finais geralmente são as mais desejáveis. LUCATO (1991) observou que dentre as termofixas, existem as epoxídicas que apresentam inúmeras vantagens para o desenvolvimento de projetos: 
1- Apresentam baixa viscosidade, facilitando a moldagem;

2- Fornecem baixa contração, evitando tensões residuais;

3- Possibilitam a cura à temperatura ambiente;

4- Possuem alto módulo de elasticidade e compressão;

5- Propiciam aplicações estruturais de alto desempenho.

Entretanto, as resinas epoxídicas apresentam características negativas tais como: aderência indesejável nas paredes do molde em que estão sendo processadas (BLASS, 1985), além disso não possuem a característica de reciclagem pois pertencem ao grupo das resinas termofixas. Apesar das características negativas apresentadas pelas resinas epoxídicas, ainda hoje elas são usadas em grande escala para o desenvolvimento de projetos estruturais, justificando sua utilização neste trabalho.

\section{Fibras (Fase Dispersa)}

As fibras constituem o segundo material na composição de alguns compósitos reforçados, tendo a importante missão de suportar os esforços provenientes da matriz. Elas se apresentam basicamente em duas formas: fibra contínua ou fibra picada. Um importante fator a ser considerado no projeto com compósitos reforçados é a orientação que a fibra assume no produto final. As propriedades mecânicas finais também dependem fortemente da quantidade de fibra empregada (fração volumétrica) e da forma que o material é processado. Fibras em forma de mantas e fios (fibra contínua) se caracterizam por fornecer reforços apenas na direção que estão dispostas, já os tecidos ortogonais (fibra contínua) permitem reforços em duas direções e as fibras picadas produzem na sua grande maioria reforços aleatórios. Portanto, o arranjo pode ser unidirecional, bidirecional ou aleatório. Os dois primeiros possuem características anisotrópicas, ou seja, suas propriedades dependem das direções do reforço no produto final (HANDBOOK of COMPOSITES, 1982). A orientação é então escolhida levando em consideração as direções dos esforços que atuam no componente. Outro aspecto a ser considerado é o comprimento da fibra, que caracterizará a rigidez de um compósito reforçado. Isto ocorre porque a rigidez do laminado depende diretamente da magnitude de tensão que a matriz consegue transmitir para as fibras. Tal fenômeno de transmissão de carregamento é função do comprimento das fibras e da adesão da mesma à matriz. Sendo assim, CALLISTER (1985) define comprimento crítico de fibra, dado por: 


$$
1_{c}=\frac{\sigma_{\mathrm{f}} \mathrm{d}}{\tau_{\mathrm{f}}}
$$

onde:

$1_{c}=$ comprimento crítico

$\sigma_{\mathrm{f}}=$ tensão de ruptura a tração

$\tau_{\mathrm{f}}=$ tensão de ruptura ao cisalhamento

$\mathrm{d}=$ diâmetro da fibra

Caso o comprimento da fibra seja igual a $1_{c}$, tem-se que o nível de tensão aplicada na peça é totalmente transmitida para a fibra, localizando o máximo carregamento na sua parte central. Se o laminado possui fibras mais longas (contínuas), a eficiência do reforço aumenta pois o máximo carregamento se distribui ao longo de boa parte da fibra. Já os componentes com fibras abaixo do comprimento crítico apresentam deformações na matriz ao redor das fibras, o que leva a uma não transferência adequada de tensão, e a um pequeno efeito de reforço por parte da fibra. Das inúmeras fibras existentes, a fibra de vidro é a mais comumente utilizada tanto na forma picada como na forma contínua devido às suas diversas aplicações, propriedades mecânicas relativamente boas e baixo custo. A TABELA (2.1.2-1) compara algumas propriedades da fibra de vidro (E-glass) com outras fibras que possuem custos mais elevados.

TABELA (2.1.2-1) - Propriedades de fibras de reforço para compósitos

\begin{tabular}{|l|c|c|c|}
\hline \multicolumn{1}{|c|}{ Fibra } & $\begin{array}{c}\text { Densidade } \rho \\
\left(\mathrm{Mg} / \mathrm{m}^{3}\right)\end{array}$ & $\begin{array}{c}\text { Módulo de Young } \\
\text { da fibra- } \mathrm{E}_{\mathrm{f}}(\mathrm{GPa})\end{array}$ & $\begin{array}{c}\text { Resistência à Tração } \\
\text { da fibra- } \sigma_{\mathrm{tf}}(\mathrm{MPa})\end{array}$ \\
\hline Fibra de Vidro(tipo E) & 2,54 & 70 & 2200 \\
\hline Aramida (Kevlar49) & 1,45 & 130 & 2900 \\
\hline SiC(Nicalon) & 2,60 & 250 & 2200 \\
\hline Alumina & 3,90 & 380 & 1400 \\
\hline Boro & 2,65 & 420 & 3500 \\
\hline $\begin{array}{l}\text { Polietileno com alto } \\
\text { peso molecular }\end{array}$ & 0,97 & 172 & 2964 \\
\hline Carbono & 1,86 & 380 & 2700 \\
\hline
\end{tabular}

MATTHEWS AND RAWLINGS (1994)

Tais informações tornam as fibras de vidro muito atrativas para a produção de compósitos principalmente com fibras contínuas. Desta forma, o presente trabalho visa a utilização de fibra de vidro contínua na forma de tecido ortogonal como material reforçante da matriz epoxídica. 


\section{Interface Fibra com Matriz}

Um ponto que merece grande atenção está relacionado à interface fibra-matriz. Para garantir que os esforços sejam transmitidos de uma fase para a outra, deve-se propiciar uma forte adesão entre a fibra de vidro (material inorgânico) e a matriz epoxídica (material orgânico). Caso não haja esta forte interação, o material ficará sujeito a falhas, tais como delaminações, e estará sujeito à propagações de trincas em maiores escalas. (SHACKELFORD, 1996). Este fato influi diretamente na escolha dos materiais a serem empregados, pois a combinação de quaisquer fases nem sempre propiciará a interação adequada fibra-matriz, sendo as vezes necessário um tratamento superficial nas fibras para que estas interajam de uma maneira melhor com as matrizes.

Como já foi comentado, os materiais compósitos possuem geralmente propriedades superiores aos materiais comuns, basta agora saber como determiná-las.

\subsubsection{Propriedades Elásticas}

As propriedades elásticas tais como módulos de elasticidade, módulos de cisalhamento e coeficiente de Poisson dos materiais compósitos poliméricos reforçados são muito atrativas para utilização destes em projetos de componentes mecânicos, pois, como foi comentado, é possível projetar o material de acordo com os carregamentos. Para isto, tornase necessário saber como determinar estas propriedades mecânicas visando uma futura otimização do material. Desta forma, são utilizados dois métodos:

A) Determinação das propriedades mecânicas através da Regra das Misturas

B) Determinação das propriedades mecânicas através de ensaios laboratoriais

Após a determinação dessas propriedades, usa-se um procedimento de cálculo bastante usual para material compósito reforçado que está baseado na Teoria Clássica de Laminados (Classical Laminates Theory). Tal teoria fornece resultados aproximados devido à complexidade das características do laminado. As propriedades elásticas de um material compósito são tratadas de forma diferenciada, pois dependem fortemente das propriedades, orientação e distribuição de cada camada. Sendo assim, VINSON \& SIERAKOWSKI (1987) analisaram os materiais compósitos sob dois pontos de vista: micromecânico e macromecânico. Pela FIGURA (2.1.3-1) é possível verificar que a abordagem micromecânica trata da fração volumétrica e propriedades da fibra bem como da matriz para caracterizar a lâmina sem levar em conta a estrutura interna dos elementos constituintes. Já a abordagem macromecânica toma uma combinação das propriedades das lâminas para 
caracterizar o laminado. Neste instante a microestrutura da lâmina é ignorada e as propriedades longitudinais e perpendiculares de alinhamento das fibras são reconhecidas. Assim, o elemento estrutural resultante (uma viga, uma placa ou uma casca) é constituído por uma combinação sistemática de lâminas.

Segundo HULL (1981) algumas suposições devem ser feitas quando utiliza-se a Teoria Clássica de Laminados:

-O material é ortotrópico, ou seja, apresenta três eixos de simetria;

-O material apresenta homogeneidade na sua composição;

-As camadas (lâminas) estão perfeitamente aderidas, não havendo deslocamento relativo entre as mesmas;

-Considera-se estado plano de tensões em cada camada;

-As propriedades finais dependem da orientação de cada camada relativa a outra subsequente.

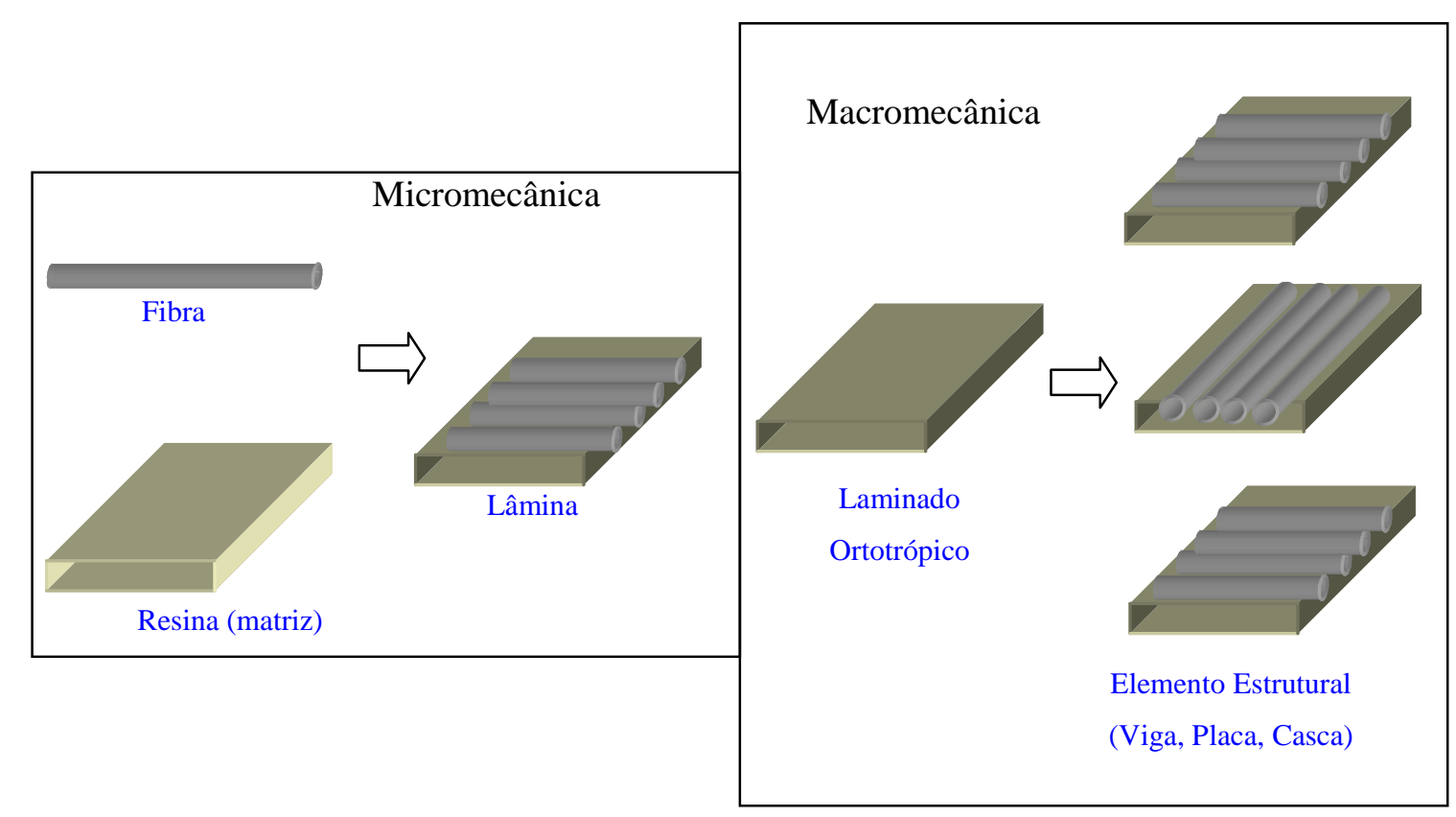

FIGURA (2.1.3-1) - Abordagem micromecânica e macromecânica

VINSON \& SIERAKOWSKI (1987)

\section{A) Propriedades mecânicas determinadas pela Regra das Misturas}

Para a análise de tensões, considera-se que a tração ou compressão aplicada paralelamente à fibra fornece as mesmas deformações para a matriz e para a fibra. Se a adesão entre as duas fases é perfeita então as tensões são dadas por: 


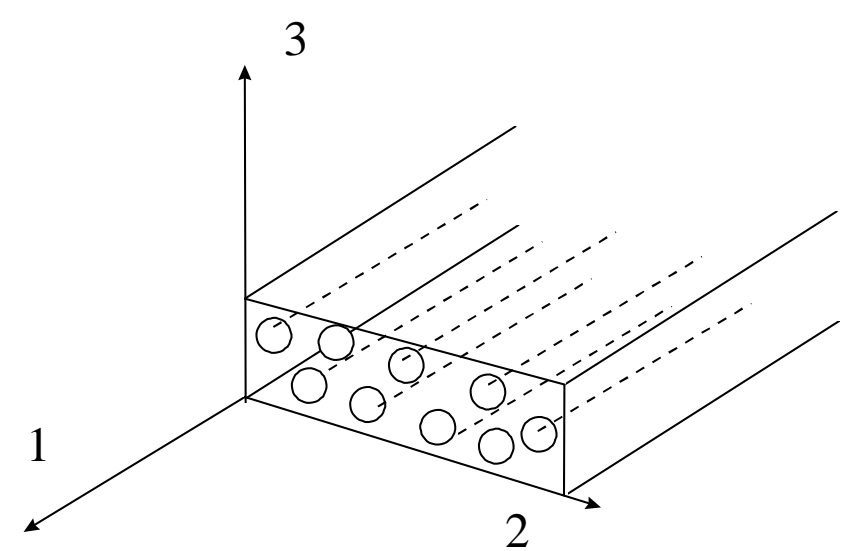

FIGURA (2.1.3-2) - O laminado e suas direções principais

HULL (1981)

$$
\begin{aligned}
& \sigma_{\mathrm{f}}=\varepsilon_{1} \cdot \mathrm{E}_{\mathrm{f}} \\
& \sigma_{\mathrm{m}}=\varepsilon_{1} \cdot \mathrm{E}_{\mathrm{m}}
\end{aligned}
$$

onde:

$\sigma_{\mathrm{m}}=$ Tensão aplicada na matriz

$\sigma_{\mathrm{f}}=$ Tensão aplicada na fibra

$\varepsilon_{1}=$ Deformação relativa na direção principal 1(longitudinal à fibra)

$\mathrm{E}_{\mathrm{f}}=$ Módulo de Elasticidade da fibra

$\mathrm{E}_{\mathrm{m}}=$ Módulo de Elasticidade da matriz

Observando a FIGURA (2.1.3-2), é possível visualizar as direções principais 1, 2 e 3. Sendo que a direção 1 esta alinhada com a fibra, a direção 2 é perpendicular a fibra e pertence ao plano do laminado. E para finalizar, a direção 3 é perpendicular ao plano do laminado.

A tensão média é dada por:

$$
\mathrm{P}=\sigma_{1} \cdot \mathrm{A}
$$

onde:

$\mathrm{P}=$ Força aplicada

$\sigma_{1}=$ Tensão aplicada na direção principal (1)

A = Área da secção transversal

Tem-se que: 


$$
\mathrm{P}=\mathrm{P}_{\mathrm{f}}+\mathrm{P}_{\mathrm{m}}
$$

onde:

$\mathrm{P}_{\mathrm{f}}=$ Força aplicada na fibra

$\mathrm{P}_{\mathrm{m}}=$ Força aplicada na matriz

Sendo assim:

$$
\begin{aligned}
& \mathrm{P}_{\mathrm{f}}=\sigma_{\mathrm{f}} \cdot \mathrm{A}_{\mathrm{f}} \\
& \mathrm{P}_{\mathrm{m}}=\sigma_{\mathrm{m}} \cdot \mathrm{A}_{\mathrm{m}}
\end{aligned}
$$

Então:

$$
\mathrm{P}=\sigma_{\mathrm{f}} \cdot \mathrm{A}_{\mathrm{f}}+\sigma_{\mathrm{m}} \cdot \mathrm{A}_{\mathrm{m}}
$$

onde:

$\mathrm{A}_{\mathrm{f}}=$ Área da seção transversal da fibra

$\mathrm{A}_{\mathrm{m}}=$ Área da seção transversal da matriz

Dada as relações:

$$
\begin{gathered}
\sigma_{1}=\varepsilon_{1} \cdot \mathrm{E}_{1} \\
\mathrm{~V}_{\mathrm{i}}=\frac{\mathrm{A}_{\mathrm{i}}}{\mathrm{A}}, \mathrm{i}=\mathrm{m} \text { ou } \mathrm{f}
\end{gathered}
$$

onde:

$\mathrm{V}_{\mathrm{i}}=$ Fração volumétrica de fibra ou matriz

$\mathrm{E}_{1}=$ Módulo de Elasticidade do compósito na direção principal

Substituindo as equações (2.1.3-1 e 2.1.3-2) e as relações acima na equação (2.1.3-7) tem-se que:

$$
\mathrm{E}_{1}=\mathrm{E}_{\mathrm{f}} \cdot \mathrm{V}_{\mathrm{f}}+\mathrm{E}_{\mathrm{m}} \cdot \mathrm{V}_{\mathrm{m}}
$$

Como,

$$
\mathrm{V}_{\mathrm{f}}+\mathrm{V}_{\mathrm{m}}=1
$$

Então,

$$
\mathrm{E}_{1}=\mathrm{E}_{\mathrm{f}} \cdot \mathrm{V}_{\mathrm{f}}+\mathrm{E}_{\mathrm{m}} \cdot\left(1-\mathrm{V}_{\mathrm{f}}\right)
$$

onde:

$\mathrm{E}_{1}=$ Módulo de Elasticidade do compósito na direção principal 
Se um raciocínio análogo for usado para solicitações perpendiculares à fibra e de cisalhamento à lâmina tém-se a seguinte equação :

$$
\mathrm{P}=\frac{\left(\mathrm{P}_{\mathrm{f}} \mathrm{V}_{\mathrm{f}}+\eta \mathrm{P}_{\mathrm{m}} \mathrm{V}_{\mathrm{m}}\right)}{\left(\mathrm{V}_{\mathrm{f}}+\eta \mathrm{V}_{\mathrm{m}}\right)}
$$

Para a determinação dos módulos de cisalhamento $\left(G_{12}\right.$ e $\left.G_{23}\right)$ do módulo de elasticidade transversal e perpendicular a lâmina, bem como do coeficiente de Poisson do compósito, VINSON \& SIERAKOWSKI (1987) apud HAHN (1980) determinaram a seguinte tabela:

TABELA (2.1.2-2) - Constantes Elásticas

\begin{tabular}{|c|c|c|c|c|}
\hline Constante Elástica & $P$ & $\mathrm{P}_{\mathrm{f}}$ & $\mathrm{P}_{\mathrm{m}}$ & $\eta$ \\
\hline$v_{12}$ & $v_{12}$ & $v_{12 \mathrm{f}}$ & $v_{\mathrm{m}}$ & 1 \\
\hline $\mathrm{G}_{12}$ & $1 / \mathrm{G}_{12}$ & $1 / \mathrm{G}_{12 \mathrm{f}}$ & $1 / \mathrm{G}_{\mathrm{m}}$ & $\eta_{6}$ \\
\hline $\mathrm{G}_{23}$ & $1 / \mathrm{G}_{23}$ & $1 / \mathrm{G}_{23 \mathrm{f}}$ & $1 / \mathrm{G}_{\mathrm{m}}$ & $\eta_{4}$ \\
\hline $\mathrm{k}_{\mathrm{t}}$ & $1 / \mathrm{k}_{\mathrm{t}}$ & $1 / \mathrm{k}_{\mathrm{t}}$ & $1 / \mathrm{k}_{\mathrm{m}}$ & $\eta_{\mathrm{k}}$ \\
\hline
\end{tabular}

VINSON \& SIERAKOWSKI (1987)

De acordo com a TABELA (2.1.2-2) e a equação (2.1.3-13) é possível calcular o coeficiente de Poisson da lâmina de compósito através dos coeficientes da fibra e da matriz. Já para os cálculos das demais constantes, surge a necessidade de mais equações, tais como:

$$
\eta_{6}=\frac{1+\frac{\mathrm{G}_{\mathrm{m}}}{\mathrm{G}_{12 \mathrm{f}}}}{2}
$$

onde:

$1 / \mathrm{G}_{12}=$ inverso do módulo de cisalhamento do compósito no plano 1-2

$1 / \mathrm{G}_{12 \mathrm{f}}=$ inverso do módulo de cisalhamento da fibra

$1 / \mathrm{G}_{\mathrm{m}}=$ inverso do módulo de cisalhamento da matriz dado por $\mathrm{G}_{\mathrm{m}}=\frac{\mathrm{E}_{\mathrm{m}}}{2 .\left(1+v_{\mathrm{m}}\right)}$ caso a matriz seja isotrópica e $v_{\mathrm{m}}$ seja o coeficiente de Poisson da matriz.

$\overline{\text { HAHN, H. T.(1980).Simplified formulas for elastic moduli of unidirectional continous fiber }}$ composites.Fall. Composites Technology Review. 
Além disso, tem-se que:

$$
\eta_{4}=\frac{3-4 v_{\mathrm{m}}+\frac{\mathrm{G}_{\mathrm{m}}}{\mathrm{G}_{23 \mathrm{f}}}}{4 .\left(1-v_{\mathrm{m}}\right)}
$$

onde:

$1 / \mathrm{G}_{23}=$ inverso do módulo de cisalhamento do compósito no plano 2-3

$1 / \mathrm{G}_{23 \mathrm{f}}=$ inverso do módulo de cisalhamento da fibra

$1 / \mathrm{G}_{\mathrm{m}}=$ inverso do módulo de cisalhamento da matriz dado por $\mathrm{G}_{\mathrm{m}}=\frac{\mathrm{E}_{\mathrm{m}}}{2 .\left(1+v_{\mathrm{m}}\right)}$ caso a matriz seja isotrópica e $v_{\mathrm{m}}$ seja o coeficiente de Poisson da matriz.

Com base ainda na equação (2.1.3-13) é possível determinar os módulos transversais e perpendiculares à lâmina. Para tal cálculo tem-se que:

$$
\mathrm{E}_{22}=\mathrm{E}_{33}=\frac{4 \mathrm{k}_{\mathrm{t}} \mathrm{G}_{23}}{\mathrm{k}_{\mathrm{t}}+\mathrm{mG}_{23}}
$$

onde:

$$
\mathrm{m}=1+\frac{4 \mathrm{k}_{\mathrm{t}} v_{12}}{\mathrm{E}_{11}}
$$

$\mathrm{k}_{\mathrm{t}}$ é calculado através da equação (2.1.3-13) sendo:

$$
\eta_{\mathrm{k}}=\frac{1+\frac{\mathrm{G}_{\mathrm{m}}}{\mathrm{k}_{\mathrm{f}}}}{2 .\left(1-v_{\mathrm{m}}\right)}
$$

onde:

$$
\begin{aligned}
& \mathrm{k}_{\mathrm{f}}=\frac{\mathrm{E}_{\mathrm{f}}}{2 \cdot\left(1-v_{\mathrm{f}}\right)} \\
& \mathrm{k}_{\mathrm{m}}=\frac{\mathrm{E}_{\mathrm{m}}}{2 \cdot\left(1-v_{\mathrm{mf}}\right)}
\end{aligned}
$$

TSAI \& HANH (1980) notaram que para situações em que $\mathrm{G}_{\mathrm{m}} / \mathrm{G}_{\mathrm{f}}<0,05$ tem-se:

$$
\eta_{6}=0,5 ; \eta_{4}=\frac{3-4 v_{\mathrm{m}}}{4 .\left(1-v_{\mathrm{m}}\right)} \text { e } \eta_{\mathrm{k}}=\frac{1}{2 \cdot\left(1-v_{\mathrm{m}}\right)}
$$


Além disso ambos também afirmaram no mesmo trabalho que se a matriz utilizada for resina epoxi com coeficiente de Poisson igual a 0,35 pode-se adotar:

$$
\eta_{4} \approx 0,662 \quad \text { e } \quad \eta_{\mathrm{k}} \approx 0,77
$$

Tais equações desenvolvidas anteriormente são chamadas de Regra das Misturas (Rule of Mixtures) e tornam viável determinar as propriedades elásticas de uma lâmina unidirecional através das propriedades da fibra e da matriz bem como das suas respectivas porcentagens na formação do compósito. Vale ressaltar aqui que essas propriedades podem sofrer variações significativas sob a ação de alta temperatura (próxima à temperatura de decomposição do material) e umidade. A atuação combinada desses dois agentes pode provocar duplo efeito de deterioração no desempenho estrutural dos compósitos com matriz polimérica. Entretanto, de acordo com os objetivos do presente trabalho analisou-se as amostras a temperatura ambiente (entre $20^{\circ} \mathrm{C}$ e $30^{\circ} \mathrm{C}$ ) podendo assim desconsiderar tais efeitos térmicos e higrotérmicos. Portanto, as equações que serão posteriormente deduzidas não apresentam parcelas correspondentes às tensões e deformações provenientes do aumento da temperatura ou do aumento da umidade.

\section{B) Propriedades mecânicas determinadas via ensaios laboratoriais}

Pelo que foi exposto até o presente momento, existe uma grande dificuldade de se prever as propriedades elásticas do compósito somente com dados referentes aos seus constituintes, ou seja propriedades individuais da fibra e resina. Muitas vezes torna-se necessário a execução de ensaios mecânicos representativos em espécies unidirecionais. As propriedades mecânicas medidas podem então ser usadas para a estimativa de desempenho de compósitos multidirecionais, ou seja, aqueles que apresentam várias camadas orientadas em direções diferentes. São efetuados ensaios experimentais para a determinação das cinco propriedades mecânicas fundamentais: módulos de elasticidade à tração e compressão longitudinais, à tração e compressão transversais e ao cisalhamento. Entretanto, para ensaios mecânicos em compósitos, CARVALHO (1996) descreve algumas particularidades:

1. Ensaios mecânicos que são executados para a determinação de propriedades mecânicas do material estão fundamentados na aplicação de teoria básica de mecânica. Tal teoria é aplicada satisfatoriamente para materiais elásticos homogêneos e isotrópicos, o que não é o caso em compósitos reforçados com fibras, onde a não homogeneidade, a anisotropia e a não elasticidade dificultam a aplicação de tais conceitos. 
2. As maiores dificuldades surgem devido:

- influência de efeitos de borda ("end-effects");

- geração de níveis de carregamento adequados sem causar danos ao material;

- uso de dimensões apropriadas (em particular espessura) em relação à escala de heterogeneidade do material;

3. A anisotropia possui algumas conseqüências práticas, tais como:

- Severos efeitos de borda ("end-effects"), que dependem da geometria da amostra (specimen) e do grau de anisotropia;

- Falha prematura em fixações ou em pontos de aplicação de carga;

- Delaminação prematura em arestas vivas ("free edges") ou aparecimento de outros mecanismos de falha;

-Grandes diferenças em propriedades do material, como por exemplo, módulo à tração, que é governado pelas propriedades da fibra e módulo ao cisalhamento, governado basicamente pelas propriedades da matriz.

4.Testes em compósitos são geralmente de alto custo pois:

- Os materiais são na sua maioria caros;

- A fabricação de amostras e corpos de prova demanda atenção meticulosa à detalhes;

5. Dependendo do caso, normas (ASTM, ISO, DIN, etc.) podem ser bastante adequadas; enquanto que em outros podem ser totalmente inadequadas.

Após a determinação das propriedades elásticas de uma lâmina seja através da Regra das Misturas ou de ensaios, utiliza-se da Teoria Clássica de Laminados para assim obter a rigidez à flexão estrutural do laminado completo. Seguindo este raciocínio considere então, um pequeno elemento de uma lâmina de espessura constante (FIGURA (2.1.3-3)), onde os eixos principais são designados por $1 \mathrm{e} 2$, sendo que a direção 1 é paralela às fibras e a direção 2 é normal a elas. 


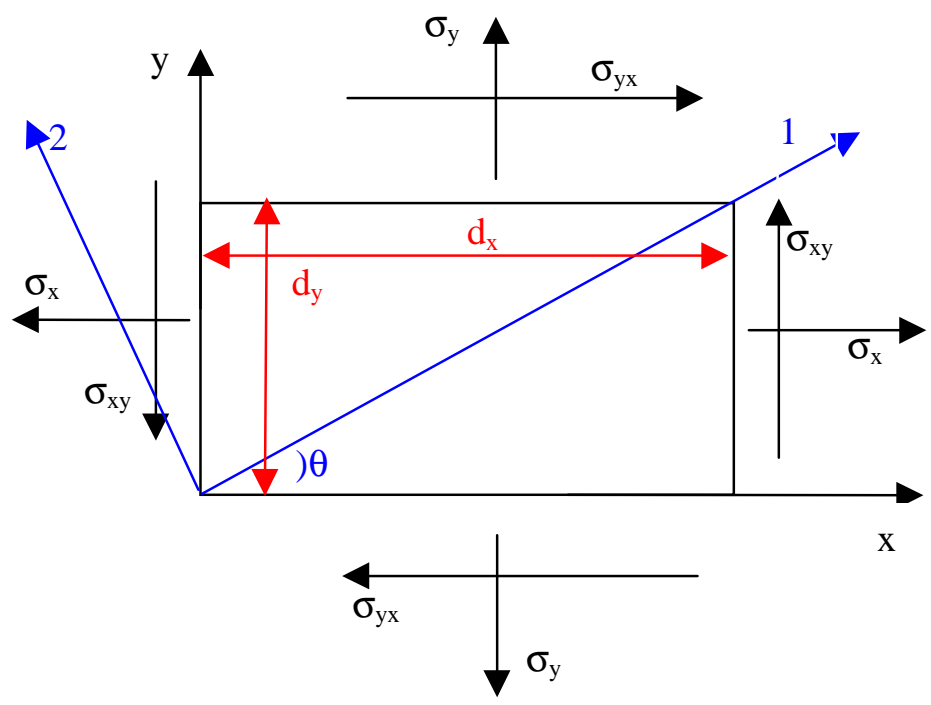

FIGURA (2.1.3-3) - Lâmina de material compósito VINSON \& SIERAKOWSKI (1986)

Baseado no equilíbrio de forças que relaciona $\sigma_{\mathrm{x}}, \sigma_{\mathrm{y}}$ e $\sigma_{\mathrm{xy}}$ a $\sigma_{1}, \sigma_{2}$ e $\sigma_{12}$ tem-se:

$$
\left[\begin{array}{c}
\sigma_{1} \\
\sigma_{2} \\
\sigma_{12}
\end{array}\right]=[\mathrm{T}]_{\mathrm{CL}}\left[\begin{array}{c}
\sigma_{\mathrm{x}} \\
\sigma_{\mathrm{y}} \\
\sigma_{\mathrm{xy}}
\end{array}\right]
$$

onde:

$$
[\mathrm{T}]_{\mathrm{CL}}=\left[\begin{array}{ccc}
\mathrm{m}^{2} & \mathrm{n}^{2} & 2 \mathrm{mn} \\
\mathrm{n}^{2} & \mathrm{~m}^{2} & -2 \mathrm{mn} \\
-\mathrm{mn} & \mathrm{mn} & \left(\mathrm{m}^{2}-\mathrm{n}^{2}\right)
\end{array}\right]
$$

onde:

$$
\begin{aligned}
& \mathrm{m}=\cos (\theta) \\
& \mathrm{n}=\operatorname{sen}(\theta)
\end{aligned}
$$

CL indica o caso clássico bidimensional

Analogamente as relações de deformação são dadas por:

$$
\left[\begin{array}{c}
\varepsilon_{1} \\
\varepsilon_{2} \\
\varepsilon_{12}
\end{array}\right]=[\mathrm{T}]_{\mathrm{CL}}\left[\begin{array}{c}
\varepsilon_{\mathrm{x}} \\
\varepsilon_{\mathrm{y}} \\
\varepsilon_{\mathrm{xy}}
\end{array}\right]
$$


Para o caso tridimensional, deve-se levar em conta as tensões tangenciais (cisalhamento) bem como suas deformações que são dadas por:

$$
\left[\begin{array}{l}
\varepsilon_{1} \\
\varepsilon_{2} \\
\varepsilon_{3} \\
\varepsilon_{4} \\
\varepsilon_{5} \\
\varepsilon_{6}
\end{array}\right]=[\mathrm{T}]\left[\begin{array}{c}
\varepsilon_{\mathrm{x}} \\
\varepsilon_{\mathrm{y}} \\
\varepsilon_{\mathrm{z}} \\
\varepsilon_{\mathrm{yz}} \\
\varepsilon_{\mathrm{xz}} \\
\varepsilon_{\mathrm{xy}}
\end{array}\right]
$$

$$
\left[\begin{array}{c}
\sigma_{1} \\
\sigma_{2} \\
\sigma_{3} \\
\sigma_{4} \\
\sigma_{5} \\
\sigma_{6}
\end{array}\right]=[\mathrm{T}]\left[\begin{array}{c}
\sigma_{\mathrm{x}} \\
\sigma_{\mathrm{y}} \\
\sigma_{\mathrm{z}} \\
\sigma_{\mathrm{yz}} \\
\sigma_{\mathrm{xz}} \\
\sigma_{\mathrm{xy}}
\end{array}\right]
$$

onde:

$$
[\mathrm{T}]=\left[\begin{array}{cccccc}
\mathrm{m}^{2} & \mathrm{n}^{2} & 0 & 0 & 0 & 2 \mathrm{mn} \\
\mathrm{n}^{2} & \mathrm{~m}^{2} & 0 & 0 & 0 & -2 \mathrm{mn} \\
0 & 0 & 1 & 0 & 0 & 0 \\
0 & 0 & 0 & \mathrm{~m} & -\mathrm{n} & 0 \\
0 & 0 & 0 & \mathrm{n} & \mathrm{m} & 0 \\
-\mathrm{mn} & \mathrm{mn} & 0 & 0 & 0 & \left(\mathrm{~m}^{2}-\mathrm{n}^{2}\right)
\end{array}\right]
$$

Portanto:

$$
\left[\begin{array}{c}
\varepsilon_{\mathrm{x}} \\
\varepsilon_{\mathrm{y}} \\
\varepsilon_{\mathrm{z}} \\
\varepsilon_{\mathrm{yz}} \\
\varepsilon_{\mathrm{xz}} \\
\varepsilon_{\mathrm{xy}}
\end{array}\right]=[\mathrm{T}]^{-1}\left[\begin{array}{c}
\varepsilon_{1} \\
\varepsilon_{2} \\
\varepsilon_{3} \\
\varepsilon_{4} \\
\varepsilon_{5} \\
\varepsilon_{6}
\end{array}\right]
$$

$$
\left[\begin{array}{c}
\sigma_{\mathrm{x}} \\
\sigma_{\mathrm{y}} \\
\sigma_{\mathrm{z}} \\
\sigma_{\mathrm{yz}} \\
\sigma_{\mathrm{xz}} \\
\sigma_{\mathrm{xy}}
\end{array}\right]=[\mathrm{T}]^{-1}\left[\begin{array}{c}
\sigma_{1} \\
\sigma_{2} \\
\sigma_{3} \\
\sigma_{4} \\
\sigma_{5} \\
\sigma_{6}
\end{array}\right]
$$

onde:

$[\mathrm{T}]^{-1}$ - inversa de $[\mathrm{T}]$

Utilizando a Lei de Hooke para relacionar tensão e deformação, produz-se a equação geral de uma lâmina de material compósito reforçado com fibra em termos das 3 direções principais $(1,2,3)$. 


$$
\left[\begin{array}{c}
\sigma_{1} \\
\sigma_{2} \\
\sigma_{3} \\
\sigma_{4} \\
\sigma_{5} \\
\sigma_{6}
\end{array}\right]=\frac{\left[\begin{array}{cccccc}
\mathrm{Q}_{11} & \mathrm{Q}_{12} & \mathrm{Q}_{13} & 0 & 0 & 0 \\
\mathrm{Q}_{21} & \mathrm{Q}_{22} & \mathrm{Q}_{23} & 0 & 0 & 0 \\
\mathrm{Q}_{31} & \mathrm{Q}_{32} & \mathrm{Q}_{33} & 0 & 0 & 0 \\
0 & 0 & 0 & 2 \mathrm{Q}_{44} & 0 & 0 \\
0 & 0 & 0 & 0 & 2 \mathrm{Q}_{55} & 0 \\
0 & 0 & 0 & 0 & 0 & 2 \mathrm{Q}_{66}
\end{array}\right]}{\downarrow}
$$

[Q]: Matriz de rigidez de uma lâmina (valores provenientes da Teoria Clássica de Elasticidade)

onde:

$$
\begin{aligned}
& \mathrm{Q}_{11}=\frac{\mathrm{E}_{11}\left(1-v_{23} v_{32}\right)}{\Delta} \\
& \mathrm{Q}_{22}=\frac{\mathrm{E}_{22}\left(1-v_{31} v_{13}\right)}{\Delta} \\
& \mathrm{Q}_{33}=\frac{\mathrm{E}_{33}\left(1-v_{12} v_{21}\right)}{\Delta} \\
& \mathrm{Q}_{44}=\mathrm{G}_{23} \\
& \mathrm{Q}_{55}=\mathrm{G}_{13} \\
& \mathrm{Q}_{66}=\mathrm{G}_{12} \\
& \mathrm{Q}_{12}=\frac{\mathrm{E}_{11}\left(v_{21}+v_{31} v_{23}\right)}{\Delta}=\frac{\mathrm{E}_{22}\left(v_{12}+v_{32} v_{13}\right)}{\Delta} \\
& \mathrm{Q}_{13}=\frac{\mathrm{E}_{11}\left(v_{31}+v_{21} v_{32}\right)}{\Delta}=\frac{\mathrm{E}_{22}\left(v_{13}+v_{12} v_{23}\right)}{\Delta} \\
& \mathrm{Q}_{23}=\frac{\mathrm{E}_{22}\left(v_{32}+v_{12} v_{31}\right)}{\Delta}=\frac{\mathrm{E}_{33}\left(v_{23}+v_{21} v_{13}\right)}{\Delta} \\
& \Delta=1-v_{12} v_{21}-v_{23} v_{32}-v_{31} v_{13}-2 v_{21} v_{32} v_{13}
\end{aligned}
$$

Após a dedução da matriz de rigidez de uma lâmina parte-se para a dedução da rigidez de um laminado que na verdade é constituído por um sequenciamento de lâminas empilhadas. Portanto, o laminado é um conjunto de lâminas que poderá ser moldado de acordo com a solicitação exigida na estrutura. Considere então, um laminado composto por $\mathrm{N}$ lâminas, para a k-ésima lâmina, tem-se: 


$$
\left[\begin{array}{c}
\sigma_{\mathrm{x}} \\
\sigma_{\mathrm{y}} \\
\sigma_{\mathrm{z}} \\
\sigma_{\mathrm{yz}} \\
\sigma_{\mathrm{xz}} \\
\sigma_{\mathrm{xy}}
\end{array}\right]_{\mathrm{K}}\left[\begin{array}{c}
\varepsilon_{\mathrm{x}} \\
\varepsilon_{\mathrm{y}} \\
\varepsilon_{\mathrm{z}} \\
\varepsilon_{\mathrm{yz}} \\
\varepsilon_{\mathrm{xz}} \\
\varepsilon_{\mathrm{xy}}
\end{array}\right]_{\mathrm{K}}
$$

onde:

$$
\begin{gathered}
{[\overline{\mathrm{Q}}]_{\mathrm{K}}=[\mathrm{T}]^{-1} \cdot[\mathrm{Q}]_{\mathrm{K}} \cdot[\mathrm{T}]} \\
\text { onde: }
\end{gathered}
$$

[T] é a matriz expressa por (2.1.3-23)

Nesse laminado com espessura h e suas várias lâminas com espessura $h_{k}$, como mostra a FIGURA (2.1.3-4), a tensão resultante é dada por duas parcelas:

$$
\begin{aligned}
& {\left[\begin{array}{c}
\mathrm{N}_{\mathrm{x}} \\
\mathrm{N}_{\mathrm{y}} \\
\mathrm{N}_{\mathrm{xy}} \\
\mathrm{Q}_{\mathrm{x}} \\
\mathrm{Q}_{\mathrm{y}}
\end{array}\right]=\int_{-\mathrm{h} / 2}^{\mathrm{b} / 2}\left[\begin{array}{c}
\sigma_{\mathrm{x}} \\
\sigma_{\mathrm{y}} \\
\sigma_{\mathrm{xy}} \\
\sigma_{\mathrm{xz}} \\
\sigma_{\mathrm{xy}}
\end{array}\right] \mathrm{dz}} \\
& {\left[\begin{array}{c}
\mathrm{M}_{\mathrm{x}} \\
\mathrm{M}_{\mathrm{y}} \\
\mathrm{M}_{\mathrm{xy}}
\end{array}\right]=\int_{-\mathrm{h} / 2}^{\mathrm{h} / 2}\left[\begin{array}{c}
\sigma_{\mathrm{x}} \\
\sigma_{\mathrm{y}} \\
\sigma_{\mathrm{xy}}
\end{array}\right] \mathrm{zdz}}
\end{aligned}
$$




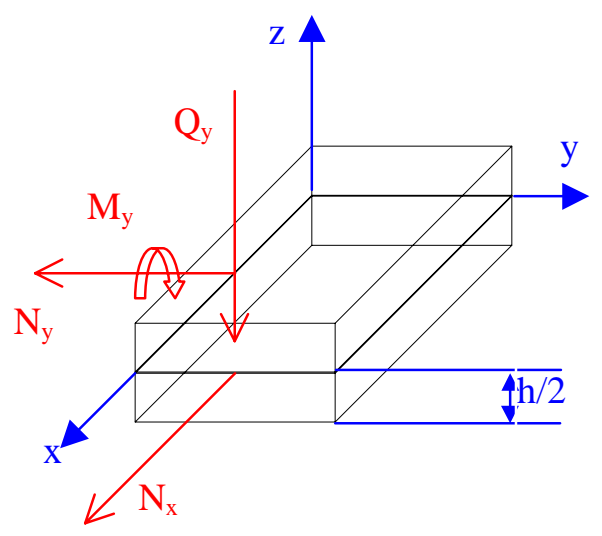

FIGURA (2.1.3-4) - Tensões Normais (N), Tensões de Cisalhamento (Q) e Momentos (M) atuantes no laminado

Como o laminado possui uma espessura fina, é possível assumir a deformação em z igual a zero, portanto $\sigma_{\mathrm{z}}$ será nula e o equacionamento acima terá a seguinte forma:

$$
\left[\begin{array}{c}
\mathrm{N}_{\mathrm{X}} \\
\mathrm{N}_{\mathrm{Y}} \\
\mathrm{N}_{\mathrm{XY}}
\end{array}\right]=\sum_{\mathrm{K}=1}^{\mathrm{n}}\left\{\int_{\mathrm{h}_{\mathrm{K}-1}}^{\mathrm{h}_{\mathrm{K}}}[\overline{\mathrm{Q}}]_{\mathrm{K}}\left[\begin{array}{c}
\varepsilon_{\mathrm{x} 0} \\
\varepsilon_{\mathrm{y} 0} \\
\varepsilon_{\mathrm{xy} 0}
\end{array}\right] \mathrm{dz}+\int_{\mathrm{h}_{\mathrm{K}-1}}^{\mathrm{h}_{\mathrm{K}}}[\overline{\mathrm{Q}}]_{\mathrm{K}}\left[\begin{array}{c}
\mathrm{K}_{\mathrm{x}} \\
\mathrm{K}_{\mathrm{y}} \\
\mathrm{K}_{\mathrm{xy}}
\end{array}\right] \mathrm{zdz}\right\}(2.1 .3-30)
$$

Ou seja:

$$
[\mathrm{N}]=[\mathrm{A}]\left[\varepsilon_{0}\right]+[\mathrm{B}][\mathrm{K}]
$$

onde:

$$
\begin{aligned}
& {[\mathrm{A}]=\int_{\mathrm{h}_{\mathrm{K}-1}}^{\mathrm{h}_{\mathrm{K}}}[\overline{\mathrm{Q}}]_{\mathrm{K}} \mathrm{dz}=\text { Matriz que reflete a rigidez à tração e à compressão }} \\
& {\left[\varepsilon_{0}\right]=\left[\begin{array}{c}
\varepsilon_{\mathrm{x} 0} \\
\varepsilon_{\mathrm{y} 0} \\
\varepsilon_{\mathrm{xy} 0}
\end{array}\right]=\text { Componentes de deformação no plano }} \\
& {[\mathrm{B}]=\int_{\mathrm{K}_{\mathrm{K}-1}}^{\mathrm{h}_{\mathrm{K}}}[\overline{\mathrm{Q}}]_{\mathrm{K}} \mathrm{zdz}=\text { Matriz de acoplamento entre a rigidez planar e a rigidez à }}
\end{aligned}
$$

flexão

$$
[K]=\left[\begin{array}{c}
K_{x} \\
K_{y} \\
K_{x y}
\end{array}\right]=\text { Componentes de rotação de corpo rígido }
$$

Além disso tem-se para os momentos atuantes: 


$$
\left[\begin{array}{c}
\mathrm{M}_{\mathrm{X}} \\
\mathrm{M}_{\mathrm{Y}} \\
\mathrm{M}_{\mathrm{XY}}
\end{array}\right]=\sum_{\mathrm{K}=1}^{\mathrm{n}}\left\{\int_{\mathrm{h}_{\mathrm{K}-1}}^{\mathrm{h}_{\mathrm{K}}}[\overline{\mathrm{Q}}]_{\mathrm{K}}\left[\begin{array}{c}
\varepsilon_{\mathrm{x} 0} \\
\varepsilon_{\mathrm{y} 0} \\
\varepsilon_{\mathrm{xy} 0}
\end{array}\right] \mathrm{zdz}+\int_{\mathrm{h}_{\mathrm{K}-1}}^{\mathrm{h}_{\mathrm{K}}}[\overline{\mathrm{Q}}]_{\mathrm{K}}\left[\begin{array}{c}
\mathrm{K}_{\mathrm{x}} \\
\mathrm{K}_{\mathrm{y}} \\
\mathrm{K}_{\mathrm{xy}}
\end{array}\right] \mathrm{z}^{2} \mathrm{dz}\right\}
$$

Ou seja:

$$
[\mathrm{M}]=[\mathrm{B}]\left[\varepsilon_{0}\right]+[\mathrm{D}][\mathrm{K}]
$$

onde:

$$
[D]=\int_{h_{K}-1}^{h_{K}}[\bar{Q}]_{K} z^{2} d z=\text { Matriz que reflete a rigidez à flexão }
$$

Em suma:

$$
\left[\begin{array}{l}
{[\mathrm{N}]} \\
{[\mathrm{M}]}
\end{array}\right]=\left[\begin{array}{ll}
{[\mathrm{A}]} & {[\mathrm{B}]} \\
{[\mathrm{B}]} & {[\mathrm{D}]}
\end{array}\right]\left[\begin{array}{l}
{\left[\varepsilon_{\mathrm{o}}\right]} \\
{[\mathrm{K}]}
\end{array}\right]
$$

Para determinar as tensões de cisalhamento $\mathrm{Q}_{\mathrm{x}}$ e $\mathrm{Q}_{\mathrm{y}}$ definidas na equação (2.1.3-28), assume-se que estas tensões são distribuídas parabolicamente ao longo da espessura do laminado. Em contraste com as discontinuidades na interface entre as lâminas, usa-se uma função contínua $\mathrm{f}(\mathrm{z})$ como função de ponderação ao qual consiste com Reissner (VINSON \& SIERAKOWSKI, 1987):

$$
\begin{aligned}
& \mathrm{Q}_{\mathrm{x}}=2 \cdot\left(\mathrm{A}_{55} \varepsilon_{\mathrm{xz}}+\mathrm{A}_{45} \varepsilon_{\mathrm{yxz}}\right) \\
& \mathrm{Q}_{\mathrm{y}}=2 \cdot\left(\mathrm{A}_{45} \varepsilon_{\mathrm{xz}}+\mathrm{A}_{44} \varepsilon_{\mathrm{yxz}}\right)
\end{aligned}
$$

onde:

$$
\mathrm{A}_{\mathrm{ij}}=\frac{5}{4} \sum_{\mathrm{k}=1}^{\mathrm{N}}\left(\overline{\mathrm{Q}}_{\mathrm{ij}}\right)_{\mathrm{k}}\left[\mathrm{h}_{\mathrm{k}}-\mathrm{h}_{\mathrm{k}-1}-\frac{4}{3}\left(\mathrm{~h}_{\mathrm{k}}^{3}-\mathrm{h}_{\mathrm{k}-1}^{3}\right) \frac{1}{\mathrm{~h}^{2}}\right]
$$

Portanto, de uma forma geral, tem-se:

$$
\left[\begin{array}{c}
\mathrm{N}_{\mathrm{x}} \\
\mathrm{N}_{\mathrm{y}} \\
\mathrm{N}_{\mathrm{xy}} \\
\mathrm{M}_{\mathrm{x}} \\
\mathrm{M}_{\mathrm{y}} \\
\mathrm{M}_{\mathrm{xy}}
\end{array}\right]=\left[\begin{array}{llllll}
\mathrm{A}_{11} & \mathrm{~A}_{12} & 2 \mathrm{~A}_{16} & \mathrm{~B}_{11} & \mathrm{~B}_{12} & 2 \mathrm{~B}_{16} \\
\mathrm{~A}_{12} & \mathrm{~A}_{22} & 2 \mathrm{~A}_{26} & \mathrm{~B}_{12} & \mathrm{~B}_{22} & 2 \mathrm{~B}_{26} \\
\mathrm{~A}_{16} & \mathrm{~A}_{26} & 2 \mathrm{~A}_{66} & \mathrm{~B}_{16} & \mathrm{~B}_{26} & 2 \mathrm{~B}_{66} \\
\mathrm{~B}_{11} & \mathrm{~B}_{12} & 2 \mathrm{~B}_{16} & \mathrm{D}_{11} & \mathrm{D}_{12} & 2 \mathrm{D}_{16} \\
\mathrm{~B}_{12} & \mathrm{~B}_{22} & 2 \mathrm{~B}_{26} & \mathrm{D}_{12} & \mathrm{D}_{22} & 2 \mathrm{D}_{26} \\
\mathrm{~B}_{16} & \mathrm{~B}_{26} & 2 \mathrm{~B}_{66} & \mathrm{D}_{16} & \mathrm{D}_{26} & 2 \mathrm{D}_{66}
\end{array}\right]\left[\begin{array}{c}
\varepsilon_{\mathrm{x}_{0}} \\
\varepsilon_{\mathrm{y}_{0}} \\
\varepsilon_{\mathrm{xy}_{0}} \\
\mathrm{~K}_{\mathrm{x}} \\
\mathrm{K}_{\mathrm{y}} \\
\mathrm{K}_{\mathrm{xy}}
\end{array}\right]
$$




$$
\text { e } \quad\left[\begin{array}{l}
\mathrm{Q}_{\mathrm{y}} \\
\mathrm{Q}_{\mathrm{x}}
\end{array}\right]=\left[\begin{array}{ll}
2 \mathrm{~A}_{44} & 2 \mathrm{~A}_{45} \\
2 \mathrm{~A}_{45} & 2 \mathrm{~A}_{55}
\end{array}\right]\left[\begin{array}{l}
\varepsilon_{\mathrm{yz}} \\
\varepsilon_{\mathrm{xz}}
\end{array}\right]
$$

Caso o laminado seja simétrico a matriz [B] será nula. Para isso é necessário existir uma sequência de empilhamento das lâminas de tal forma que o plano que divide a espessura ao meio se torne uma espécie de espelho. Por exemplo, um laminado com ângulos de orientação $0^{\circ}, 90^{\circ}, 90^{\circ}$ e $0^{\circ}$ pode ser considerado simétrico, pois o plano que divide a espessura ao meio é tal como um espelho. Assim, toma-se como amostras laminados simétricos para evitar efeitos de acoplamento. Para finalizar, constata-se que a rigidez final do laminado depende em parte da sequência de empilhamento das lâminas (stacking sequence) para a determinação das matrizes [B] e [D] o que já não ocorre para a determinação da matriz [A] que independe desta sequência. De qualquer forma verifica-se assim, a importância da disposição das fibras sobre o laminado. Essa característica única presente nos compósitos reforçados com fibras faz com que esses materiais sejam muito atrativos para o desenvolvimento de projetos. Principalmente em projetos que requerem uma maior leveza sem comprometer a sua resistência, exemplos disso são as estruturas aeronáuticas e automobilísticas.

\subsection{Requisitos de Projeto}

Desde muitos anos o homem combina propriedades de materiais diferentes para atingir seus objetivos. Um exemplo disso eram os Sumarianos que há 4000 A.C. (Antes de Cristo) adicionavam palha ao barro para aumentar a resistência de seus tijolos (ANSYS User's Manual, 1995). Embora os benefícios trazidos pelos materiais compósitos sejam conhecidos há milhares de anos, apenas há alguns anos atrás é que se desenvolveu a tecnologia desses materiais (TSAI, 1986). O avião F.111 foi um dos primeiros modelos a incorporar esta tecnologia. Para se ter uma idéia, o Boeing 767 possui 2 toneladas em material compósito (TSAI, 1986). As características que combinam alta resistência e baixa densidade estrutural, portanto redução de peso, chamaram a atenção da indústria automobilística. Foi pensando nisso que a Ford Motor Company em 1979 desenvolveu um protótipo de carro com alguns componentes feitos em material compósito (carbono e epoxi). O protótipo simplesmente pesava $570 \mathrm{Kg}$ a menos que a versão em aço, só o eixo de transmissão sofreu uma redução de 57\% do seu valor original. (DHARAM, 1979). Atualmente a Chrisler vem desenvolvendo um projeto baseado na aplicação de compósitos 
em seus veículos, tal projeto é conhecido como CCV (Composite Concept Vehicle). Em 1997, a companhia americana apresentou um protótipo a base de compósitos na feira internacional de veículos em Frankfurt. Além da indústria aeronáutica e automobilística outras indústrias vem cada vez mais fazendo uso desses materiais, é o caso da indústria náutica, de artigos esportivos, da construção civil e aeroespacial como mostra o trabalho desenvolvido por UMEKAWA \& MOMOSHIMA (1992).

Por outro lado, durante muitos anos os engenheiros utilizaram apenas materiais isotrópicos para o desenvolvimento de projetos. Com o avanço tecnológico e o aumento da concorrência a indústria teve que repensar novas técnicas de como projetar, forçando o engenheiro a não ser um mero selecionador de material, mas também um projetista de materiais. De acordo com TSAI (1986), projetar com qualquer material é mais arte do que ciência, entretanto, projetar com material compósito é muito mais ciência do que arte, pois tudo deve se basear na Teoria de Laminados. O autor propõe a criação de 4 níveis para simplificar a abordagem de um projeto em material compósito:

1- Projeto para otimização dos materiais: a formulação que envolve a contribuição da fibra e da matriz e os efeitos higrotérmicos devem estar relacionados com a rigidez e a resistência do laminado;

2- Projeto para otimização estrutural: a Teoria de Laminados com algumas simplificações permite prever de maneira rápida um laminado simétrico ou anti-simétrico;

3- Projeto para otimização da resistência: a abordagem das tensões principais é recomendada para os casos com presença de carregamento simples; para os casos com carregamentos combinados necessita-se de uma abordagem sobre a sequência de empilhamento das lâminas;

4- Projeto para minimizar a deformação ou incrementar a estabilidade elástica (problemas de flambagem): necessita-se também de uma abordagem sobre a sequência de empilhamento das lâminas.

WILLING (1993) simplificou esta idéia, citando algumas regras para projetar com materiais compósitos tais como: tentar obter paredes com pequena espessura, evitar acúmulo de massa, evitar a formação de bolhas, prever como será a desmoldagem da superfície durante o processo de fabricação etc. Nota-se que elas são muito parecidas com regras para projetar peças plásticas. Entretanto, deve-se sempre atentar para os limites que governam os projetos tais como: tensões, deformações e deslocamentos permitidos. Segundo CARVALHO (1996), o componente final fabricado em material compósito deve satisfazer 
não somente os requisitos de rigidez e resistência mecânica, mas também deve ser aceitável em termos de custos. Na FIGURA (2.2-1) é dada uma proposta de ciclo de projeto para material compósito. Os requisitos de projeto estão presentes na primeira etapa do ciclo e alguns destes requisitos são brevemente discutidos a seguir:

\section{Caracterização de material e testes:}

A caracterização do material quando se trabalha com compósitos é de fundamental importância no projeto de componentes feitos a partir deste tipo de material. Testes podem ser executados durante toda a vida do componente, com os mais diferentes propósitos, como por exemplo, determinação de parâmetros de projeto, testes de desempenho em serviço e controle/garantia de qualidade.

\section{Resistência estática:}

Basicamente a determinação da resistência estática de um compósito é feita em duas fases ( no caso de laminates):

1- As tensões e deformações em cada camada (layer) são determinadas

2- Os efeitos das tensões e deformações na resistência global da estrutura são determinados através de um modelo matemático (como por exemplo a Teoria Clássica de Laminados, Classical Laminates Theory - CLT).

\section{Resistência à fadiga:}

O comportamento à fadiga de compósitos difere dos metais em muitos aspectos. Por exemplo, compósitos unidirecionais carregados somente a tração apresentam geralmente limites de fadiga com níveis de tensões superiores que os níveis limites de ruptura (ROSEN, 1987). Contudo, maiores danos acontecem quando carregados em compressão ou ciclos tração-compressão. Falhas por fadiga em compósitos são geralmente acompanhadas por danos extensivos à todo material, em vez da formação de uma falha predominante como ocorre em materiais isotrópicos. Quatro mecanismos básicos de falha estão presentes: formação de trincas na camada de um compósito, delaminação, quebra das fibras, e ruptura da interface fibra-matriz. Qualquer combinação destes mecanismos pode causar falha por fadiga. Atualmente, o desenvolvimento de procedimentos de análise de fadiga em compósitos é objeto de intensa pesquisa e já existem alguns procedimentos tradicionalmente usados para metais que estão sendo gradativamente adaptados para prever falhas em compósitos (WANG, 1987). 


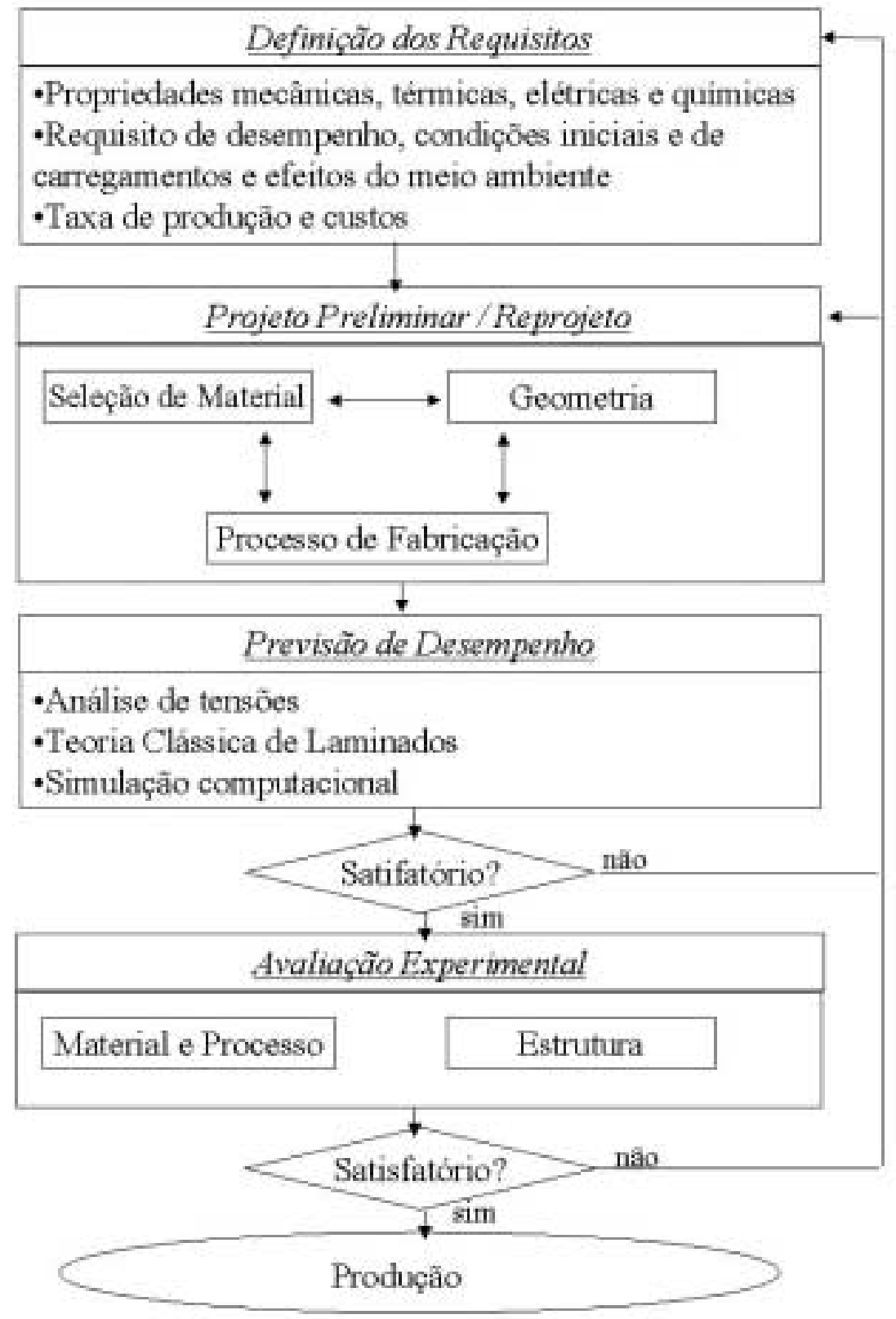

FIGURA (2.2-1) - Ciclo de projeto para compósitos

(CARVALHO, 1996)

\section{Fatores de segurança:}

Para se antever possíveis sobrecargas da estrutura, cargas menores não previstas em projeto, diferenças nas condições ambientais, simplificações e suposições nos cálculos, bem como incertezas nas propriedades do material, fatores de segurança são normalmente aplicados quando projeta-se com compósitos. Isto é também válido para materiais isotrópicos convencionais, sendo que a diferença no caso de compósitos é que a variação das propriedades do material como resultado do processamento pode ser muito maior do que nos 
materiais convencionais e que o modo de falha não é completamente previsível. Apesar do senso comum de que tais fatores de segurança são necessários, não existe uma padronização geral na sua determinação (LOSSIE, 1990). Já existindo normas para certas aplicações específicas como por exemplo, "The British Standard for pressure vessels" para vasos de pressão (BRITISH STANDARDS INSTITUTION, 1987).

\section{Efeitos ambientais:}

Aspectos relativos ao meio-ambiente, dependendo dos constituintes do compósito, podem afetar consideravelmente as propriedades mecânicas do mesmo. Altas diferenças de temperatura em aeronáutica e absorção de substâncias na indústria química são exemplos significativos deste tipo problema.

\section{Tolerância à danos:}

O termo "damage-tolerant design" é normalmente utilizado para descrever uma estratégia de projeto na qual o componente é projetado de tal forma que a integridade da estrutura é mantida mesmo que um "defeito" de uma certa extensão esteja presente. Estes "defeitos" podem aparecer devido a uma série de fatores como furos, rasgos, extremidades livres ou causado por danos em serviço, como delaminações e/ou trincas. Em adição a estes fatores e outros já mencionados, como fadiga e concentrações de tensão, há ainda fatores a serem considerados, como defeitos de fabricação e danos causados por impacto.

\section{Custos:}

Componentes em compósitos devem ter custo-efetivos, em vez de simplesmente possuir materiais de alto desempenho. Uma avaliação global de custos deve ser cuidadosamente executada. Por exemplo, um componente pode ser considerado "caro" quando avaliado individualmente em termos de material e processamento, mas pode se tornar bastante atrativo quando custos globais do sistema são considerados (CARVALHO, 1996).

Além de todos esses requisitos citados anteriormente, pode-se também caracterizar como requisito de projeto, o comportamento dinâmico que a estrutura venha desenvolver em serviço. Em alguns projetos deve-se conhecer as propriedades que caracterizam o comportamento dinâmico de uma estrutura sob a ação de um determinado carregamento. $\mathrm{O}$ objetivo é evitar danos estruturais causados por vibrações indesejáveis. Para isso, procura-se: 
1- Determinar as frequências naturais da estrutura para evitar que a excitação de trabalho normal esteja próxima das mesmas;

2- Determinar os modos naturais de vibrar para reforçar os pontos mais flexíveis ou detectar locais para aliviar peso ou incrementar amortecimento;

3- Determinar os fatores de amortecimento modais.

O conjunto de frequências naturais, modos de vibrar e fatores de amortecimento constituem os parâmetros modais do sistema e podem ser geralmente obtidos através das Funções de Resposta em Frequência (FRF) do sistema que são basicamente constituídas por dois gráficos. O gráfico de amplitude (módulo) que pode representar o valor do deslocamento de um ponto da estrutura e o gráfico de fase que basicamente indica qual foi a direção do deslocamento. KHATRI (1995) mostra que cascas cônicas laminadas que são usadas em aviões, foguetes e mísseis, têm grandes variações nas frequências de ressonância e fatores de amortecimento quando o arranjo de orientação das fibras é alterado. ESLIMYISFAHANY \& BANERJEE (1997) demonstraram através de resultados numéricos que uma asa de avião de material compósito, com substancial efeito de acoplamento entre os modos de torção e flexão, sofrem grandes alterações nas frequências naturais quando há mudança de orientação das lâminas. Baseando-se na idéia que as orientações da fibra alteram a rigidez da estrutura que por conseguinte altera as frequências naturais, pretende-se neste trabalho levantar as FRF's de amostras estruturais na forma de vigas obtendo assim, frequências naturais e fatores de amortecimento modal para diferentes sequências de orientação das fibras sobre cada lâmina (stacking sequence). O objetivo é verificar a possibilidade de projetar o material para o requisito anteriormente especificado. De acordo com EWINS (1984), três condições estão integradas e são muito importantes para a obtenção de resultados realísticos em análises dinâmicas:

1- Conhecimento da teoria básica de vibrações;

2- Acuracidade nas medidas de vibração;

3- Análise detalhada e realística.

Com base nesta citação, faz-se agora uma pequena abordagem sobre a teoria básica de vibrações necessária para o desenvolvimento do trabalho. 


\subsection{Vibrações}

O estudo de vibrações diz respeito ao estudo dos movimentos oscilatórios de corpos e às forças que lhes são associadas. Todos os corpos dotados de massa e elasticidade são capazes de vibrar. Deste modo, a maior parte das máquinas e estruturas estão sujeitas a um certo nível de vibração e o seu projeto requer geralmente o exame de seu comportamento oscilatório.

THOMSON(1973) observou que existem duas classes gerais de vibrações: a livre e a forçada. A vibração livre acontece quando um sistema oscila sob a ação de condições iniciais não nulas (um deslocamento, por exemplo), sob a ausência da ação de qualquer força externa. Neste caso o sistema poderá vibrar com uma ou mais de suas frequências naturais, que são peculiares ao sistema dinâmico estabelecido pela distribuição de sua massa e rigidez. A vibração forçada ocorre sob a excitação de forças externas. Quando a excitação é oscilatória, o sistema linear é obrigado a vibrar na frequência da excitação. Se esta frequência coincide com uma das frequências naturais do sistema, forma-se um estado de ressonância, podendo resultar em amplas e perigosas oscilações. Esta ressonância pode ser a causa de temíveis colapsos em estruturas como as de edifícios, pontes e asas de avião. Assim sendo, é de fundamental importância o cálculo das frequências naturais em determinados projetos. Como anteriormente citado, alguns requisitos são:

- grande rigidez;

- grande resistência estrutural;

- grande tenacidade;

- grande resistência a fadiga;

- grande amortecimento estrutural que determina o comportamento dinâmico.

Segundo EWINS (1984), na análise modal analítica tem-se uma descrição do comportamento da estrutura como sendo um conjunto de modos de vibração que é conhecido por modelo modal. Este modelo é definido por um conjunto de frequiências naturais com suas correspondentes formas de vibrar e fatores de amortecimento. É importante lembrar que esta solução descreve as várias maneiras que a estrutura é capaz de vibrar naturalmente, isto é, sem nenhuma força externa ou excitação. Por fim pode-se ainda analisar como exatamente a estrutura irá vibrar devido a uma dada excitação e, especialmente, a que amplitude. Nota-se que a amplitude não dependerá apenas das propriedades inerentes à estrutura mas também da natureza e magnitude da excitação imposta.

Talvez a aplicação mais simples e comum da análise modal é a medida dos modos de vibração a fim de compará-las com os dados produzidos por uma análise numérica ou outro 
modelo teórico. Esta aplicação nasceu da necessidade de validar modelos teóricos em previsões de respostas em níveis mais complexos de excitação, tal como choques, ou outros casos de análise. Para esta aplicação, requisita-se:

1- Estimativa acurada das frequências naturais;

2- Descrição dos modos de vibrar usando o detalhamento e a acuracidade que permita sua identificação e correlação com aqueles provenientes do modelo teórico

Assim, segue agora o desenvolvimento matemático para a determinação das frequências naturais e os modos de vibrar de uma viga.

\section{Análise Modal de um Sistema Contínuo de $4^{a}$ Ordem - A Viga}

VINSON \& SIERAKOWSKI (1987) definem como elemento estrutural viga, todo aquele que possui: $b / L \quad<<1$ e $h / L<<1$ onde $b$ é largura, h é altura e $L$ é comprimento. Além disso, a estrutura deve possuir carregamento lateral no plano x-z como mostra a FIGURA (2.3-1), ocorrendo a sua flexão. Caso tenha carregamento de tração na direção x, a estrutura deve ser reconhecida como uma barra, e para finalizar, caso tenha carregamento de compressão nesta direção, a estrutura deve ser tratada como coluna.

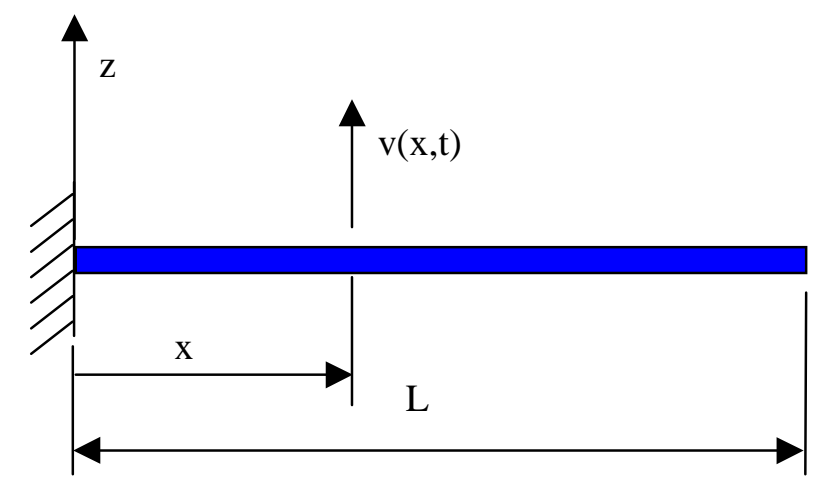

FIGURA (2.3-1) - Viga engastada-livre de comprimento L

A equação diferencial que descreve o movimento lateral de uma viga isotrópica é dada por:

$$
m \frac{\partial^{2} v}{\partial t^{2}}+c \frac{\partial v}{\partial t}-\frac{\partial}{\partial x}\left[T \frac{\partial v}{\partial x}\right]+\frac{\partial^{2}}{\partial x^{2}}\left[E I \frac{\partial^{2} v}{\partial x^{2}}\right]=f(x, t)
$$


onde:

$\mathrm{m}=$ massa da estrutura por unidade de comprimento

$\mathrm{c}=$ amortecimento da estrutura por unidade de comprimento

$\mathrm{T}=$ contribuição da rigidez à tensão plana

$\mathrm{E}=$ módulo de elasticidade do material

I = momento de inércia da secção transversal da viga

$f(x, t)=$ força de excitação

A equação (2.3-1) representa o balanço de força por unidade de comprimento que deve ocorrer em cada ponto da viga a cada instante de tempo. O termo de rigidez é constituído por dois elementos: a rigidez à tensão plana e a rigidez à flexão. A equação (2.31) é as vezes referenciada para viga espessa ou viga de Euler-Bernoulli. Quando a deformação por cisalhamento e inércias de rotação são incluídas, o modelo é chamado de viga de Timoshenko. Portanto para o modelo de viga Euler-Bernoulli vibrando livremente sem amortecimento, a equação (2.3-1) pode se reduzir a:

$$
\mathrm{m} \frac{\partial^{2} \mathrm{v}}{\partial \mathrm{t}^{2}}+\frac{\partial^{2}}{\partial \mathrm{x}^{2}}\left[\mathrm{EI} \frac{\partial^{2} \mathrm{v}}{\partial \mathrm{x}^{2}}\right]=0
$$

Assumindo movimento harmônico, tem-se:

$$
\mathrm{v}(\mathrm{x}, \mathrm{t})=\mathrm{V}(\mathrm{x}) \cos (\omega \mathrm{t}-\alpha)
$$

Substituindo (2.3-2) em (2.3-3), obtém-se:

$$
\frac{\mathrm{d}^{4} \mathrm{~V}}{\mathrm{dx}}-\lambda^{4} \mathrm{~V}=0
$$

E o autovalor da equação (2.3-4) é calculado por:

$$
\lambda^{4}=\frac{\left(\rho \mathrm{A} \omega^{2}\right)}{\mathrm{EI}}
$$

onde:

$\rho=$ densidade do material da viga

$\mathrm{A}=$ área da secção transversal

A solução geral para (2.3-4) é dada por:

$$
V(x)=A_{1} e^{\lambda x}+A_{2} e^{-\lambda x}+A_{3} e^{\lambda x}+A_{4} e^{-\lambda x}(2.3-5)
$$

A solução pode ser dividida em duas formas alternativas: 


$$
\begin{gathered}
\mathrm{V}(\mathrm{x})=\mathrm{B}_{1} \mathrm{e}^{\lambda \mathrm{x}}+\mathrm{B}_{2} \mathrm{e}^{-\lambda \mathrm{x}}+\mathrm{B}_{3} \operatorname{sen} \lambda \mathrm{x}+\mathrm{B}_{4} \cos \lambda \mathrm{x} \\
\mathrm{e}(\mathrm{x})=\mathrm{C}_{1} \operatorname{senh}(\lambda \mathrm{x})+\mathrm{C}_{2} \cosh (\lambda \mathrm{x})+\mathrm{C}_{3} \operatorname{sen}(\lambda \mathrm{x})+\mathrm{C}_{4} \cos (\lambda \mathrm{x})
\end{gathered}
$$

A determinação das constantes das equações(2.3-6) e (2.3-7) são calculadas através das condições de contorno aplicadas à equação (2.3-4). Portanto para condição de contorno engastada-livre tem-se:

$$
\begin{array}{lll}
\mathrm{V}(0)=0 & \frac{\mathrm{d}^{2} \mathrm{~V}}{\mathrm{dx}^{2} \mathrm{x}=\mathrm{L}}=0 \\
\frac{\mathrm{d} V}{\mathrm{dx}}_{\mathrm{x}=0}=0 & \text { b)Livre - } & \frac{\mathrm{d}^{3} \mathrm{~V}}{\mathrm{dx}^{3}{ }_{\mathrm{x}=\mathrm{L}}}=0
\end{array}
$$

Obtendo a chamada equação característica da viga engastada-livre (cantilever):

$$
\cos \lambda \mathrm{L} \cosh \lambda \mathrm{L}+1=0
$$

Portanto, (2.3-8) é valida para vários $\lambda l$. Alguns destes valores estão referenciados em CRAIG (1981). Assim para a p-ésima frequência natural tem-se:

$$
\omega_{\mathrm{p}}=\frac{\left(\lambda_{\mathrm{p}} \mathrm{L}\right)^{2}}{\mathrm{~L}^{2}} \sqrt{\frac{\mathrm{EI}}{\rho \mathrm{A}}}
$$

Para cada valor de $\lambda_{\mathrm{p}}$ existe um valor correspondente de $\mathrm{V}_{\mathrm{p}}(\mathrm{x})$ que são as amplitudes ao longo da viga para os respectivos p-ésimos modos de vibrar caracterizando dessa maneira as formas de vibrar da estrutura:

$$
\mathrm{V}_{\mathrm{p}}(\mathrm{x})=\mathrm{C}\left\{\cosh \left(\lambda_{\mathrm{p}} \mathrm{x}\right)-\cos \left(\lambda_{\mathrm{p}} \mathrm{x}\right)-\mathrm{k}_{\mathrm{r}}\left[\operatorname{senh}\left(\lambda_{\mathrm{p}} \mathrm{x}\right)-\operatorname{sen}\left(\lambda_{\mathrm{p}} \mathrm{x}\right)\right]\right\}
$$

onde:

$$
\mathrm{k}_{\mathrm{r}}=\left[\frac{\cosh \left(\lambda_{\mathrm{p}} \mathrm{l}\right)+\cos \left(\lambda_{\mathrm{p}} \mathrm{l}\right)}{\operatorname{senh}\left(\lambda_{\mathrm{p}} 1\right)+\operatorname{sen}\left(\lambda_{\mathrm{p}} 1\right)}\right]
$$


$\mathrm{C}=$ constante arbitrária de amplitude

VINSON \& SIERAKOWSKI (1987) assumem que a viga de material compósito vibra com a mesma função de deflexão $\left(\mathrm{V}_{\mathrm{p}}(\mathrm{x})\right)$ de um material isotrópico, sendo assim, ambas possuem as mesmas formas de vibrar. Entretanto, as frequências naturais de uma viga de material compósito são dadas por:

$$
\omega_{\mathrm{p}}=\frac{\left(\lambda_{\mathrm{p}} \mathrm{L}\right)^{2}}{\mathrm{~L}^{2}} \sqrt{\frac{\mathrm{bD}_{11}}{\rho \mathrm{A}}}
$$

onde:

$\mathrm{D}_{11}=$ componente da matriz de rigidez do laminado

Constata-se então, que a rigidez do laminado influencia diretamente a determinação das frequências naturais. Desta forma, KIN \& GUPTA (1990) verificaram qual era a influência do número de camadas e da razão de aspecto (relação entre largura e comprimento das amostras laminadas) nas frequências naturais em placas livre-livre de material compósito, constatando posteriormente algumas sensíveis alterações nas respostas das estruturas. Na mesma direção pensaram HWANG et al (1992) que realizaram ensaios modais livre-livre em placas laminadas simétricas com orientação de fibra $0^{\circ}$ e $90^{\circ}$ bem como $+45^{\circ}$ e $-45^{\circ}$, obtendo resultados diferentes.

Obtidas as frequências naturais e os modos de vibrar, caminha-se então para a determinação do amortecimento da estrutura. Segundo VAROTO (1991) os modelos matemáticos mais usados para descrever o mecanismo de amortecimento são o modelo viscoso e o histerético, também identificado como amortecimento estrutural. O primeiro tem as forças de amortecimento proporcionais à velocidade relativa dos pontos da estrutura. $\mathrm{O}$ segundo tem as forças proporcionais aos deslocamentos. Outro aspecto importante é saber como o amortecimento está distribuído na estrutura sendo ainda classificado como proporcional ou não proporcional. CLOUGH \& PENZIEN (1975) mostram o amortecimento viscoso proporcional como uma combinação da massa e da rigidez da estrutura. Portanto, existem várias alternativas de se modelar bem como medir o amortecimento de uma estrutura. 
Determinação do Amortecimento de um Sistema com 1 Grau de Liberdade - A Viga

A viga fixada-livre da FIGURA (2.3-1) pode ser tratada como sistema com um grau de liberdade que possui equação de movimento dada por:

$$
m \ddot{v}(t)+c \dot{v}(t)+k v(t)=p(t)
$$

onde:

$\mathrm{m}=$ massa da viga

$\mathrm{c}=$ amortecimento da viga

$\mathrm{k}=$ rigidez da viga

$\mathrm{p}(\mathrm{t})=$ carregamento dinâmico

A solução da equação admite a seguinte forma para $p(t)=0$ :

$$
\mathrm{v}(\mathrm{t})=\mathrm{Ge}^{\mathrm{st}}
$$

onde:

$\mathrm{G}=$ constante

Substituindo (2.3-12) em (2.3-13) tem-se:

$$
\left(\mathrm{ms}^{2}+\mathrm{cs}+\mathrm{k}\right) \cdot \mathrm{Ge}^{\mathrm{st}}=0
$$

Então:

$$
\mathrm{s}^{2}+\frac{\mathrm{c}}{\mathrm{m}} \mathrm{s}+\omega^{2}=0
$$

onde:

$\omega_{\mathrm{n}}{ }^{2}=\mathrm{k} / \mathrm{m}$ (frequência natural quadrática do sistema)

Assim, a solução da equação (2.3-15) será: $s=-\frac{c}{2 m} \pm \sqrt{\left(\frac{c}{2 m}\right)^{2}-\omega^{2}}$

Se a raiz quadrada presente na solução for nula significa que $\omega=\mathrm{c} / 2 \mathrm{~m}$. Nestas condições o amortecimento do sistema será chamado de crítico e terá a seguinte forma:

$$
\mathrm{c}_{\mathrm{c}}=2 \mathrm{~m} \omega
$$

Então, a resposta do sistema será dada por:

$$
\mathrm{v}(\mathrm{t})=\left(\mathrm{G}_{1}+\mathrm{G}_{2} \mathrm{t}\right) \cdot \mathrm{e}^{-\omega t}
$$


onde:

$\mathrm{G}_{1}=$ constante

$\mathrm{G}_{2}=$ constante

Introduzindo as condições iniciais, obtém-se a resposta de um sistema criticamente amortecido:

$$
v(t)=[v(0)[(1+\omega t)]+\dot{v}(0) t] e^{-\omega t}
$$

Entretanto, se o amortecimento (c) for menor que o amortecimento crítico $\left(\mathrm{c}_{\mathrm{c}}\right)$, tornase conveniente expressar o amortecimento por um fator de amortecimento (amortecimento estrutural):

$$
\xi=\frac{\mathrm{c}}{\mathrm{c}_{\mathrm{c}}}=\frac{\mathrm{c}}{2 \mathrm{~m} \omega}
$$

Assim, a solução da equação de movimento será:

$$
\mathrm{s}=-\xi \omega \pm \sqrt{(\xi \omega)^{2}-\omega^{2}}
$$

E a frequência de vibração amortecida é dada por:

$$
\omega_{\mathrm{D}}=\sqrt{(\xi \omega)^{2}-\omega^{2}}
$$

A resposta do sistema é dada por:

$$
v(t)=e^{-\xi \omega t}\left(G_{1} e^{i \omega_{D} t}+G_{2} e^{-i \omega_{D} t}\right)
$$

O termo que está entre parênteses representa um movimento harmônico simples:

$$
v(t)=e^{-\xi \omega t}\left(A \cdot \operatorname{sen} \omega_{D} t+B \cdot \cos \omega_{D} t\right)
$$

Com a imposição das condições iniciais tem-se: 
$v(t)=e^{-\xi \omega t}\left(\frac{\dot{\mathrm{v}}(0)+\mathrm{v}(0) \xi \omega}{\omega_{D}} \cdot \operatorname{sen} \omega_{D} \mathrm{t}+\mathrm{v}(0) \cdot \cos \omega_{D} \mathrm{t}\right)$

A FIGURA (2.3-2) ilustra a resposta de um sistema cujo amortecimento é menor que o crítico.

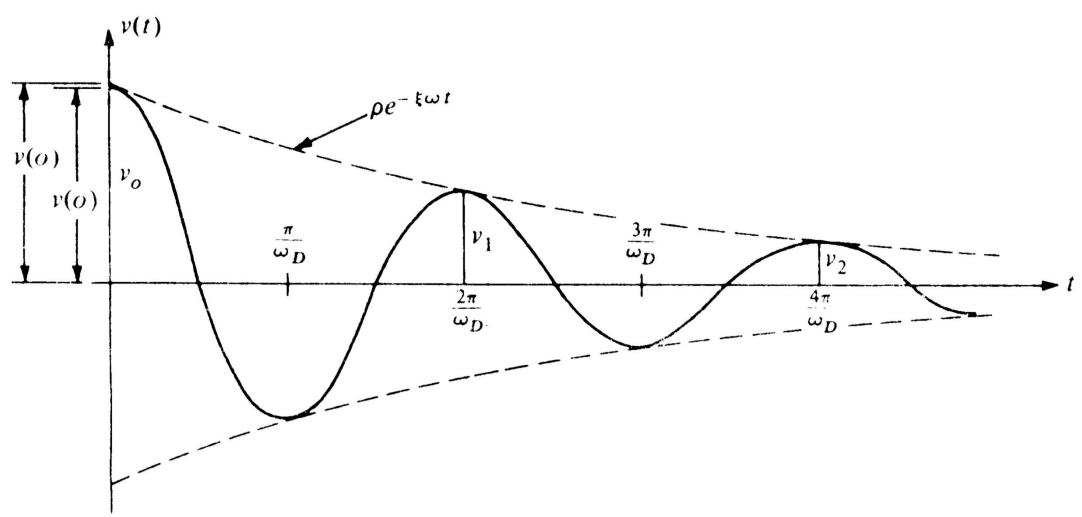

FIGURA (2.3-2) - Resposta do Sistema Sub-Amortecido

CLOUGH \& PENZIEN (1975)

Através da FIGURA (2.3-2) é possível obter a seguinte relação:

$$
\frac{\mathrm{v}_{\mathrm{n}}}{\mathrm{v}_{\mathrm{n}+1}}=\exp \left(2 \pi \xi \frac{\omega}{\omega_{\mathrm{D}}}\right)
$$

Então:

$$
\delta \equiv \ln \frac{\mathrm{v}_{\mathrm{n}}}{\mathrm{v}_{\mathrm{n}+1}}=2 \pi \xi \frac{\omega}{\omega_{\mathrm{D}}}
$$

onde:

$$
\delta=\frac{2 \pi \xi}{\sqrt{1-\xi^{2}}}(\text { decremento logarítmico })
$$

Segundo CLOUGH \& PENZIEN (1975) a equação (2.3-25) pode ser escrita como uma série expandida:

$$
\frac{\mathrm{v}_{\mathrm{n}}}{\mathrm{v}_{\mathrm{n}+1}}=\mathrm{e}^{\delta} \cong \mathrm{e}^{2 \pi \xi}=1+2 \pi \xi+\left(\frac{2 \pi \xi}{2 !}\right)+\ldots
$$


Assim , para valores de amortecimento pequenos (entre 0,05 e 0,2) é possível obter:

$$
\xi=\frac{\mathrm{v}_{\mathrm{n}}-\mathrm{v}_{\mathrm{n}+1}}{2 \pi \mathrm{v}_{\mathrm{n}+1}}
$$

E no caso do amortecimento ser muito pequeno tem-se:

$$
\xi=\frac{v_{n}-v_{n+m}}{2 m \pi v_{n+m}}
$$

onde:

$\mathrm{m}=$ número de ciclos

Para finalizar, há ainda os sistemas que possuem o amortecimento maior do que o crítico (sistema sobre-amortecido), ou seja, o amortecimento estrutural ( $\xi$ ) é maior que a unidade.

Apesar da possibilidade de classificar os sistemas como criticamente amortecidos, sub e sobre-amortecidos, é ainda muito cedo para poder prever como os mecanismos de perda de energia atuam na estrutura. Consequentemente, não é comum determinar o coeficiente de amortecimento através de uma expressão genérica para um sistema mecânico mais complexo que venha ser modelado. Por este motivo, o amortecimento em muitos sistemas estruturais deve ser calculado diretamente por métodos experimentais. CLOUGH \& PENZIEN (1975) descrevem alguns desses métodos para a determinação do amortecimento:

\section{Decaimento da Vibração-Livre}

Provavelmente o mais simples e frequentemente usado, consiste em medir o decaimento de vibrações livres. Como já foi visto anteriormente, quando um sistema de um grau de liberdade vibra livremente pode-se determinar o fator de amortecimento através de duas razões de amplitude de deslocamento desenvolvidas num intervalo de m ciclos. Então, se $v_{n}$ é a amplitude de vibração em algum tempo e $v_{n+m}$ é a amplitude após $m$ ciclos, o fator de amortecimento será dado por:

$$
\xi=\frac{\delta_{\mathrm{m}}}{2 \pi \mathrm{m}\left(\omega / \omega_{\mathrm{D}}\right)} \cong \frac{\delta_{\mathrm{m}}}{2 \pi \mathrm{m}}
$$

onde:

$$
\begin{aligned}
& \delta_{\mathrm{m}}=\ln \frac{\mathrm{v}_{\mathrm{n}}}{\mathrm{v}_{\mathrm{n}+\mathrm{m}}} \text { (decremento logarítmico) } \\
& \omega=\text { frequência natural } \\
& \omega_{\mathrm{D}}=\text { frequência natural amortecida }
\end{aligned}
$$




$$
\mathrm{m}=\text { número de ciclos }
$$

Para a maioria das estruturas, o amortecimento é menor que 0,2 então, a forma aproximada que desconsidera a mudança de frequência para o amortecimento é suficientemente acurada. A maior vantagem desse método é que exige poucos equipamentos para a instrumentação.

\section{Amplificação da Ressonância}

Outra técnica para determinar o amortecimento esta baseada no comportamento transiente da resposta harmônica e então requer uma amplificação das excitações harmônicas que são prescritas em frequências e amplitudes. Com um equipamento adequado, a resposta em frequência de uma estrutura pode ser construída através de um carregamento harmônico $\left(\mathrm{p}_{\mathrm{o}} \sin \omega \mathrm{t}\right)$ aplicado numa sequência de frequências pouco espaçadas ao qual a faixa de frequência de ressonância e o resultado das amplitudes de deslocamentos sejam tratadas como função das frequências que foram aplicadas. A FIGURA (2.3-3) mostra uma curva para uma estrutura moderadamente amortecida.

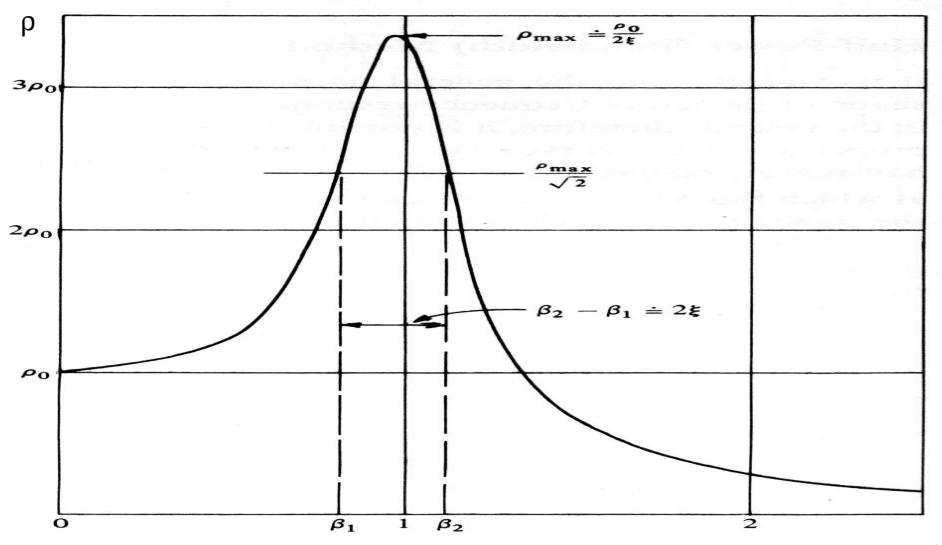

FIGURA (2.3-3) - Amplificação da Ressonância

CLOUGH \& PENZIEN (1975)

Existe então, uma relação entre o amortecimento e as amplitudes de resposta estática (frequência de excitação nula) e de resposta na ressonância.

$$
\xi=\frac{1}{2} \frac{\rho_{\mathrm{o}}}{\rho_{\beta=1}}
$$

onde: 
$\rho_{\mathrm{o}}=$ amplitude de resposta estática

$\rho_{\beta=1}=$ amplitude de resposta na ressonância

Na prática é muito difícil aplicar o valor exato da frequência de ressonância. Então é mais conveniente obter a amplitude máxima de resposta $\left(\rho_{\max }\right)$ :

$$
\xi=\frac{1}{2} \frac{\rho_{\mathrm{o}}}{\rho_{\max }} \frac{\omega}{\omega_{\mathrm{D}}} \cong \frac{1}{2} \frac{\rho_{\mathrm{o}}}{\rho_{\max }}
$$

O erro nessa aproximação consiste novamente em desconsiderar a diferença entre as frequências amortecidas e desamortecidas. O maior problema desse método é que muitos tipos de carregamento não são aplicados em frequência nula.

\section{Método "Half-Power" (Método da Meia-Potência)}

A forma da onda de resposta é controlada pela soma de amortecimentos num sistema. Então, pode-se derivar o fator de amortecimento através de muitas propriedades da curva de resposta. Uma das mais convenientes propriedades utilizadas é a largura de banda ao qual o fator de amortecimento é determinado pelas frequências onde a resposta é reduzida para $1 / \sqrt{2}$ da amplitude, ou seja, nessas frequências a potência de entrada é reduzida pela metade (pontos de meia potência).

A FIGURA (2.3-4) estabelece uma relação entre o fator de amortecimento e a largura de banda:

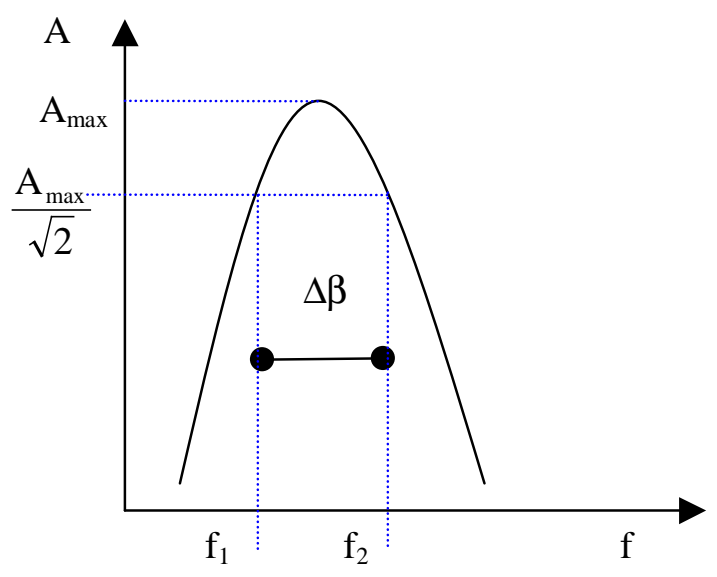

FIGURA (2.3-4) - Largura de banda na frequência de ressonância 


$$
\xi \cong \frac{\Delta \beta}{2}=\frac{\mathrm{f}_{2}-\mathrm{f}_{1}}{\mathrm{f}_{2}+\mathrm{f}_{1}}
$$

onde:

$\Delta \beta=$ largura de banda

$\mathrm{f}_{1}$ e $\mathrm{f}_{2}=$ frequências

\section{Perda de Energia por Ciclo (Teste de Ressonância)}

Se o equipamento é capaz de medir a diferença da fase entre a força de entrada e os deslocamentos resultantes, o amortecimento pode ser calculado por testes executados somente na ressonância, não havendo necessidade de construir a Função de Resposta em Frequência (FRF). O procedimento envolve estabelecer a ressonância por ajuste da frequência de entrada até a resposta ficar $90^{\circ}$ fora de fase em relação ao carregamento aplicado. Então, o carregamento aplicado é exatamente balanceado por uma força de amortecimento, tal que a diferença entre o carregamento aplicado e os deslocamentos resultantes seja graficada para um ciclo de carregamento como mostra a FIGURA (2.3-5). O resultado pode ser interpretado como um diagrama amortecimento-força-deslocamento.

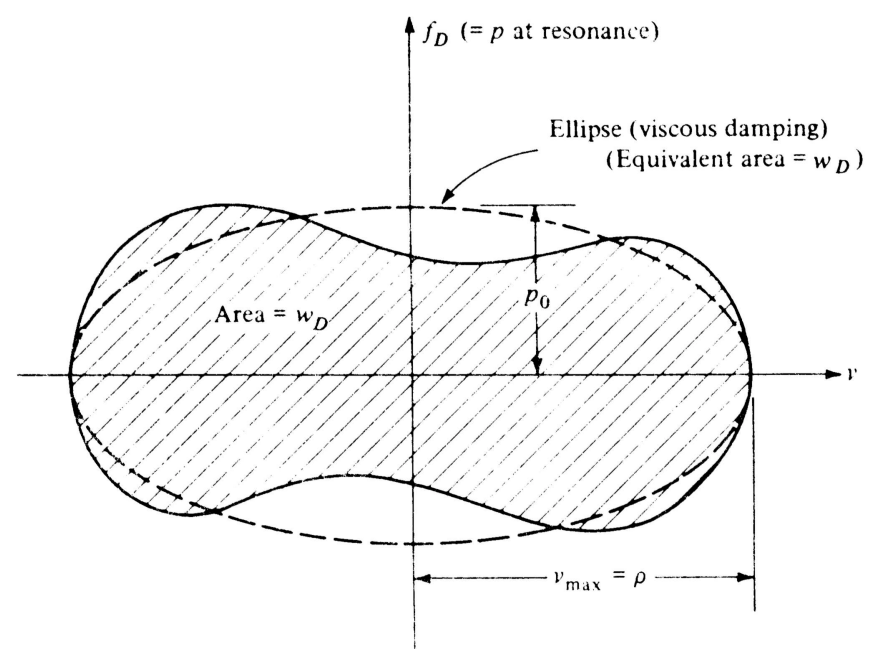

FIGURA (2.3-5) - Energia de amortecimento real e equivalente por ciclo CLOUGH \& PENZIEN (1975)

Se a estrutura possui um amortecimento viscoso linear, a curva será uma elipse. Neste caso o coeficiente de amortecimento (c) pode ser diretamente determinado a partir da máxima força de amortecimento pela máxima velocidade: 


$$
\mathrm{c}=\frac{\mathrm{f}_{\mathrm{D}, \max }}{\dot{\mathrm{v}}_{\max }}=\frac{\mathrm{p}_{\mathrm{o}}}{\omega \rho}
$$

onde:

$$
\begin{aligned}
& \dot{\mathrm{v}}_{\text {max }}=\omega \rho \\
& \rho=\mathrm{v}_{\max } \\
& \mathrm{p}_{\mathrm{o}}=\text { amplitude da elipse (eixo } \mathrm{f}_{\mathrm{D}} \text { ) }
\end{aligned}
$$

Se o amortecimento é viscoso e não-linear, a forma do diagrama não será uma elipse. Neste caso, um coeficiente equivalente de amortecimento viscoso poderia ser calculado e poderia causar a mesma perda de energia por ciclo. Em outras palavras, o amortecimento viscoso equivalente está associado ao diagrama elíptico tendo a mesma área e o mesmo máximo deslocamento. Neste sentido, a linha tracejada é equivalente a linha cheia. Então:

$$
\mathrm{p}_{\mathrm{o}}=\frac{\mathrm{w}_{\mathrm{D}}}{\pi \rho}
$$

onde:

$\mathrm{W}_{\mathrm{D}}=$ área do diagrama $=$ energia dissipada por ciclo

Substituindo (2.3-35) em (2.3-34) tem-se o coeficiente equivalente de amortecimento viscoso

$$
\mathrm{c}_{\mathrm{eq}}=\frac{\mathrm{w}_{\mathrm{D}}}{\pi \omega \rho^{2}}
$$

Em muitos casos, é mais conveniente definir o amortecimento em termos do fator de amortecimento crítico. Para esta proposta, é necessário definir também uma medida do coeficiente de amortecimento crítico da estrutura e isto pode ser expresso por:

$$
c_{\mathrm{c}}=\frac{2 \mathrm{k}}{\omega}
$$

A rigidez da estrutura pode ser obtida utilizando a mesma instrumentação para medir o amortecimento. Tem-se: 


$$
\mathrm{k}=\frac{2 \mathrm{w}_{\mathrm{s}}}{\rho^{2}}
$$

onde:

$\mathrm{w}_{\mathrm{s}}$ = área do diagrama determinado pela rigidez da estrutura = energia dissipada por ciclo

Combinando (2.3-38) com (2.3-36) chega-se a:

$$
\xi=\frac{\mathrm{c}}{\mathrm{c}_{\mathrm{c}}}=\frac{\mathrm{w}_{\mathrm{D}}}{4 \pi \mathrm{w}_{\mathrm{s}}}
$$

Então, o fator de amortecimento depende diretamente da perda de energia por ciclo e da energia armazenada no máximo deslocamento. Entretanto, para alguns mecanismos de amortecimento viscoso, a perda de energia no sistema será proporcional à frequência e portanto o amortecimento também será. Outro aspecto, é que o coeficiente de amortecimento equivalente viscoso obtido é inversamente proporcional à frequência:

$$
\mathrm{c}_{\mathrm{eq}}=\xi \frac{4 \mathrm{w}_{\mathrm{s}}}{\omega \rho^{2}}
$$

Baseando-se neste conceito, LUCATO (1991) determinou o fator de amortecimento para o primeiro modo de vibrar de trens de pouso feitos de material compósito (epoxi com fibra de vidro contínua) para aviões pequenos. Segundo os resultados obtidos, as lâminas de compósito mostraram um amortecimento $62 \%$ maior quando comparadas com as lâminas de aço, constatando assim um grau de amortecimento maior que os trens de pouso convencionais (metálicos). Isto possibilitou ao projeto uma flexibilidade e resistência para absorver impactos durante pouso, decolagens e manobras no solo, não introduzindo desta forma grandes carregamentos na aeronave, sendo possível aumentar a vida em fadiga bem como proporcionar um conforto maior ao passageiro.

Embora o mecanismo de amortecimento viscoso seja conveniente para a equação de movimento de estruturas, os resultados de experimentos raramente correspondem a este tipo de comportamento de perda de energia. Em muitos casos práticos o equivalente viscoso em termos de energia por ciclo preve uma aproximação razoável dos resultados experimentais.

Um modelo matemático que possui as propriedades independentes da frequência é previsto pelo conceito de amortecimento histerético, sendo definido por uma força de amortecimento em fase com a velocidade e proporcional aos deslocamentos: 


$$
\mathrm{f}_{\mathrm{D}}=\zeta \mathrm{k}|\mathrm{v}| \frac{\dot{\mathrm{v}}}{|\dot{\mathrm{v}}|}
$$

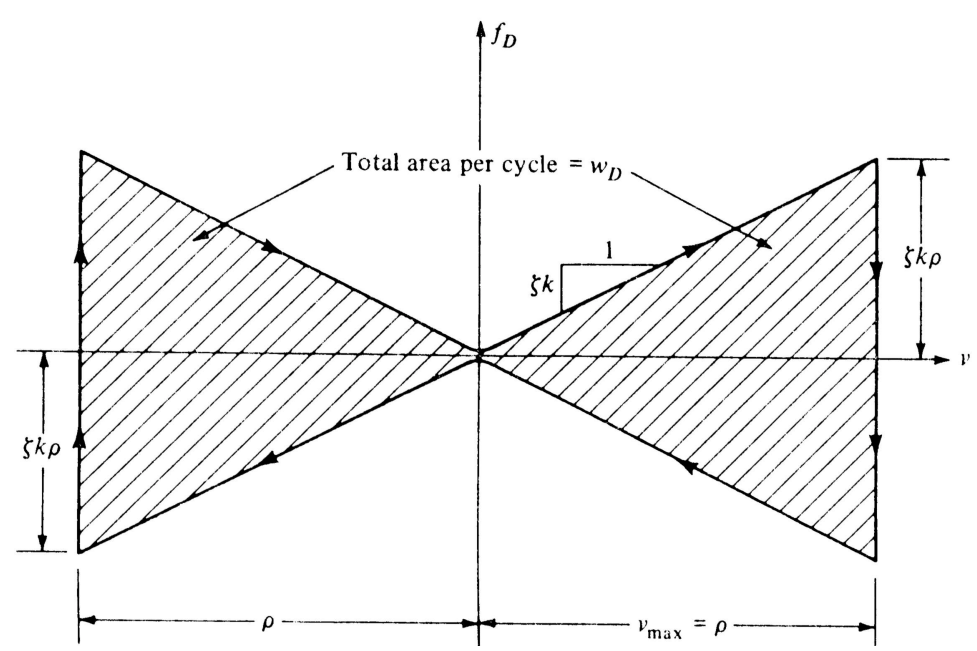

FIGURA (2.3-6) - Força de amortecimento histerético x deslocamento CLOUGH \& PENZIEN (1975)

A FIGURA (2.3-7) mostra o diagrama força-deslocamento para o amortecimento histerético durante um ciclo de deslocamento harmônico.

A energia histerética perdida por ciclo é dada por:

$$
\mathrm{w}_{\mathrm{D}}=2 \zeta \mathrm{k} \rho^{2}
$$

onde:

$\zeta=$ coeficiente de amortecimento histerético

Combinando (2.3-42) com (2.3-38) e (2.3-39), tem-se:

$$
\zeta=\pi \xi
$$

Então, fica evidente que o coeficiente de amortecimento histerético é independente da frequência na qual o teste foi executado. Em contraste, a equação (2.3-40) mostra que o amortecimento viscoso depende da frequência. 
Além dos métodos acima citados por CLOUGH \& PENZIEN (1975), EWINS(1984) descreve em seu trabalho que é possível através da FRF (Módulo e Fase) traçar o gráfico polar (Parte Imaginária da FRF contra Parte Real da FRF) mostrado na FIGURA (2.3-7).
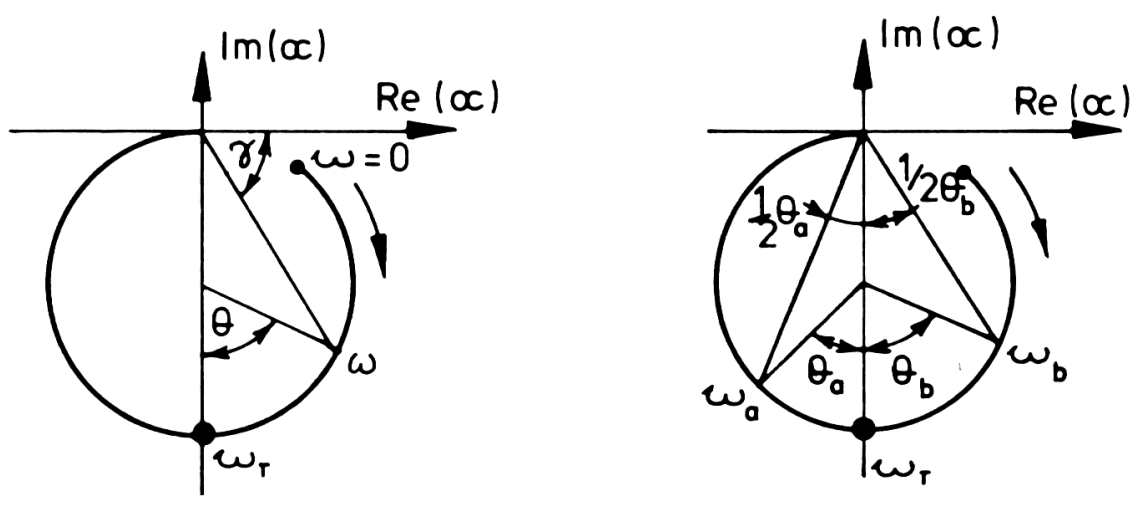

FIGURA (2.3-7) - Propriedades do gráfico polar (Círculo Modal) EWINS (1984)

O gráfico polar revela que:

$$
\operatorname{tg} \gamma=\frac{\eta_{\mathrm{r}}}{1-\left(\frac{\omega}{\omega_{\mathrm{r}}}\right)^{2}}
$$

onde:

$\gamma=$ ângulo de fase

$\eta_{\mathrm{r}}=$ fator de perda (loss factor) do modo $\mathrm{r}$

$\omega_{\mathrm{r}}=$ frequência natural do modo $\mathrm{r}$

Através de propriedades geométricas, tem-se que:

$$
\operatorname{tg}\left(90^{\circ}-\gamma\right)=\operatorname{tg}(\theta / 2)=\frac{1-\left(\frac{\omega}{\omega_{\mathrm{r}}}\right)^{2}}{\eta_{\mathrm{r}}}
$$

Nota-se que através das propriedades do círculo modal é possível analisar um sistema com multíplos graus de liberdade mesmo sem conhecer exatamente a localização da frequência natural. Então, examina-se o espaçamento relativo de pontos medidos ao redor do 
círculo próximo de cada ressonância, para que seja possível determinar este valor. Sendo assim, dois pontos específicos do círculo $\left(\omega_{\mathrm{a}}\right.$ e $\left.\omega_{\mathrm{b}}\right)$ foram tomados, tal que $\omega_{\mathrm{b}}<\omega_{\mathrm{r}}$ e $\omega_{\mathrm{a}}>\omega_{\mathrm{r}}$ :

$$
\operatorname{tg}\left(\theta_{\mathrm{b}} / 2\right)=\frac{1-\left(\frac{\omega_{\mathrm{b}}}{\omega_{\mathrm{r}}}\right)^{2}}{\eta_{\mathrm{r}}} \quad \text { e } \quad \operatorname{tg}\left(\theta_{\mathrm{a}} / 2\right)=\frac{\left(\frac{\omega_{\mathrm{a}}}{\omega_{\mathrm{r}}}\right)^{2}-1}{\eta_{\mathrm{r}}}
$$

Assim, a expressão exata de $\eta_{\mathrm{r}}$ é dada por:

$$
\eta_{\mathrm{r}}=\frac{\omega_{\mathrm{a}}^{2}-\omega_{\mathrm{b}}^{2}}{\omega_{\mathrm{r}}^{2}\left(\operatorname{tg}\left(\theta_{\mathrm{a}} / 2\right)+\operatorname{tg}\left(\theta_{\mathrm{b}} / 2\right)\right)}
$$

Para estruturas levemente amortecidas, ou seja, com $\eta_{\mathrm{r}}$ abaixo de 3\%. É possível simplificar a expressão em:

$$
\eta_{\mathrm{r}} \approx \frac{2\left(\omega_{\mathrm{a}}-\omega_{\mathrm{b}}\right)}{\omega_{\mathrm{r}}\left(\operatorname{tg}\left(\theta_{\mathrm{a}} / 2\right)+\operatorname{tg}\left(\theta_{\mathrm{b}} / 2\right)\right)}
$$

Entretanto, sabe-se que: $\eta_{\mathrm{r}}=2 \zeta_{\mathrm{r}}$. Portanto, o fator de amortecimento modal $\left(\zeta_{\mathrm{r}}\right)$ para uma estrutura levemente amortecida é dado por:

$$
\zeta_{\mathrm{r}} \approx \frac{\left(\omega_{\mathrm{a}}-\omega_{\mathrm{b}}\right)}{\omega_{\mathrm{r}}\left(\operatorname{tg}\left(\theta_{\mathrm{a}} / 2\right)+\operatorname{tg}\left(\theta_{\mathrm{b}} / 2\right)\right)}
$$

Portanto, é possível obter o amortecimento modal pelo equacionamento dado acima, para uma estrutura em análise considerada como um sistema contínuo que possui múltiplos graus de liberdade. Entretanto, neste ponto, torna-se necessário o uso do método de KENNEDY \& PANCU que é capaz de determinar um sistema de um grau de liberdade equivalente ao modo requisitado para a viga em estudo (LIRANI, 1985), fazendo com que um círculo se ajuste ao modo desejado para análise. Tal método é muito simples e desconsidera a influência que os demais modos gera sobre o modo desejado, realizando o ajuste através de pontos escolhidos adequadamente para que seja possível determinar o centro do círculo modal (FIGURA (2.3-8)). Entretanto, segundo VAROTO (1991) a 
aplicação do método de ajustagem por KENNEDY \& PANCU restringe-se aos casos em que os modos de vibrar em estudo sejam pouco acoplados.

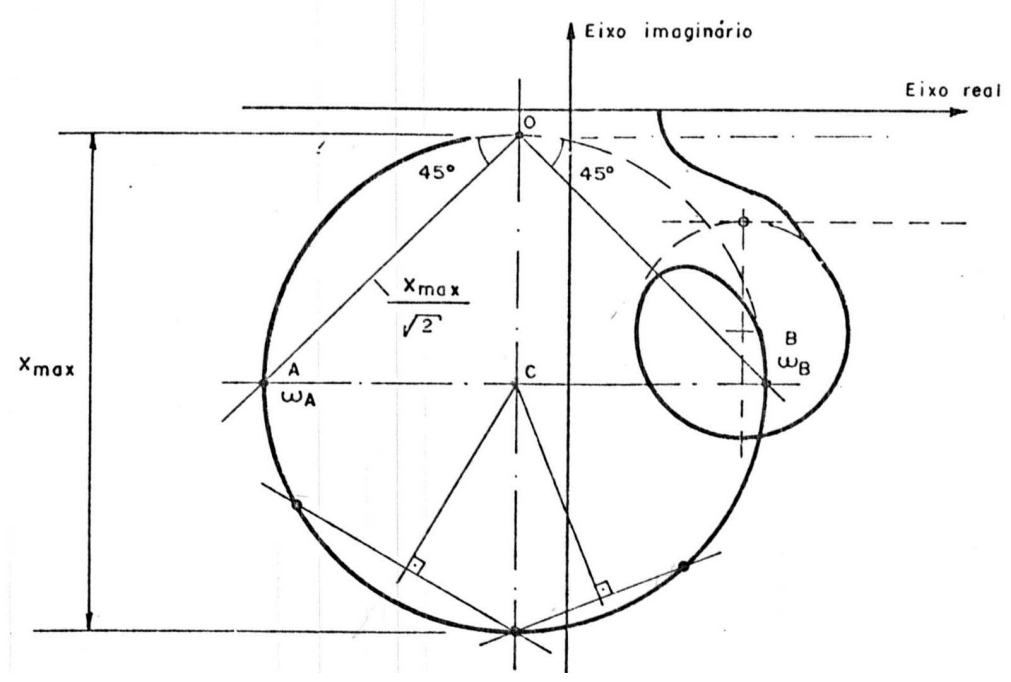

FIGURA (2.3-8) - Método de KENNEDY \& PANCU para determinação de um sistema equivalente

(LIRANI, 1985)

Assim de uma maneira geral, o fenômeno do amortecimento é objeto de pesquisa até os dias atuais, principalmente o amortecimento presente em materiais compósitos. Encontrase na literatura uma vasta coletânea de trabalhos que procuram estimar os fatores de amortecimento bem como tentativas para modelagem do fenômeno do amortecimento. Realmente, a modelagem do fenômeno de amortecimento para materiais compósitos é muito mais complexa, não produzindo até hoje resultados muito satisfatórios. Toda essa complexidade foi demonstrada por ADAMS (1982) que citou alguns fatores internos e externos que influenciam no mecanismo de amortecimento dos compósitos, tais como:

-Proporções relativas das propriedades dos reforços e matrizes (frações volumétricas);

-Dimensões do reforço;

-Orientação do reforço em relação ao carregamento;

-Tratamento superficial de alguns reforços;

-Fatores ambientais como: amplitude, frequência e temperatura.

Mesmo assim, é possível encontrar inúmeros trabalhos que tentam modelar o amortecimento através de métodos, ou então medir o amortecimento ou até mesmo tentam combinar métodos de modelagem com técnicas de medir. Um exemplo disto é o trabalho de CUDNEY \& INMAN (1989) que desenvolveram um método capaz de relacionar os parâmetros medidos em um ensaio modal (frequências naturais e fatores de amortecimento) 
com os coeficientes de um modelo de parâmetros distribuídos, que tenta estimar os parâmetros de amortecimento distribuídos na estrutura. Tentando também prever o mecanismo de amortecimento, KUSTER \& GYSIN (1990) modelaram o amortecimento de materiais compósitos como estrutural histerético. Eles partiram do módulo complexo de Young associado com as propriedades ortotrópicas e obtiveram as propriedades de amortecimento com o auxílio de um modelo discretizado em elementos finitos. GREIF \& HEBERT (1992) utilizaram duas técnicas para caracterizar dinamicamente amostras de materiais compósitos poliméricos reforçados com diferentes tipos de laminação.A primeira técnica era baseada na técnica da amplificação da ressonância, utilizando um shaker para excitar as amostras. A segunda era baseada na utilização de um viscoanalizador Metravib, que apesar de ser aconselhado para o uso de testes de viscoelasticidade em polímeros, buscou-se no trabalho estabelecer limites para a sua aplicação em compósitos. Houve uma comparação entre ambas as técnicas além de uma avalição de possíveis erros de medida, verificando a influência da orientação das lâminas nas respostas e nos fatores de amortecimento. KOO \& LEE (1995) também fizeram análises dinâmicas em material compósito, utilizando como amostra uma viga espessa sob a condição engastada-livre (cantilever). O material compósito era constituído de fibra de carbono e resina epoxídica com a presença de consideráveis deformações causadas por cisalhamento. Sendo assim, eles tentaram identificar variações nos fatores de amortecimento modal com alterações na orientação das fibras. HU \& DOKAINISH (1993) estudaram o amortecimento em compósito tendo como ponto de vista uma análise macromecânica, desenvolveram dois modelos:

1- Modelo viscoelástico de amortecimento

2- Modelo da capacidade de amortecimento específico

Com base nestes modelos, uma investigação é feita para mostrar efeitos de alguns parâmetros tais como: razão de aspecto entre lado e espessura, módulo principal, número total de camadas, arranjo na laminação e condições de contorno.

Nota-se, através destes e outros inúmeros trabalhos que a capacidade de amortecimento permite reduzir amplitudes de oscilação na ressonância, abrindo dessa forma mais uma variável para que o projetista possa utilizar no desenvolvimento de um projeto a base de material compósito polimérico reforçado. Entretanto por vias desses mesmos trabalhos constata-se que a modelagem do mecanismo de amortecimento é algo muito complexo e uma estimativa das frequências naturais desamortecidas e dos modos de vibrar já seria de grande valor para o desenvolvimento inicial de um projeto. Portanto, estas estimativas tornam-se assim, muito atrativas para uma implementação computacional. Desta 
forma, aumenta-se a velocidade de obtenção dos resultados através de técnicas computacionais. Como é sabido, já faz alguns anos que as ferramentas computacionais vêm auxiliando cada vez mais o desenvolvimento de projetos, seja através da possibilidade de construção de modelos geométricos ou seja através da resolução de equações complexas. Sendo assim, atualmente os programas de cálculo de engenharia (CAE - Computer Aided Engineer) estão cada vez mais difundidos no ambiente de projetos, e através de métodos numéricos computacionais torna-se possível obter boas estimativas de resultados. O Método dos Elementos Finitos é um desses métodos que estimam resultados, tais como: gradientes de tensão, gradientes de deformação, frequências naturais, modos de vibrar, gradientes de temperatura, etc. Segue então na próxima seção uma breve discussão sobre o método e como ele é aplicado a problemas de vibração.

\subsection{Método dos Elementos Finitos}

De acordo com a FIGURA (2.2-1), a simulação numérica é a terceira etapa a ser desenvolvida para projetar um componente em material compósito. Ou seja, após a identificação das necessidades do projeto das quais incluem os requisitos, segue a segunda etapa que tem por objetivo determinar o material, a geometria da peça e o processo. Esses três componentes desta etapa devem estar presentes em um único ambiente integrado como discute CARVALHO (1996); assim torna-se viável obter um componente que atenda às necessidades de projeto conciliado com o menor custo possível. Dessa forma, de acordo com os requisitos de projeto, escolhe-se o material que por sua vez determina o tipo de processo que determinará a geometria da peça. Entretanto, a geometria da peça muitas vezes pode especificar o tipo de processo que será utilizado, e este estabelecerá o material e as devidas proporções de material aglomerante e reforçante. Essa peça final deverá então ser analisada através do uso de critérios de resistência, Teoria Clássica de Laminados e cálculo via Método dos Elemento Finitos.

Para prever o desempenho de componentes mecânicos, o projetista dispõe hoje de uma série de ferramentas matemáticas que podem ser aplicadas. Soluções analíticas podem ser usadas em certos casos, mas sua aplicação é limitada a situações específicas onde uma solução matemática da estrutura pode ser encontrada. Uma maneira mais abrangente de tratar problemas estruturais consiste no uso de métodos numéricos de análise. Apesar de tais métodos fornecerem soluções aproximadas, em muitos casos é a única maneira que os projetistas dispõem para encontrar as respostas que procuram. 
O Método dos Elementos Finitos considera a região de solução do problema formada por pequenos elementos interconectados entre si. A região em estudo é analiticamente modelada ou aproximada por um conjunto de elementos discretos pré-definidos. Uma vez que estes elementos possam ser colocados juntos em um número incontável de diferentes configurações, tem-se formas geométricas bastante complexas modeladas. Além disso, possibilita que o projetista tenha bastante flexibilidade na aplicação de cargas e condições de contorno, o que torna este método o mais amplamente utilizado em análises estruturais nos dias de hoje.

O Método dos Elementos Finitos é aplicável a uma grande faixa de problemas de valores de contorno em engenharia. Em um problema de valor de contorno, uma solução é procurada na região do corpo (domínio), enquanto nos contornos desta região os valores das variáveis dependentes (ou suas derivadas) são conhecidos.

De acordo com HUEBNER (1994) o método pode ser sumarizado basicamente em 3 etapas: pré-processamento, solução (solver) e pós-processamento.

\section{Pré-Processamento}

É a etapa de preparação do problema para posteriormente solucioná-lo. É nesta fase que se faz a modelagem do fenômeno, assumindo hipóteses, condições iniciais, condições de contorno e carregamentos, assim como a escolha do elemento, das propriedades dos materiais e da geometria que representará a forma do componente a ser analisado. A seguir são descritas 2 subetapas importantes para o pré-processamento:

- Discretização do contínuo - o contínuo é o corpo físico mostrado na FIGURA (2.4-1), estrutura ou sólido que está sendo analisado. A discretização visualizada na FIGURA (2.4-2) pode ser simplesmente descrita como o processo no qual o domínio é subdividido em um sistema equivalente de elementos finitos, os quais podem ser por exemplo triângulos ou quadriláteros para problemas em duas dimensões ou tetraedros e hexaedros em três dimensões. Estes elementos possuem os chamados nós que podem ser internos ou externos, ou seja, pertencem ao interior do elemento ou estão localizados nas arestas do mesmo. Embora venha se tentando automatizar o processo de subdivisão do domínio, este processo permanece dependendo essencialmente do julgamento e experiência do engenheiro; 


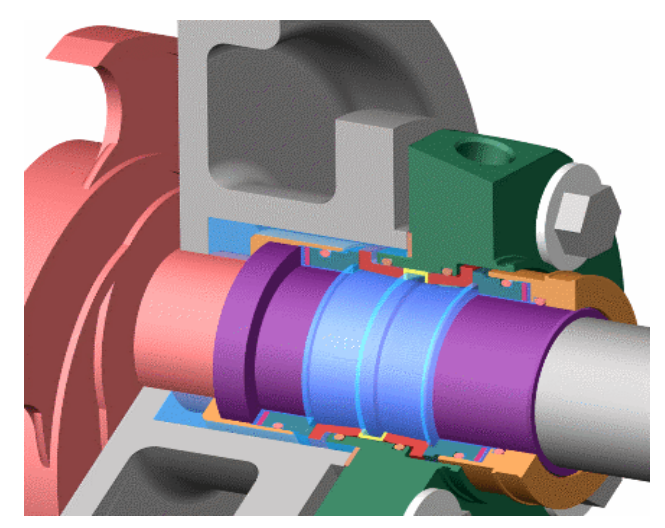

FIGURA (2.4-1) - O contínuo

- Seleção das funções de interpolação - as funções de interpolação ou deslocamento assumidas representam apenas aproximadamente a distribuição exata ou real dos deslocamentos. Geralmente, a forma adotada para as funções de interpolação é a polinomial, pela simplicidade de manipulação matemática. Existem três fatores inter-relacionados que influenciam a seleção da função de interpolação: escolha do tipo e do grau da função (como normalmente o tipo adotado é o polinomial, apenas o grau deve ser escolhido), o tipo das variáveis de campo que descrevem o modelo (normalmente, os deslocamentos nos nós ou suas derivadas) e finalmente, o modelo deve satisfazer certos requisitos que garantam que o resultado numérico se aproxime da solução correta;

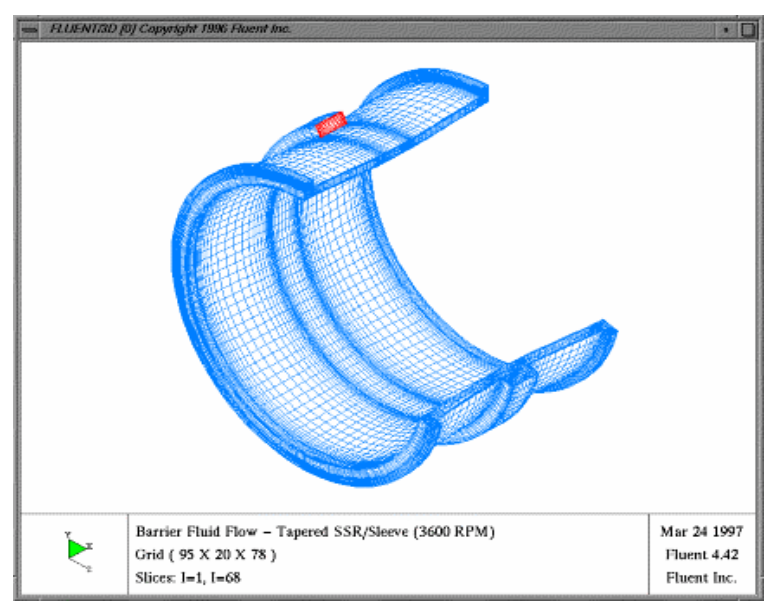

FIGURA (2.4-2) - O contínuo discretizado por inúmeros elementos 


\section{Solução (solver)}

A solução do problema tem como ponto de partida o modelo configurado na etapa anterior. Portanto, a acuracidade das respostas depende basicamente da capacidade do engenheiro em abstrair o fenômeno. A solução é baseada em um algoritmo numérico que visa solucionar da maneira mais rápida e acurada, uma equação diferencial com condições de contorno e/ou condições iniciais impostas pelo modelo. A seguir são descritas algumas subetapas para solucionar um problema:

- Obtenção da matriz de rigidez elementar - a matriz de rigidez consiste dos coeficientes das equações de equilíbrio derivadas das propriedades geométricas e do material de um elemento e pode ser obtida pelo uso do princípio da mínima energia potencial. A rigidez relaciona os deslocamentos nodais às forças aplicadas nos nós. A relação de equilíbrio entre a matriz de rigidez $[\mathrm{k}]$, o vetor força nodal $\{\mathrm{F}\}$ e o vetor deslocamento nodal $\{\mathrm{u}\}$ é expressa como um conjunto de equações algébricas lineares simultâneas, $[\mathrm{k}]\{\mathrm{u}\}=\{\mathrm{F}\}$. A matriz de rigidez para um elemento depende da função de interpolação, da geometria do elemento e das propriedades locais do material;

- Montagem das equações algébricas para todo o domínio - este processo inclui a montagem da matriz de rigidez global para todo o corpo a partir das matrizes de rigidez elementares e do vetor força global a partir dos vetores força elementares. Em geral, a base para um método de montagem é a exigência das interconecções nodais. Os deslocamentos em um nó devem ser os mesmos para todos os elementos adjacentes;

- Soluções para os deslocamentos desconhecidos - as equações algébricas montadas no passo anterior são resolvidas para os deslocamentos desconhecidos. Em problemas lineares, esta é uma aplicação relativamente direta das técnicas de álgebra matricial. Entretanto, para problemas não-lineares, as soluções desejadas são obtidas por uma sequência de passos, cada qual envolvendo a modificação da matriz de rigidez e/ou do vetor força;

- Cálculo das deformações e tensões elementares a partir dos deslocamentos nodais - em certos casos, os deslocamentos nodais são as variáveis em estudo para a solução. Muitas vezes, entretanto, outras quantidades derivadas das variáveis desconhecidas, tais como tensões e deformações, devem ser calculadas. Em geral, tensão e deformação são proporcionais às derivadas dos deslocamentos.

Um aspecto importante é que esses algoritmos numéricos podem ser implementados computacionalmente para agilizar o cálculo. Atualmente é possível encontrar no mercado pacotes computacionais tais como: ANSYS, NASTRAN, ABAQUS e outros. Cada um possuindo facilidades e dificuldades para a modelagem de problemas. 


\section{Pós-Processamento}

Esta é a última etapa. Ela depende apenas das necessidades do engenheiro que está modelando o problema. Ou seja, ela é o conjunto solução da equação diferencial que descreve o fenômeno em estudo como demonstra a FIGURA (2.4-3), podendo ser:

- Deslocamentos nodais;

- Deformações da geometria;

- Gradientes de tensão de acordo com o critério de resistência escolhido;

- Gradientes de temperatura;

- Deslocamentos nodais ao longo do tempo;

- Frequências naturais e modos de vibrar da estrutura.

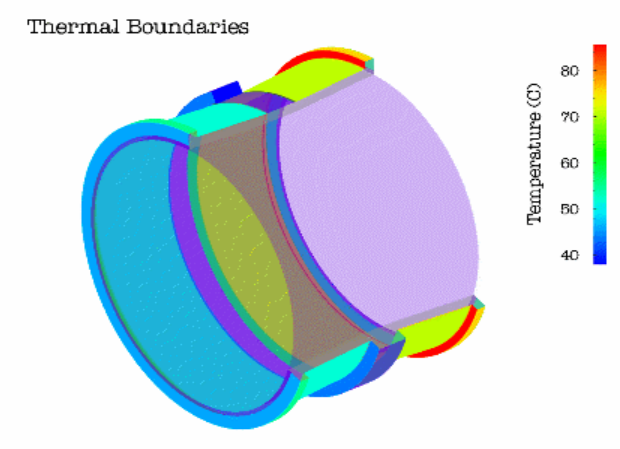

FIGURA (2.4-3) - Típico Pós-Processamento de um pacote comercial

Esses recursos implementados computacionalmente permitem estimar a solução de um problema complexo em um tempo relativamente pequeno, fazendo com que se otimize o tempo de desenvolvimento de projetos de materiais isotrópicos ou anisotrópicos (como exemplo os materiais compósitos) sujeitos a carregamentos estáticos, térmicos, dinâmicos e outros.

Portanto, através do Método dos Elementos Finitos calcula-se as matrizes de massa e rigidez do modelo em análise para depois obter as frequências naturais e os modos de vibrar, desconsiderando os efeitos de amortecimento.

\section{Análise Modal via Método dos Elementos Finitos}

É importante lembrar que um dos primeiros passos é a discretização do contínuo. Portanto, o modelo da viga será discretizado em vários elementos cada qual possuindo massa, rigidez e amortecimento. HUEBNER (1994) descreve que o comportamento 
dinâmico de uma estrutura elástica discretizada possui em algum instante de tempo a energia potencial dada pelo seguinte funcional:

$$
\begin{aligned}
\prod^{(\mathrm{e})}\left(\{\tilde{\delta}\}^{(\mathrm{e})}\right) & \left.=\frac{1}{2} \iint_{\mathrm{A}^{(\mathrm{e})}}[\mid \tilde{\delta}\rfloor^{(\mathrm{e})}[\mathrm{B}]^{\mathrm{T}(\mathrm{e})}[\mathrm{C}]^{(\mathrm{e})}[\mathrm{B}]^{(\mathrm{e})}\{\tilde{\delta}\}^{(\mathrm{e})}-2[\tilde{\delta}]^{(\mathrm{e})}[\mathrm{B}]^{\mathrm{T}(\mathrm{e})}[\mathrm{C}]^{(\mathrm{e})}\left\{\varepsilon_{0}^{*}\right\}^{(\mathrm{e})}\right] \mathrm{t}^{(\mathrm{e})} \mathrm{dA} \mathrm{A}^{(\mathrm{e})} \\
& -\iint_{\mathrm{A}^{(\mathrm{e})}}\left[\mathrm{F}^{*}\right\rfloor^{(\mathrm{e})}\{\tilde{\delta}\}^{(\mathrm{e})} \mathrm{t}^{(\mathrm{e})} \mathrm{dA}^{(\mathrm{e})}-\iint_{\mathrm{C}_{1}^{(\mathrm{e})}}\left[\mathrm{T}^{*}\right]^{(\mathrm{e})}\{\tilde{\delta}\}^{(\mathrm{e})} \mathrm{d} \mathrm{S}^{(\mathrm{e})}
\end{aligned}
$$

onde:

$\prod^{(\mathrm{e})}=$ funcional discretizado para cada elemento

$\{\tilde{\delta}\}^{(\text {e) }}=$ vetor campo de deslocamentos

$[\mathrm{B}]^{(\mathrm{e})}=$ matriz que relaciona deformação com deslocamento

$[\mathrm{C}]^{(\mathrm{e})}=$ matriz de rigidez, ao qual toma diferentes formas dependendo do problema considerado

$\left\{\varepsilon_{0}^{*}\right\}^{(\mathrm{e})}=$ vetor de deformações iniciais

$\left\lfloor F^{*}\right\rfloor^{(\mathrm{e})}=$ forças de corpo

$\left\lfloor\mathrm{T}^{*}\right\rfloor^{(\mathrm{e})}=$ forças de superfície (atuam nos contornos)

$t^{(e)}=$ espessura do elemento

Supondo que o contínuo fosse discretizado por um elemento tridimensional, tem-se que os campos de deslocamento seriam expressos por:

$$
\{\tilde{\delta}\}^{\mathrm{e}}=\left(\begin{array}{c}
\mathrm{u}(\mathrm{x}, \mathrm{y}, \mathrm{z}, \mathrm{t}) \\
\mathrm{v}(\mathrm{x}, \mathrm{y}, \mathrm{z}, \mathrm{t}) \\
\mathrm{w}(\mathrm{x}, \mathrm{y}, \mathrm{z}, \mathrm{t})
\end{array}\right)^{\mathrm{e}}=\left(\begin{array}{c}
\sum \mathrm{Ni}(\mathrm{x}, \mathrm{y}, \mathrm{z}) \mathrm{u}_{\mathrm{i}}(\mathrm{t}) \\
\sum \mathrm{Ni}(\mathrm{x}, \mathrm{y}, \mathrm{z}) \mathrm{v}_{\mathrm{i}}(\mathrm{t}) \\
\sum \mathrm{Ni}(\mathrm{x}, \mathrm{y}, \mathrm{z}) \mathrm{w}_{\mathrm{i}}(\mathrm{t})
\end{array}\right)^{\mathrm{e}}
$$

onde:

$\mathrm{u}, \mathrm{v}, \mathrm{w}=$ componentes de deslocamento dependentes do tempo nas três direções $(\mathrm{x}, \mathrm{y}, \mathrm{z})$

$\mathrm{Ni}=$ funções de interpolação ou funções de forma 
O objetivo do problema passa a ser encontrar as funções de interpolação que minimizem o funcional dado acima. Como estas funções são determinadas pelos elementos que discretizam o contínuo, a escolha do elemento ideal para a discretização é de suma importância para a acuracidade das respostas, pois elas determinaram as matrizes de massa, rigidez e amortecimento.

Resolvido o problema da discretização, o problema agora torna-se solucionar a equação governante para problemas dinâmicos, que depende das propriedades elementares:

$$
[\mathrm{M}]^{(\mathrm{e})},[\mathrm{C}]^{(\mathrm{e})} \text { e }[\mathrm{K}]^{(\mathrm{e})}
$$

Segundo o ANSYS User's Manual Theory (1995), as matrizes elementares referenciadas acima são calculadas da seguinte forma:

$$
[\mathrm{M}]^{(\mathrm{e})}=\rho_{\mathrm{c}} \int_{\mathrm{vol}}[\mathrm{N}]^{\mathrm{T}}[\mathrm{N}] \mathrm{d} \mathrm{dvol}
$$

onde:

$[\mathrm{M}]^{(\mathrm{e})}=$ matriz de massa elementar (consistente)

$\rho_{\mathrm{c}}=$ densidade do compósito

$[\mathrm{N}]=$ matriz de funções de interpolação

$$
[\mathrm{K}]^{(\mathrm{e})}=\int_{\text {vol }}[\mathrm{B}]^{\mathrm{T}}[\mathrm{D}][\mathrm{B}] \mathrm{dvol}
$$

onde:

$[\mathrm{K}]^{(\mathrm{e})}=$ matriz de rigidez elementar

[B] = matriz deformação-deslocamento, baseada nas funções de forma do elemento

[D] = matriz de elasticidade do laminado (definido como ortotrópico)

onde:

$$
[D]^{-1}=\left[\begin{array}{cccccc}
1 / \mathrm{E}_{\mathrm{x}} & -v_{\mathrm{xy}} / \mathrm{E}_{\mathrm{x}} & -v_{\mathrm{xz}} / \mathrm{E}_{\mathrm{x}} & 0 & 0 & 0 \\
-v_{\mathrm{yx}} / \mathrm{E}_{\mathrm{x}} & 1 / \mathrm{E}_{\mathrm{y}} & -v_{\mathrm{yz}} / \mathrm{E}_{\mathrm{x}} & 0 & 0 & 0 \\
-v_{\mathrm{zx}} / \mathrm{E}_{\mathrm{x}} & -v_{\mathrm{zy}} / \mathrm{E}_{\mathrm{x}} & 1 / \mathrm{E}_{\mathrm{z}} & 0 & 0 & 0 \\
0 & 0 & 0 & 1 / \mathrm{G}_{\mathrm{xy}} & 0 & 0 \\
0 & 0 & 0 & 0 & 1 / \mathrm{G}_{\mathrm{yz}} & 0 \\
0 & 0 & 0 & 0 & 0 & 1 / \mathrm{G}_{\mathrm{xz}}
\end{array}\right]
$$

$\{\mathrm{F}(\mathrm{t})\}^{(\mathrm{e})}=$ vetor de forças que atua no elemento

$[\mathrm{C}]^{(\mathrm{e})}=$ depende do modelo de amortecimento adotado 
A montagem das matrizes globais é tido como o próximo passo para a solução do problema. Sendo assim, o pacote computacional realiza a montagem das matrizes globais automaticamente através das matrizes elementares:

$$
[\mathrm{M}]\{\ddot{\delta}\}+[\mathrm{C}]\{\dot{\delta}\}+[\mathrm{K}]\{\delta\}=\{\mathrm{F}(\mathrm{t})\}
$$

onde:

$[\mathrm{M}]=$ matriz de massa global

$[\mathrm{C}]$ = matriz de amortecimento global

$[\mathrm{K}]$ = matriz de rigidez global

$\{\mathrm{F}(\mathrm{t})\}=$ vetor de forças global

Tanto $[\mathrm{M}]$ como $[\mathrm{C}]$ podem ser calculadas como concentradas ou distribuídas. Para o cálculo da concentrada, considera-se que a propriedade está localizada nos nós. Isto aumenta a velocidade de cálculo porém reduz a acuracidade dos resultados, acontecendo justamente o contrário com as propriedades distribuídas. Uma vez que as matrizes globais são montadas, falta considerar condições iniciais nulas ou não, sistemas amortecidos ou não-amortecidos, forças harmônicas, periódicas, aperiódicas... Inicia-se assim a solução do problema para um sistema com $\mathrm{N}$ graus de liberdade não amortecido:

$$
[\mathrm{M}]_{\mathrm{NxN}}\{\ddot{\delta}\}_{\mathrm{Nx} 1}+[\mathrm{K}]_{\mathrm{NxN}}\{\delta\}_{\mathrm{Nx} 1}=\{\mathrm{F}(\mathrm{t})\}_{\mathrm{Nx} 1}
$$

Para a determinação das frequências naturais não há necessidade do vetor de forças, então:

$$
[\mathrm{M}]_{\mathrm{N} \times \mathrm{N}}\{\ddot{\delta}\}_{\mathrm{N} 1}+[\mathrm{K}]_{\mathrm{NxN}}\{\delta\}_{\mathrm{N} 1}=0
$$

A solução geral da equação (2.4-9) para condições iniciais não nulas é dada por:

$$
\{\delta\}=\{\phi\} . \mathrm{e}^{\lambda \mathrm{t}}
$$

onde:

$\{\phi\}=$ vetor de elementos reais ou complexos $(\mathrm{Nx} 1)$

$\lambda=$ número complexo

Aplicando (2.4-10) em (2.4-9) obtém-se: 


$$
\left[\lambda^{2}[\mathrm{M}]+[\mathrm{K}]\right] .\{\phi\}=\{0\}
$$

A equação (2.4-11) possuirá solução não nula se:

$$
\operatorname{det}\left[\lambda^{2}[\mathrm{M}]+[\mathrm{K}]\right]=0
$$

Tem-se assim, segundo VAROTO (1991) apud NEWLAND (1989), que a equação acima constitui-se de um autoproblema onde existem $\mathrm{N}$ pares de autovalores $\lambda_{\mathrm{r}}$ imaginários puros. As frequências naturais são obtidas diretamente à partir destes autovalores através da seguinte relação:

$$
\lambda_{\mathrm{r}}= \pm \mathrm{i} \omega_{\mathrm{r}}
$$

onde:

$\omega_{\mathrm{r}}=$ frequência natural do modo $\mathrm{r}$

$\mathrm{i}=\sqrt{-1}$ (unidade imaginária)

Então, para cada frequência natural deve-se resolver um sistema homogêneo de ordem $\mathrm{N}$ :

$$
\left[-\omega_{\mathrm{r}}^{2}[\mathrm{M}]+[\mathrm{K}]\right] .\left\{\phi_{\mathrm{r}}\right\}=\{0\}
$$

Ou então:

$$
\left[D_{\mathrm{r}}\right] .\left\{\phi_{\mathrm{r}}\right\}=\{0\}
$$

Como a matriz $\left[D_{\mathrm{r}}\right]$ é função das frequências naturais $\left(\omega_{\mathrm{r}}\right)$, haverá diferentes matrizes para cada modo de vibrar. Portanto para cada valor de $\omega_{\mathrm{r}}$ a equação é satisfeita por infinitos vetores $\left\{\phi_{\mathrm{r}}\right\}$ paralelos entre si. Por outro lado, é possível obter a forma de vibrar para uma determinada frequência natural em função de um dos $\mathrm{N}$ elementos de $\left\{\phi_{\mathrm{r}}\right\}$ através da equação (2.4-15). Assim, fica determinado o chamado modelo modal que é formado por uma matriz diagonal cujo os elementos estão relacionados com as frequências naturais e uma matriz modal cuja suas colunas correspondem aos modos de vibrar da estrutura:

NEWLAND, D. E. (1987). On the modal analysis of non-conservative linear sytem. Journal of Sound and Vibration, 112 (1). p. 69-96. 


$$
\left[\omega_{\mathrm{r}}^{2}\right]=\left[\begin{array}{lllll}
\omega_{1}^{2} & & & \\
& \omega_{2}^{2} & & & \\
& & \cdot & & \\
& & & \cdot \\
& & & \omega_{\mathrm{n}}^{2}
\end{array}\right]
$$

onde:

$\left[\omega_{\mathrm{r}}^{2}\right]=$ matriz diagonal das frequências naturais quadráticas (ordem $\mathrm{N}$ )

$$
[\phi]=\left[\begin{array}{ccccc}
\phi_{11} & \phi_{12} & \cdot & \cdot & \phi_{1 \mathrm{n}} \\
\phi_{21} & \phi_{22} & & & \cdot \\
\cdot & \cdot & & & \cdot \\
\cdot & \cdot & & \cdot \\
\phi_{\mathrm{n} 1} & \phi_{\mathrm{n} 2} & \cdot & . & \phi_{\mathrm{nn}}
\end{array}\right]
$$

onde:

$$
[\phi]=\left[\left\{\phi_{1}\right\}\left\{\phi_{2}\right\} \ldots\left\{\phi_{\mathrm{n}}\right\}\right]=\text { matriz dos modos de vibrar do sistema }
$$

O chamado modelo modal possui solução única para $\left[\omega_{\mathrm{r}}^{2}\right]$, entretanto de acordo com VAROTO (1991) apud MEIROVITCH (1980), a matriz modal não será única e os seus N modos de vibrar formam uma base de vetores linearmente independentes no espaço $\mathrm{R}^{\mathrm{n}}$.

CLOUGH \& PENZIEN (1975) descrevem que os modos de vibrar possuem propriedades determinadas a partir de suas deflexões que são produzidas por forças de inércia atuando como carregamentos aplicados. Desta forma, a equação (2.4-14) é reorganizada da seguinte maneira:

$$
[\mathrm{K}] .\left\{\phi_{\mathrm{r}}\right\}=\omega_{\mathrm{r}}^{2}[\mathrm{M}]\left\{\phi_{\mathrm{r}}\right\}
$$

Se ambos os lados da equação forem pré-multiplicados pelo vetor transposto do modo s, tem-se:

$$
\left\{\phi_{\mathrm{s}}\right\}^{\mathrm{T}}[\mathrm{K}] .\left\{\phi_{\mathrm{r}}\right\}=\omega_{\mathrm{r}}^{2}\left\{\phi_{\mathrm{s}}\right\}^{\mathrm{T}}[\mathrm{M}]\left\{\phi_{\mathrm{r}}\right\}
$$
limited, London. 
Se a equação (2.4-18) for escrita para o modo s e em seguida tiver ambos os lados multiplicados pelo vetor transposto do modo $\mathrm{r}$, tem-se:

$$
\left\{\phi_{\mathrm{r}}\right\}^{\mathrm{T}}[\mathrm{K}] .\left\{\phi_{\mathrm{s}}\right\}=\omega_{\mathrm{s}}^{2}\left\{\phi_{\mathrm{r}}\right\}^{\mathrm{T}}[\mathrm{M}]\left\{\phi_{\mathrm{s}}\right\}
$$

Subtraindo a equação (2.4-19) da (2.4-20):

$$
\left(\omega_{\mathrm{r}}^{2}-\omega_{\mathrm{s}}^{2}\right) \cdot\left\{\phi_{\mathrm{r}}\right\}^{\mathrm{T}}[\mathrm{M}]\left\{\phi_{\mathrm{s}}\right\}=0
$$

Para $\omega_{\mathrm{r}} \neq \omega_{\mathrm{s}}$ tem-se:

$$
\left\{\phi_{\mathrm{r}}\right\}^{\mathrm{T}}[\mathrm{M}]\left\{\phi_{\mathrm{s}}\right\}=0
$$

E a partir da equação (2.4-19), tem-se para $\omega_{\mathrm{r}} \neq \omega_{\mathrm{s}}$ :

$$
\left\{\phi_{\mathrm{r}}\right\}^{\mathrm{T}}[\mathrm{K}]\left\{\phi_{\mathrm{s}}\right\}=0
$$

As relações (2.4-22) e (2.4-23) são conhecidas como relações de ortogonalidade dos modos de vibrar. Se $\omega_{\mathrm{r}}=\omega_{\mathrm{s}}$ então:

$$
\begin{aligned}
& \left\{\phi_{\mathrm{r}}\right\}^{\mathrm{T}}[\mathrm{M}]\left\{\phi_{\mathrm{s}}\right\}=\mathrm{m}_{\mathrm{r}} \\
& \left\{\phi_{\mathrm{r}}\right\}^{\mathrm{T}}[\mathrm{K}]\left\{\phi_{\mathrm{s}}\right\}=\mathrm{k}_{\mathrm{r}}
\end{aligned}
$$

onde:

$\mathrm{m}_{\mathrm{r}}=$ coeficiente de massa generalizada (massa modal)

$\mathrm{k}_{\mathrm{r}}=$ coeficiente de rigidez generalizada (rigidez modal)

Para os $\mathrm{N}$ modos de vibrar, tem-se:

$$
\begin{aligned}
& {[\phi]^{\mathrm{T}}[\mathrm{M}][\phi]=\left[\mathrm{m}_{\mathrm{r}}\right]} \\
& {[\phi]^{\mathrm{T}}[\mathrm{K}][\phi]=\left[\mathrm{k}_{\mathrm{r}}\right]}
\end{aligned}
$$

onde:

$\left[\mathrm{m}_{\mathrm{r}}\right]=$ matriz de massa modal

$\left[\mathrm{k}_{\mathrm{r}}\right]=$ matriz de rigidez modal

Como já foi comentado anteriormente, a matriz modal é composta de colunas sujeitas a fatores de escala. Assim, os valores de $\mathrm{m}_{\mathrm{r}}$ e $\mathrm{k}_{\mathrm{r}}$ não são únicos para um determinado modo 
de vibrar. Entretanto, a frequência natural do modo r é constante e agora pode ser calculada por:

$$
\omega_{\mathrm{r}}=\sqrt{\frac{\mathrm{k}_{\mathrm{r}}}{\mathrm{m}_{\mathrm{r}}}}
$$

Além de contribuir para o cálculo das frequências naturais, o coeficiente de massa generalizada permite a realização da normalização dos modos de vibrar:

$$
\left\{\hat{\phi}_{\mathrm{r}}\right\}=\left(\mathrm{m}_{\mathrm{r}}\right)^{-1 / 2} \cdot\left\{\phi_{\mathrm{r}}\right\}
$$

onde:

$\left\{\hat{\phi}_{\mathrm{r}}\right\}=$ modo de vibrar $\mathrm{r}$ normalizado em relação a sua massa modal

Sendo assim, todos os modos de vibrar normalizados podem ser calculados determinando as seguintes equações:

$$
\begin{aligned}
& {[\hat{\phi}]^{\mathrm{T}}[\mathrm{M}][\hat{\phi}]=[\mathrm{I}]} \\
& {[\hat{\phi}]^{\mathrm{T}}[\mathrm{K}][\hat{\phi}]=\left[\omega_{\mathrm{r}}^{2}\right]}
\end{aligned}
$$

Utilizando um pacote comercial de elementos finitos HE, WANG \& TANG (1993) fizeram uma análise modal para prever o comportamento de asas de avião feitas de material compósito. $\mathrm{O}$ estudo realizado permitiu pensar num projeto que viesse a minimizar o problema de flutter (grandes amplitudes de vibração em determinadas frequências que levam à fadiga do material) em asas através da alteração da rigidez global. ZABARAS \& PERVEZ(1990) fizeram uma aproximação do amortecimento como sendo viscoso e o introduziram em análises dinâmicas via Método dos Elementos Finitos, obtendo respostas transientes amortecidas. Eles examinaram a importância do amortecimento na resposta transiente do laminado bem como os efeitos da orientação da fibra, da razão de aspecto do laminado e da sequência de empilhamento no comportamento das amostras. RIKARDS et al (1993) buscaram alternativas para decrementar a energia de vibração em estruturas, projetando estas com as frequências de excitação desejada e utilizando materiais com camadas viscoelásticos. Desta forma, estruturas do tipo sanduíches sob carregamentos dinâmicos foram analisadas via Método dos Elementos Finitos. Utilizando também um pacote comercial AHMADIAN \& MANTENA (1996) analisaram pórticos feitos de material compósito, epoxi reforçado por fibra de carbono e fibra de vidro, estudando o comportamento dinâmico variando a proporção dos reforçantes. Dessa forma, constataram através de ensaios e análises numéricas via Método dos Elementos Finitos que as frequências naturais desamortecidas da estrutura se alteravam com mudanças na proporção de material. 
BANERJEE \& WILLIAMS (1996) apresentaram na formulação uma matriz de rigidez dinâmica exata para uma viga de compósito, incluindo os efeitos de deformação por cisalhamento e inércia de rotação (viga de Timoshenko), tendo derivado uma expressão analítica explícita para cada um dos elementos da matriz de rigidez dinâmica através do uso de um pacote computacional. Comparações entre os resultados numéricos e os resultados da literatura demonstraram uma boa convergência. ZAPFE \& LESIEUTRE (1997) apresentaram um processo iterativo para análise dinâmica. Tal processo é usado para refinar sucessivamente a forma assumida pelo campo de deslocamentos, resultando na distribuição de tensão e deformação. O modelo inclui os efeitos de cisalhamento transversal e inércias de rotação e melhora a estimativa da função de correção do cisalhamento. RAO \& GANESAN (1997) analisaram a resposta harmônica de vigas de material compósito através do Método dos Elementos Finitos, incorporando o efeito de Poisson na formulação das equações constitutivas. Eles calcularam as tensões interlaminares e fizeram um estudo parametrizado, investigando a influência do perfil do laminado. QIAN et al (1997) apresentaram um método para identificar propriedades elásticas e de amortecimento em materiais compósitos através de dados provenientes de testes de vibração. O modelo analisado foi baseado em elementos finitos e considera o efeito de deformação de cisalhamento transversal e o amortecimento histerético. As constantes elásticas e os fatores de amortecimento são selecionados como parâmetros, sendo utilizados para minimizar uma função erro que contém os desvios entre as respostas experimentais e teóricas.

Estes são alguns exemplos de aplicação do Método dos Elementos Finitos (MEF) para auxiliar o desenvolvimento de projetos. Segue no próximo capítulo uma descrição de como o método auxiliará o desenvolvimento deste trabalho. 


\section{CAPÍtULO 3.}

\section{MATERIAIS E MÉTODOS}

O presente trabalho foi desenvolvido junto ao laboratório de CAD/CAE do Departamento de Engenharia Mecânica, USP - São Carlos, contando com o apoio do laboratório de Dinâmica e da oficina do LAMAFE (Laboratório de Máquinas-Ferramentas) também integrantes do Departamento de Engenharia Mecânica, USP - São Carlos.

\subsection{Materiais e Equipamentos}

\section{Oficina do LAMAFE}

$\mathrm{Na}$ oficina do LAMAFE confeccionou-se as amostras em fibra de vidro e resina epoxi. Tomou-se como base o equacionamento desenvolvido na seção 2.1.3 para obtenção das propriedades elásticas do material compósito. Sendo assim, segue abaixo tabelas referentes aos materiais (fibra de vidro e resina) especificando o valor das propriedades necessárias para a determinação do compósito.

TABELA (3.1-1) - Propriedades da fibra de vidro tipo E (E-glass)

\begin{tabular}{|c|c|c|}
\hline PROPRIEDADE & UNIDADE & VALOR \\
\hline$\left.{ }^{*}\right)$ Módulo de Elasticidade $\left(\mathrm{E}_{\mathrm{f}}\right)$ & $\mathrm{GPa}$ & 72 \\
\hline$(*)$ Densidade $\left(\rho_{\mathrm{f}}\right)$ & $10^{3} \mathrm{~kg} / \mathrm{m}^{3}$ & 2,56 \\
\hline$\left.{ }^{*}\right)$ Coeficiente de Poisson $\left(\mathrm{v}_{12 \mathrm{f}}\right)$ & - & 0,22 \\
\hline
\end{tabular}

(*) ENGINEERED MATERIALS HANDBOOK (1987) 
TABELA (3.1-2) - Propriedades de uma resina epoxi para fins estruturais

\begin{tabular}{|c|c|c|}
\hline PROPRIEDADE & UNIDADE & VALOR \\
\hline$(*)$ Módulo de elasticidade $\left(\mathrm{E}_{\mathrm{m}}\right)$ & $\mathrm{GPa}$ & 4 \\
\hline$(*)$ Densidade $\left(\rho_{\mathrm{m}}\right)$ & $10^{3} \mathrm{~kg} / \mathrm{m}^{3}$ & 1,3 \\
\hline$(*)$ Coeficiente de Poisson $\left(v_{\mathrm{m}}\right)$ & - & 0,4 \\
\hline
\end{tabular}

(*) HULL (1981)

Portanto, através das equações da seção 2.1.3 juntamente com a fração volumétrica da fibra e da resina que participaram da composição do material final calculou-se as propriedades mecânicas para uma lâmina de material compósito suposto transversalmente isotrópico.

TABELA (3.1-3) - Propriedades de uma lâmina de material compósito

\begin{tabular}{|c|c|c|c|}
\hline PROPRIEDADE & UNIDADE & VALOR $\left.{ }^{*}\right)$ & VALOR $(* *)$ \\
\hline Módulos de elasticidade & & & \\
Paralelo a fibra $\left(\mathrm{E}_{1}\right)$ & $\mathrm{GPa}$ & 44,8 & 45,0 \\
Perpendicular a fibra $\left(\mathrm{E}_{2}\right)$ & $\mathrm{GPa}$ & 11,27 & 12,0 \\
\hline Densidade $\left(\rho_{\mathrm{c}}\right)$ & $\mathrm{kg} / \mathrm{m}^{3}$ & 1780 & 1940 \\
\hline Módulos de Cisalhamento & & & \\
$\left(\mathrm{G}_{12}\right)$ & $\mathrm{GPa}$ & 4,86 & 4,40 \\
$\left(\mathrm{G}_{23}\right)$ & $\mathrm{GPa}$ & 4,45 & - \\
\hline Coeficiente de Poisson $\left(\mathrm{v}_{12}\right)$ & - & 0,28 & 0,25 \\
\hline Fração Volumétrica & $\%$ & 60 & 60 \\
Fibra $\left(\mathrm{V}_{\mathrm{f}}\right)$ & $\%$ & 40 & 40 \\
Matriz $\left(\mathrm{V}_{\mathrm{m}}\right)$ & & & \\
\hline \multicolumn{2}{|r|}{}
\end{tabular}

(*) Regra das Misturas

(**) ENGINEERED MATERIALS HANDBOOK (1987)

Nota-se que os valores calculados através da Regra das Misturas especificada por VINSON \& SIERAKOWSKI (1987) são coerentes com os valores apresentados pelo ENGINEERED MATERIALS HANDBOOK (1987). Entretanto, vale recordar que essas propriedades elásticas podem também ser obtidas através de alguns ensaios de amostras de laminados padronizadas. É o caso da norma ASTM D3039/D3039M - 95a, que permite a 
identificação dos módulos de elasticidade $\left(\mathrm{E}_{1}\right.$ e $\mathrm{E}_{2}$ ), além do coeficiente de Poisson. Porém, para o presente trabalho optou-se por simplicidade pelo uso da Regra das Misturas.

\section{Laboratório de Dinâmica}

No laboratório de Dinâmica utilizou-se equipamentos básicos necessários para execução dos ensaios de vibração das amostras. Antes da execução dos ensaios, tais equipamentos foram calibrados segundo suas cartas de calibração fornecidas pelo fabricante (BRÜEL \& KJAER, 1987):

- analisador espectral BRÜEL \& KJAER (B\&K) (modelo 2032) para diferentes tipos de análise dinâmica tanto no domínio do tempo como no domínio da frequência, com dois canais e comunicação com microcomputadores;

- martelo de impacto $\mathrm{B} \& \mathrm{~K}$;

- acelerômetros B\&K

Tipo 4375

Sensibilidade à Carga $-0,319 \mathrm{pC} / \mathrm{m} \cdot \mathrm{s}^{-2}$ ou $3,13 \mathrm{pC} / \mathrm{g}$

Sensibilidade à Tensão $-0,499 \mathrm{mV} / \mathrm{ms}^{-2}$ ou $4,89 \mathrm{mV} / \mathrm{g}$

Massa $=2,4 \mathrm{~g}$

- células de carga piezoelétricas B\&K - transdutor de força

Tipo 8200

Sensibilidade à Carga $-3,17 \mathrm{pC} / \mathrm{m} \cdot \mathrm{s}^{-2}$ ou $31 \mathrm{pC} / \mathrm{g}$

Sensibilidade à Tensão $-2,56 \mathrm{mV} / \mathrm{ms}^{-2}$ ou $25,2 \mathrm{mV} / \mathrm{g}$

Massa $=21 \mathrm{~g}$

- amplificador de carga B\&K 2626;

\section{Laboratório de CAD/CAE}

No laboratório de $\mathrm{CAD} / \mathrm{CAE}$ realizou-se as análises numéricas via Método dos Elementos Finitos (MEF), sendo necessário:

Hardware

-Estação de trabalho (Work Station): IBM RISC e periféricos com potência de cálculo (260 SPEC.FP.92), 128Mb de memória e 4,5Gb de disco.

\section{Software}

-CAE (Computer Aided Engineer): ANSYS(Versão 5.2) em plataforma UNIX. 


\subsection{Metodologia}

A metodologia constituiu-se basicamente de quatro etapas sequênciais:

$1^{\mathrm{O}}$-Confecção das amostras (Processo de laminação)

Através do processo conhecido como Hand Lay-Up (moldagem manual) confeccionou-se 2 tipos de amostras que foram chamadas de 2 casos de estudo. Antes porém de especificar esses casos, vale ressaltar que o processo de codificação de laminados (laminate code) é algo difícil de ser padronizado. (TSAI, 1986). A codificação de laminados trata de como deve-se convencionar a ordem dos ângulos de cada lâmina para explicitar um laminado completo, por exemplo, para TSAI (1986) o laminado da FIGURA (3.2-1) deve ser explicitado por $\left[0_{3} / 90_{2} / 45 /-45_{3} /-45_{3} / 45 / 90_{2} / 0_{3}\right]_{\mathrm{T}}$ ou $\left[0_{3} / 90_{2} / 45 /-45_{3}\right]_{\mathrm{s}}$.

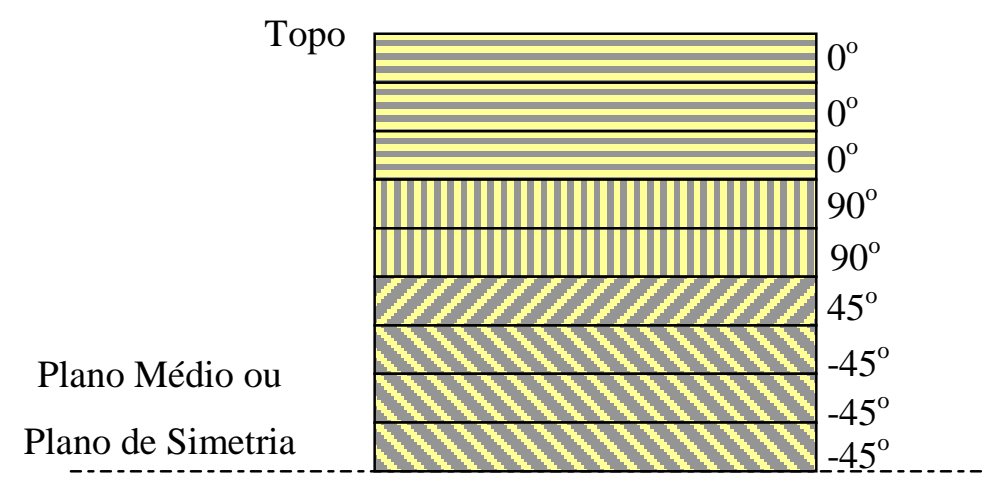

FIGURA (3.2-1) - Laminado com os respectivos ângulos de orientação de cada camada

De acordo com a convenção de TSAI (1986) tem-se que o laminado pode começar a ser especificado a partir da base ou do topo indo em direção ao plano de simetria, caso este seja simétrico. Outro detalhe são os subíndices que acompanham os respectivos ângulos de camada que designam quantas camadas haverá com tal ângulo. Já o subíndice $\mathrm{T}$ indica total de camadas e o S presença de simetria. Seguindo a convenção de TSAI, tem-se os seguintes casos especificados:

Caso1 - Laminado simétrico com um total de 20 camadas: [45/-45/45/ 45/45/-45/45/-45/0/90]s. Vide FIGURA (3.2-2): 


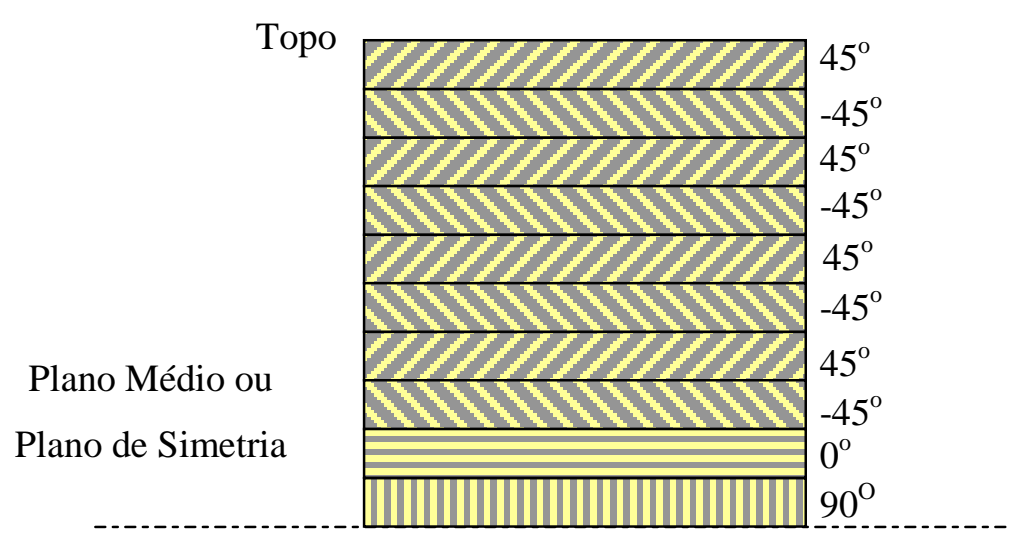

FIGURA (3.2-2) - Laminado do Caso 1

Caso2 - Laminado simétrico com um total de 20 camadas: [0/90/0/90/0/90/0/90/0/90]. Vide FIGURA (3.2-3):

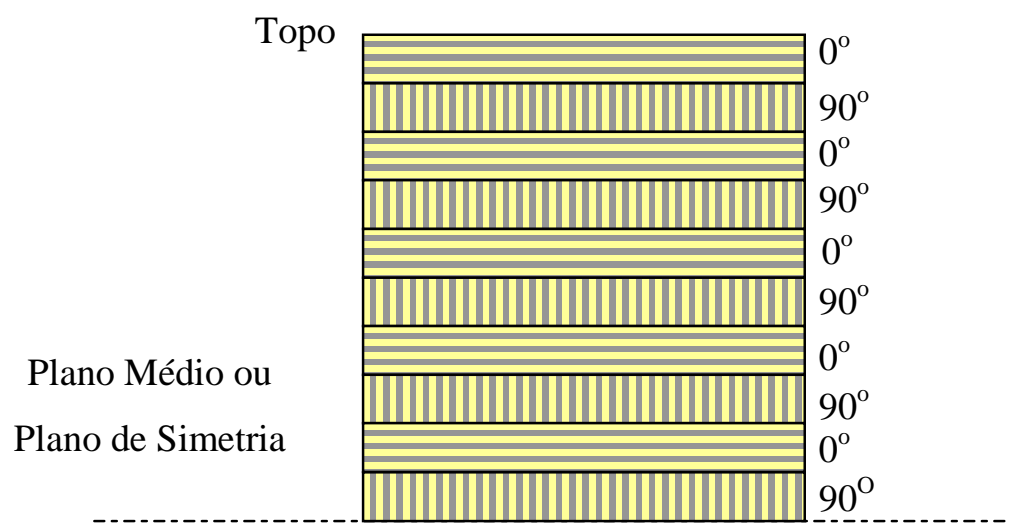

FIGURA (3.2-3) - Laminado do Caso 2

$2^{\circ}$-Análise Modal via Método dos Elementos Finitos (MEF)

Com as propriedades elásticas do compósito gera-se um modelo teórico baseado no Método dos Elementos Finitos e obtém-se as matrizes de massa e rigidez da estrutura discretizada. Sendo assim, através da solução das equações de movimento e desconsiderando o efeito do amortecimento torna-se possível estimar as frequências naturais desamortecidas e os seus respectivos modos de vibrar. 


\section{$3^{\mathrm{o}}$-Análise Modal Experimental}

Através dos ensaios de vibração das amostras realizados em laboratório é possível levantar as Funções de Resposta em Frequência (FRF) para cada caso de estudo, e assim obter as frequências naturais amortecidas e os seus respectivos fatores de amortecimento através de um círculo modal ajustado (EWINS, 1984).

$4^{\circ}$-Análise dos resultados obtidos nos ensaios e validação do modelo em elementos finitos.

A princípio compara-se os resultados obtidos (frequências naturais e fatores de amortecimento) no Caso1 com o resultados do Caso2, verificando a influência da sequência de empilhamento das lâminas. Por fim, compara-se as estimativas do cálculo numérico com os resultados experimentais para uma possível validação do modelo teórico em elementos finitos.

\subsubsection{Confecção das Amostras}

As características do produto final determinam o método pelo qual o componente é combinado e moldado, levando em consideração a porcentagem de fibra em relação à resina, à orientação e ao tipo do reforço, ao tipo da resina e à forma de processamento. A literatura apresenta inúmeras formas de processamento. Só em VINSON E SIERAKOWSKI (1987) destacam-se inúmeras técnicas para confeccionar peças em material compósito. Elas vão desde técnicas manuais como é o caso de Hand Lay-Up, passando por técnicas completamente automatizadas, como é o caso da "bobinagem" ou enrolamento filamentar (Filament Winding) e da moldagem por injeção, até chegar em técnicas que utilizam plasma. Segundo VINSON E SIERAKOWSKI (1987), o processo de Hand Lay-Up é o mais indicado para testes em laboratórios e coleta de dados, caso ele seja usado em escala industrial, existe uma máquina de lay-up mostrada na FIGURA (3.2.1-1) a fim de obter menos falhas e a um custo menor. A Japan Reinforced Plastics Society (1990) revelou que apesar do crescimento da automação (TABELA 3.2.1-1), o processo de Hand Lay-Up é ainda muito utilizado para a fabricação de peças plásticas reforçadas por fibra (Fiber Reinforced Plastic-FRP). 
TABELA (3.2.1-1) - Processo de Fabricação de FRP durante 1986-1990

\begin{tabular}{|c|c|c|c|c|c|}
\hline Processo (\%) & 1986 & 1987 & 1988 & 1989 & 1990 \\
\hline Hand Lay-Up & 4 & 26 & 28 & 28 & 25 \\
\hline Spray-up & 15 & 16 & 16 & 18 & 18 \\
\hline Molding Compound & 26 & 32 & 34 & 30 & 31 \\
\hline Press Molding & 4 & 4 & 4 & 6 & 8 \\
\hline Filament Winding & 6 & 8 & 5 & 6 & 6 \\
\hline Pultrusion & 11 & 10 & 8 & 8 & 7 \\
\hline Outros & 4 & 4 & 5 & 4 & 5 \\
\hline
\end{tabular}

Japan Reinforced Plastics Society (1990)

Para os componentes fabricados a partir de materiais compósitos reforçados por fibras, faz-se uso de rolos de fibras (tapes) pré-impregnadas (prepreg) com resina, bem como uma sala limpa para uma melhor laminação. Esses rolos são estirados sobre uma placa que serve como uma superfície de referência, o ângulo de deposição das fibras depende dos requisitos de projeto e assim monta-se o laminado. Um cuidado que deve ser tomado é que faz-se necessária a presença de um elemento desmoldante entre as fibras pré-impregnadas com resina e a placa de referência para que o compósito posteriormente venha descolar com facilidade. Então, após a impregnação das fibras, basta levar todo conjunto para um processo conhecido como vacuum bagging ou para uma autoclave onde ocorrerá a cura da resina. No processo de vacuum bagging o laminado será submetido a alta pressão através de uma bolsa que o envolverá e poderá ser curado à temperatura ambiente ou então em um forno a temperatura controlada. Já na autoclave, o laminado será curado sob efeito de alta pressão e temperatura. A pressão presente em ambas situações faz com que haja uma melhor compactação do conjunto de fibras com a resina. 


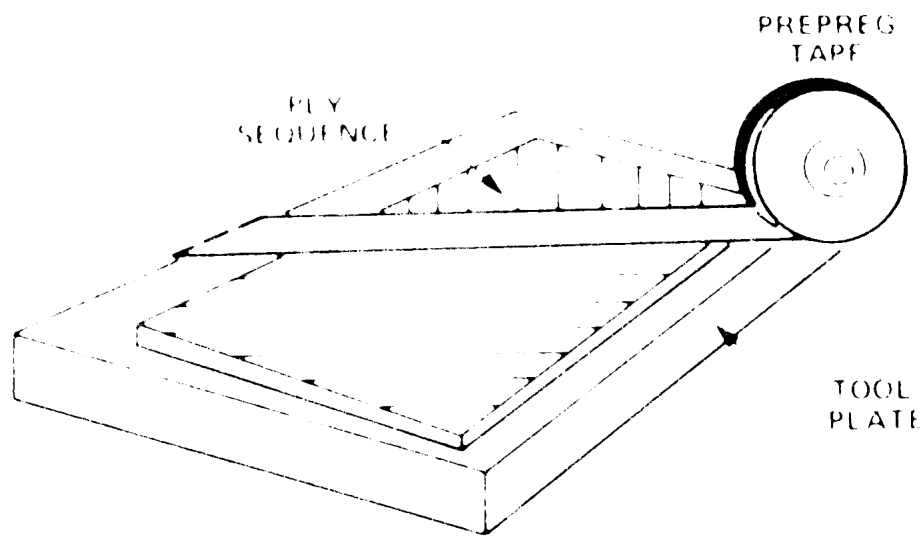

FIGURA (3.2.1-1) - Máquina de Lay-Up

VINSON E SIERAKOWSKI (1987)

Para o presente trabalho, o processo de Hand Lay-Up seguido de um processo de cura sob pressão se mostrou adequado pois não requer equipamentos complexos, reduzindo o custo de fabricação das amostras. Além disso, um projeto de componentes que será moldado por Hand Lay-Up tem a característica de ser bastante flexível. Entretanto, um aspecto negativo a ser destacado é que um processo manual torna a qualidade da peça dependente da perícia do operador, devendo-se assim, tomar muito cuidado para manter a maior uniformidade possível das amostras. Outro ponto que merece destaque é a adequação do processo de Hand Lay-Up às condições existentes no laboratório. Seguem assim a descrição das várias etapas para a obtenção das amostras:

$\underline{1^{a} \text { Etapa: }}$ certifica-se que o ambiente de trabalho esteja limpo e faz-se o uso de luvas, pois a fibra é suscetível à contaminação;

$\underline{2^{a} \text { Etapa: }}$ prepara-se o molde para receber as camadas do laminado. Por exemplo, uma placa de aço inoxidável é usada como superfície de referência. Nela aplica-se uma camada de durex e depois um revestimento de nylon para garantir que a primeira lâmina não irá aderir ao molde, facilitando a remoção da peça (atuando como desmoldante);

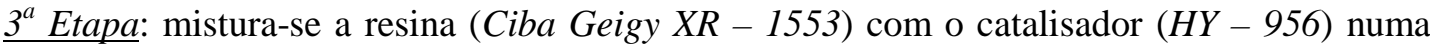
proporção bastante precisa de 5/1, ou seja , para cada 5 partes de resina é necessária 1 parte de catalisador, para tal faz-se então previamente uma pesagem. Vale ressaltar, que o 
processo de laminação deve ser realizado imediatamente, pois a polimerização ocorre num curto intervalo de tempo;

4 Etapa: após a pesagem do tecido de fibra bidirecional (Owens-Corning-Standard E-Glass Fiberglass Cloth), coloca-se este sobre a placa com o ângulo de orientação desejado. Destaca-se neste momento que a massa de tecido será igual à massa de resina mais catalisador; ou seja, antes de ocorrer o processo de prensagem haverá no laminado $50 \% \mathrm{em}$ massa de reforço e de matriz.

5 $5^{a}$ Etapa: deposita-se uma camada de resina sobre a fibra, espalhando-a de maneira homogênea com o auxílio de uma espátula;

6 $\sigma^{a}$ Etapa: repeti-se as $4^{\mathrm{a}}$ e $5^{\mathrm{a}}$ etapas até atingir o número de camadas desejado (10 camadas de tecido bidirecional), tomando sempre o cuidado em empilhar as camadas de tecido de acordo com a orientação requisitada, como é demonstrado pela FIGURA (3.2.1-2);

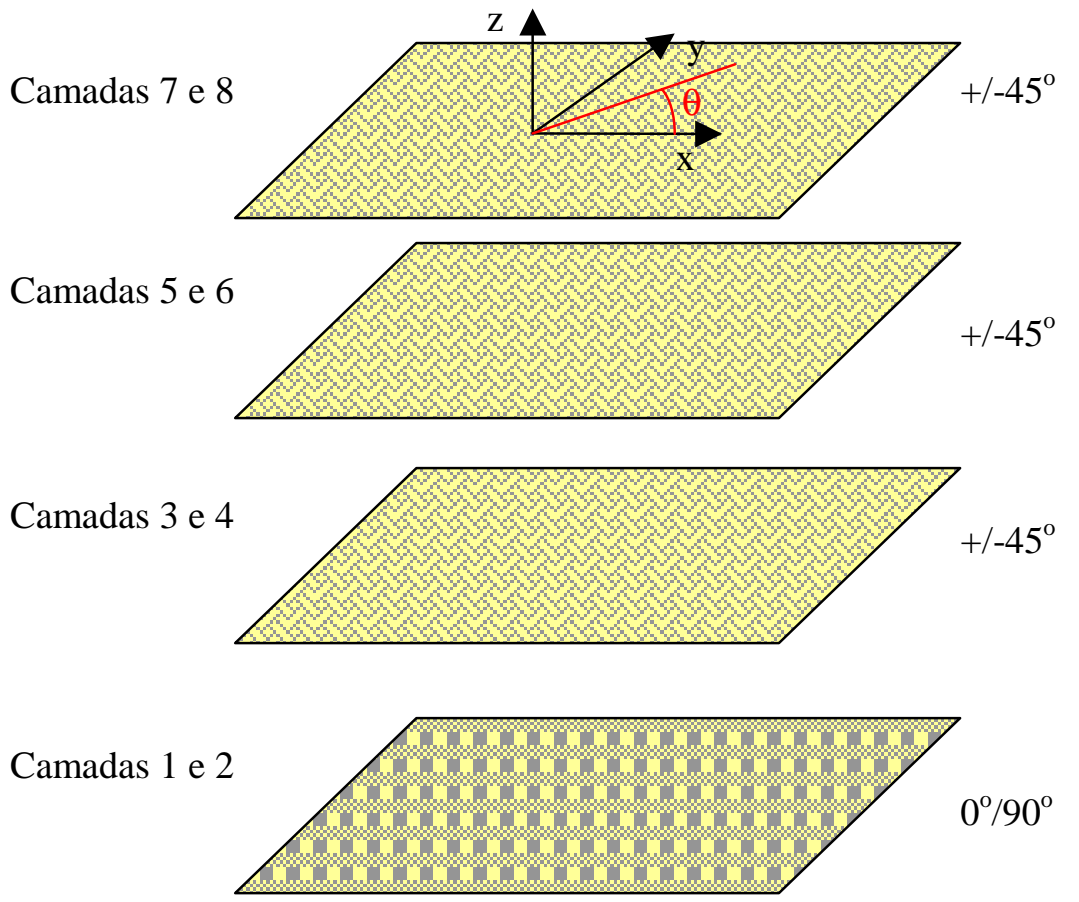

FIGURA (3.2.1-2) - Sequência de Empilhamento (stacking sequence) 
$\underline{7^{a} \text { Etapa: }}$ coloca-se sobre o laminado outra placa de aço inoxidável revestida de durex e envolvida por nylon. E afim de se obter uma melhor compactação do laminado aplica-se pressão através de grampos fixados e igualmente distribuídos sobre vigas de madeira que estão sob as placas de aço, tudo isso é feito para se obter uma distribuição homogênea de pressão. Então todo este conjunto é levado para uma estufa onde ocorre um processo de cura da resina sob uma temperatura de aproximadamente $50^{\circ} \mathrm{C}$, como mostra as FIGURAS (3.2.13 e 3.2.1-4);
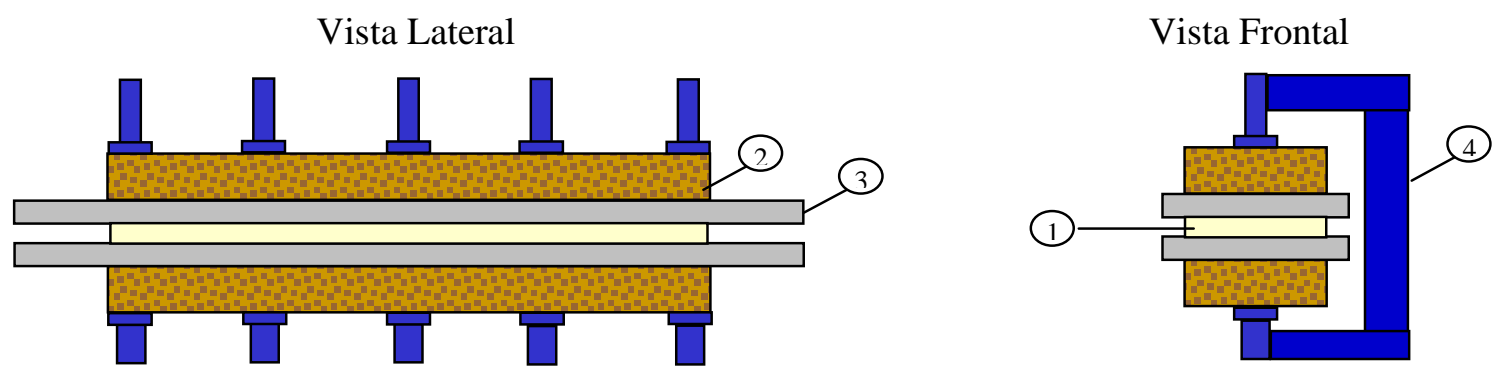
1- Laminado
2- Viga de Madeira
3- Chapa de Aço
4- Grampo tipo C

FIGURA (3.2.1-3) - Laminado prensado pelos grampos e a madeira

Cura do Laminado sob Pressão

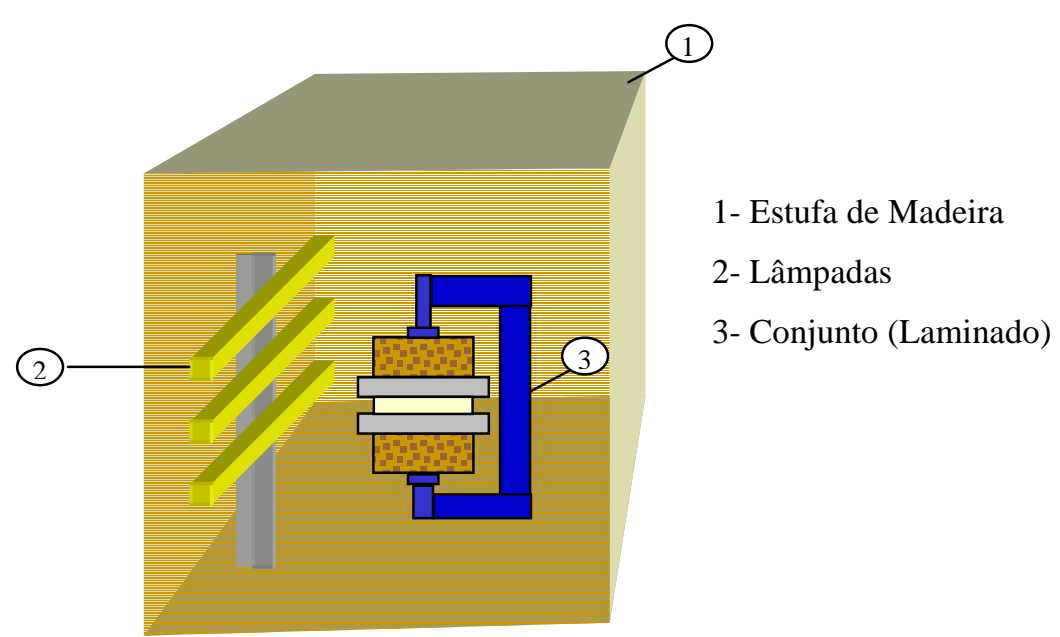

FIGURA (3.2.1-4) - Laminado sofrendo o processo de cura sob pressão 


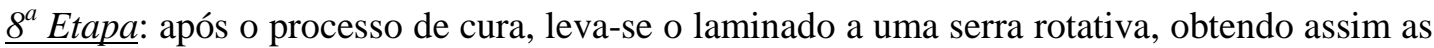
amostras nas dimensões desejadas (FIGURA (3.2.1-5)) Por fim, uma operação de lixamento nas bordas fornece um acabamento à peça. As amostras então são pesadas e os resultados refletem o quanto de matriz e fibra estão presentes no laminado final, através desses valores torna-se possível calcular as frações volumétricas de fibra e matriz .HULL (1981).

Amostra

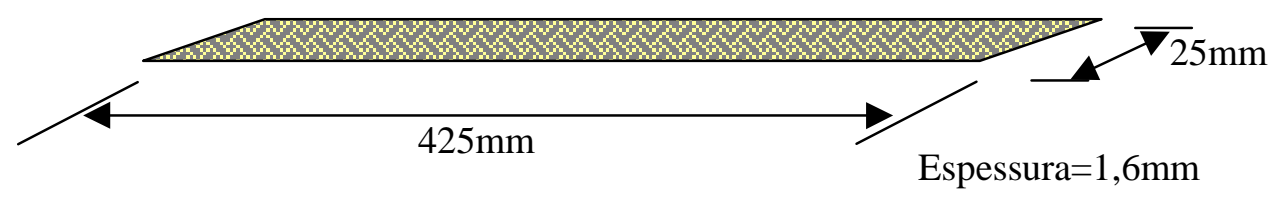

Massa 28g

FIGURA (3.2.1-5) - Dimensões da Amostra

\subsubsection{Análise Modal via Método dos Elementos Finitos}

O modelo teórico foi gerado através do CAE (Computer Aided Engineer) comercial ANSYS52. Segundo o ANSYS User's Manual (1995) é mais difícil modelar materiais compósitos do que isotrópicos, pois eles requerem um cuidado especial ao especificar as propriedades do material bem como ao definir a orientação das fibras em cada camada (vide APÊNDICE A). De acordo com a proposta de HUEBNER (1994), o problema foi solucionado seguindo as três etapas essênciais para a utilização do Método dos Elementos Finitos: etapa de pré-processamento, solução (solver) e etapa de pós-processamento.

\section{Pré-Processamento}

A modelagem das amostras ensaiadas em laboratório é constituída por:

Construção da geometria - as amostras são vigas finas, estreitas e longas; podendo ser modeladas de acordo com a FIGURA (3.2.2-1). 


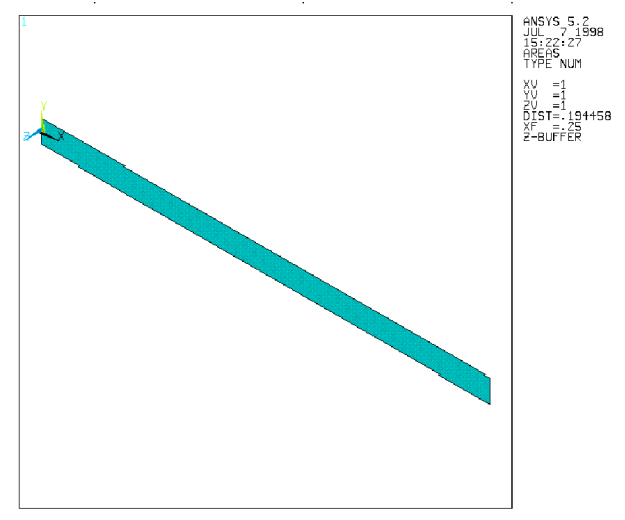

FIGURA (3.2.2-1) - Geometria do modelo

Propriedades dos Materiais - o material para este caso é considerado ortotrópico e necessita dos valores de $\mathrm{E}_{1}$ (módulo de Young paralelo à fibra $-\mathrm{E}_{\mathrm{x}}$ ), $\mathrm{E}_{2}$ (módulo de Young perpendicular à fibra $-\mathrm{E}_{\mathrm{y}}$ ), $\mathrm{E}_{3}$ (módulo de Young perpendicular a lâmina - $\mathrm{E}_{\mathrm{z}}$ ), $\mathrm{v}_{12}$ (coeficiente de Poisson - $v_{x y}$ ), $G_{12}$ e $G_{23}$ (módulos ao cisalhamento $-G_{x y}, G_{y z}$ e $G_{x z}$ ) e a $\rho_{c}$ (densidade do compósito) para se efetuar os devidos cálculos. A TABELA (3.2.2-1) mostra os valores e as respectivas propriedades calculadas através da Regra das Misturas que foram utilizadas no cálculo numérico.

TABELA (3.2.2-1) - Propriedades adotadas na análise

\begin{tabular}{|c|c|}
\hline PROPRIEDADE & $\begin{array}{c}\text { VALOR }(*) \\
\text { Unidade (Sistema Internacional) }\end{array}$ \\
\hline $\mathrm{E}_{1}\left(\mathrm{E}_{\mathrm{x}}\right)^{*}$ & $44,8 \times 10^{9}$ \\
\hline $\mathrm{E}_{2}\left(\mathrm{E}_{\mathrm{y}}=\mathrm{E}_{\mathrm{z}}\right)^{*}$ & $11,27 \times 10^{9}$ \\
\hline $\mathrm{G}_{12}\left(\mathrm{G}_{\mathrm{xy}}=\mathrm{G}_{\mathrm{xz}}\right)^{*}$ & $4,86 \times 10^{9}$ \\
\hline $\mathrm{G}_{23}\left(\mathrm{G}_{\mathrm{yz}}\right)^{*}$ & $4,45 \times 10^{9}$ \\
\hline$\rho_{\mathrm{c}}(\text { densidade })^{*}$ & 1780 \\
\hline$v_{12}\left(v_{\mathrm{xy}}\right)^{*}$ & 0,28 \\
\hline
\end{tabular}

()$^{*}$ variáveis especificadas pelo ANSYS52 (vide APÊNDICE A)

(*) valores provenientes da TABELA (3.1-3) 
Escolha do Elemento para a discretização do contínuo - segundo ANSYS User's Manual Procedure (1995), o elemento SHELL99 é um dos mais adequados para análise de laminados, pois permite a escolha do ângulo de orientação da fibra bem como a espessura da lâmina. Assim, a espessura do modelo do laminado fica determinada pela soma das espessuras das lâminas que constitui o elemento. O SHELL99 possui 8 nós (I,J,K,L,M,N,O,P) no total sendo três por aresta e cada um possuindo 6 graus de liberdade, podendo ser dispostos na base, no topo ou no meio do laminado. As camadas são designadas por números ( $L N$ - Layer Number) que aumentam da base do laminado até o topo, a última camada quantifica o número total de camadas existentes no laminado $(N L$ - Total Number of Layer). Sendo assim, como a fibra utilizada na confecção das amostras está na forma de tecido, optou-se em especificar 20 camadas pois cada camada de tecido corresponde a 2 diferentes orientações de fibra (fibras a $0^{0}$ e a $90^{\circ}$ ). Ao final do processo de discretização, o modelo ficou com um total de 46 elementos e 189 nós.

Condições de Contorno - vinculações de engastamento são colocadas numa das extremidades do modelo, simulando o engastamento da viga na base rígida.

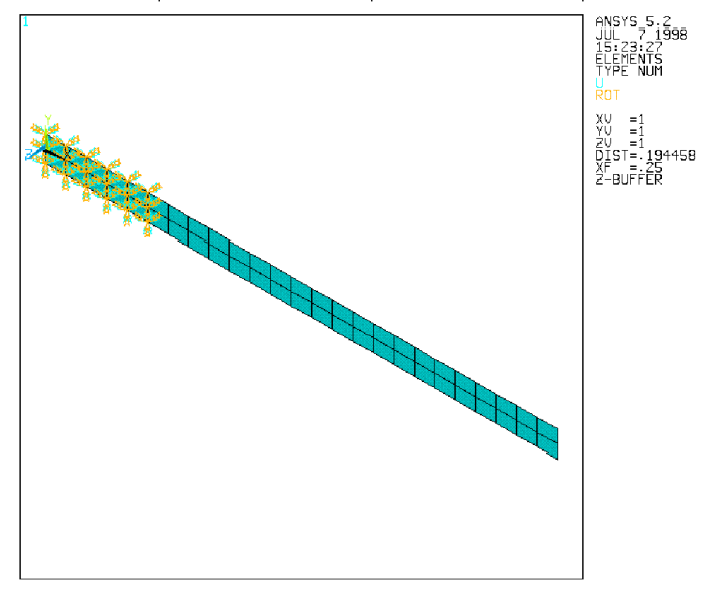

FIGURA (3.2.2-2) - Modelo discretizado vinculado

$\underline{\text { Carregamentos }}-$ a análise modal não exige aplicação de carregamentos.

Condições Iniciais - não são impostas condições inciais ao modelo como já foi observado anteriormente. 
Hipóteses - assume-se que o estudo é unidimensional, ou seja, o comportamento da viga é analisado somente numa direção. De acordo com o sistema de coordenadas adotado pelo ANSYS5.2, tem-se que essa direção será z.

\section{Solucão (solver)}

Após a etapa de preparação do modelo, a solução é executada automaticamente pelo solver do ANSYS52, veja maiores detalhes de processamento no APÊNDICE B.

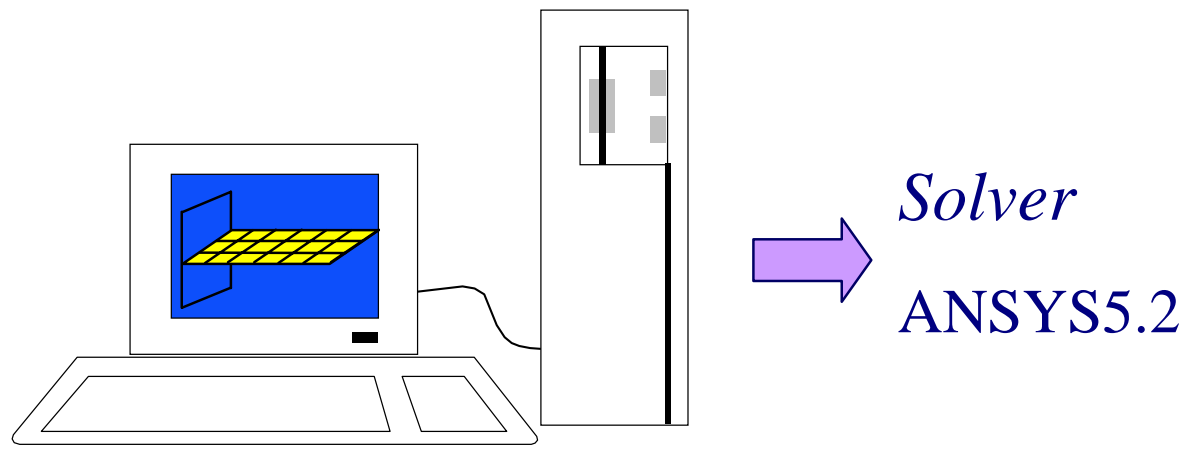

FIGURA (3.2.2-3) - Modelo a ser solucionado

\section{Pós-Processamento}

Os resultados são divididos em dois grandes grupos, ou seja, as frequências naturais desamortecidas e as seus respectivos modos de vibrar para o Caso 1 e para o Caso 2.

\subsubsection{Análise Modal Experimental}

Após a calibração dos instrumentos utilizados nos ensaios de vibração, traça-se alguns objetivos gerais para os ensaios:

1. Ensaios mecânicos em materiais fornecem dados que podem ser usados para propósitos completamente diferentes, como:

- garantia e controle de qualidade;

- comparação entre materiais e especificações;

- cálculos em projeto;

- simulação de desempenho em outras condições;

- indicação de necessidades em desenvolvimento de novos materiais;

- desenvolvimento de novas teorias. 
2. Devido aos diferentes propósitos para os quais os testes podem ser executados, a maneira como o teste é executado pode também diferir de caso a caso: o equipamento de teste, os procedimentos experimentais e o modo como os resultados são interpretados. Um tipo particular de teste pode ser satisfatório para um propósito mas inadequado para outro. $\mathrm{O}$ uso de testes não apropriados pode resultar em conclusões errôneas dos dados obtidos.

3. É importante salientar que cuidados devem ser tomados para garantir que sejam medidas propriedades do material (massa, rigidez e amortecimento). Este cuidado é válido para todos tipos de materiais, mas torna-se bastante pertinente no caso de compósitos.

Segundo McCONNELL (1995), um teste de vibração não é uma tarefa fácil, pois ele não fornece todas as respostas imediatamente, apenas serve como uma direção para guiar o raciocínio. No presente trabalho objetiva-se determinar as frequências naturais, os modos de vibrar e alguns fatores de amortecimento de interesse de vigas laminadas cujas dimensões foram apresentadas na FIGURA (3.2.1-4). McCONNELL (1995) também descreve três maneiras distintas de excitar um sistema para medir suas frequências naturais e características de amortecimento. A primeira maneira é através de um carregamento estático que pode ser aplicado e então retirado rapidamente para dar uma condição inicial ao sistema, ou seja, um deslocamento inicial diferente de zero. A segunda maneira é através de um carregamento na forma de um impulso que fornecerá ao sistema uma velocidade inicial diferente de zero. E uma terceira forma que é através de uma deflexão estática inicial juntamente com uma velocidade inicial diferente de zero para um tempo inicial igual a zero. Para o presente trabalho escolheu-se a segunda técnica, ou seja, com o auxílio de um martelo de impacto excitou-se as vigas laminadas com um carregamento de impulso.

\section{Análise Modal das Vigas Laminadas}

Segundo EWINS (1984), no teste modal, o componente vibra através de uma excitação conhecida, tendo-se um teste com condições bem controladas. Com isto, o mesmo é freqüentemente executado fora do ambiente normal de serviço da peça. Ainda integram o teste: a aquisição e análise dos dados. Pode-se dizer que as observações experimentais tem sido feitas por duas razões principais: determinar a natureza e magnitude da resposta vibratória e validar modelos teóricos e projeções. 
Uma das maiores necessidades no teste modal é a perfeita integração de três fatores:

-base teórica das vibrações;

-medição acurada das vibrações;

-análise realista e detalhada dos dados.

Sendo que seu potencial não pode ser desenvolvido em sua totalidade sem um bom entendimento das inter-relações entre estes três fatores.

Em um ensaio dinâmico deve-se estar atento tanto aos parâmetros de entrada como aos de saída, determinando-se assim as propriedades do componente pela relação:

$$
\begin{aligned}
\mathrm{X}(\omega) & =\mathrm{H}(\omega) \cdot \mathrm{F}(\omega) \\
{[\text { Resposta }] } & =[\text { Propriedades }] \times[\text { Entrada] }
\end{aligned}
$$

onde:

$X(\omega)=$ amplitude de oscilação, velocidade ou aceleração de um ponto da estrutura

$\mathrm{F}(\omega)=$ excitação efetuada na estrutura

$H(\omega)=$ Função de Resposta em Frequência (FRF)

Segundo EWINS (1984) a FRF é definida como razão entre a resposta do sistema e a excitação aplicada sobre o mesmo. Esta razão é um número complexo que possui como módulo o valor dado pela razão dos sinais de saída pelo de entrada e possui como fase o ângulo entre esses dois mesmos sinais. Caso a resposta seja dada em deslocamento, a FRF é conhecida como receptância ou compliância. Caso a resposta seja dada em velocidade, a FRF é conhecida como mobilidade. E para finalizar, caso a resposta seja dada em aceleração, a FRF é conhecida como acelerância. Entretanto, a análise pode ser avaliada tanto no domínio da frequência como no domínio do tempo e ao invés de uma multiplicação simples entre H e F, haverá uma convolução como demonstra McCONNELL (1995). A passagem de um domínio para o outro ocorre através do uso da Transformada de Fourier (TFT ou PFT) ou da Inversa da Transformada de Fourier (TIF ou PIF) como demonstra a FIGURA (3.2.3-1). 


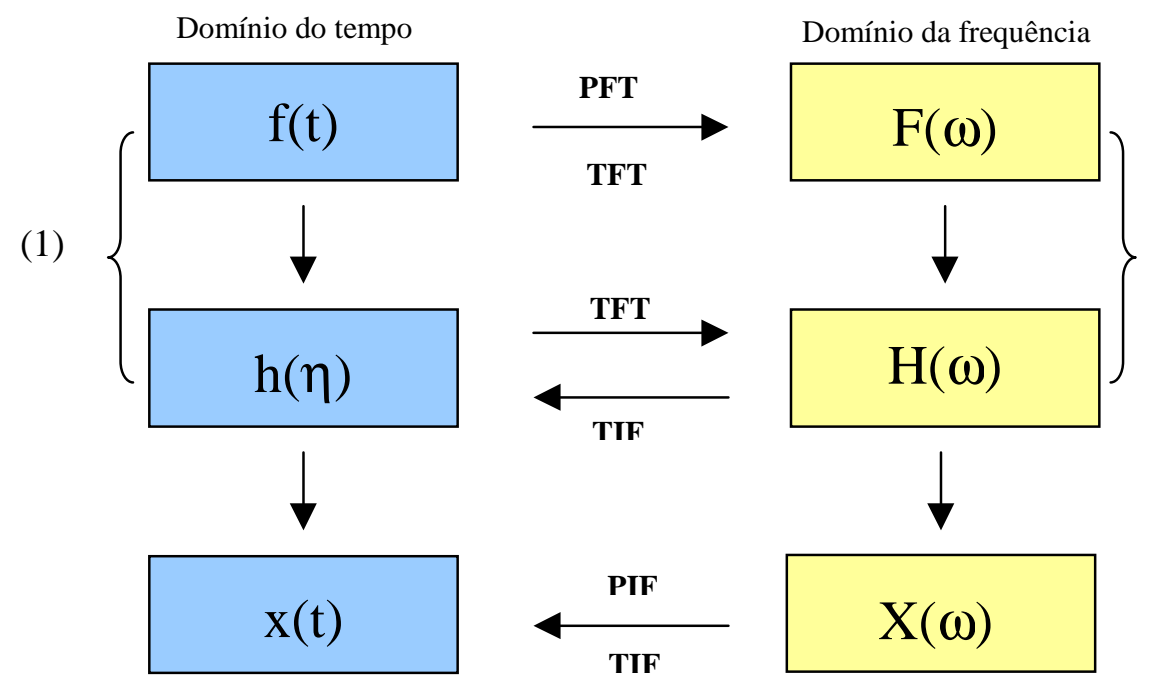

FIGURA (3.2.3-1) - Caminhos percorridos para o cálculo da resposta no domínio do tempo (1- Convolução) e da frequência (2- Multiplicação).

McCONNELL (1995).

Conhecendo-se então, o sinal de entrada e medindo a resposta de saída é possível através das relações (3.2.3-1) obter as propriedades da estrutura ensaiada. Desta forma, a chamada da Função de Resposta em Frequência é dada por $\mathrm{H}(\omega)$ de onde é possível extrair as frequências naturais e os suas respectivas formas de vibrar através do valor das amplitudes e das fases.

Através de um ensaio de impacto na amostra e com o auxílio de um analisador espectral, determina-se a FRF que relaciona a resposta dada pela amostra quando esta sofre uma entrada excitatória como um impulso, sendo possível visualizar as frequências naturais da estrutura. Nota-se, pela FIGURA (3.2.3-2) o esquema montado em laboratório para a aquisição da FRF através de um ensaio de impacto com martelo. O laminado foi engastado em uma base rígida (1), sendo assim, a estrutura pode vibrar livremente em apenas uma das suas extremidades e apenas na direção vertical. O martelo de impacto (3) realizou uma entrada impulso no sistema que respondeu numa faixa de frequência especificada (de $0 \mathrm{~Hz}$ a $400 \mathrm{~Hz}$ ). A resposta $(\mathrm{O}(\mathrm{t}))$ foi captada pelo acelerômetro (2) e juntamente com o sinal de entrada (I(t)) foram amplificados (4), obtendo-se através do analisador espectral BRUEL\&KJAER (B\&K) (5) a FRF da estrutura. 


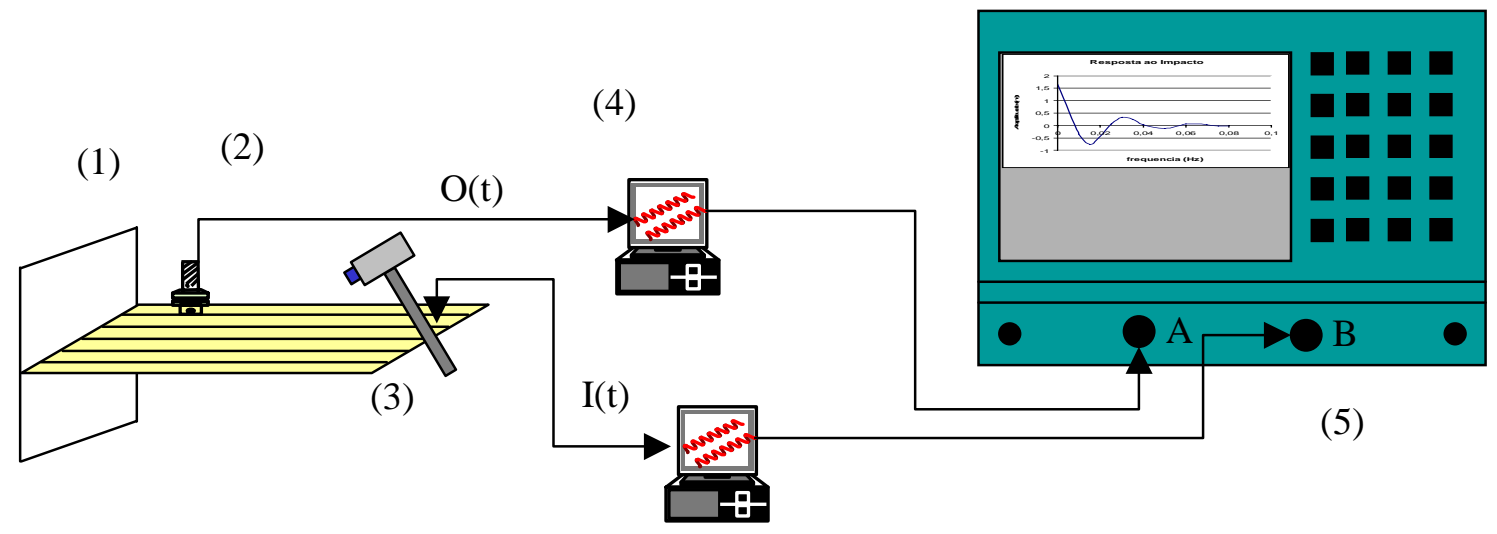

FIGURA (3.2.3-2) - Ensaio experimental

Previamente aos ensaios, realizou-se uma investigação dos pontos atrativos (FIGURA (3.2.3-3)) para excitar e captar respostas nas amostras, devido a grande flexibilidade demonstrada pelas mesmas. Assim, chegou-se aos pontos 1 (excitação), 2 e 3 (respostas) para a determinação de duas FRFs de transferência $\left(\mathrm{H}_{21}\right.$ e $\left.\mathrm{H}_{31}\right)$.

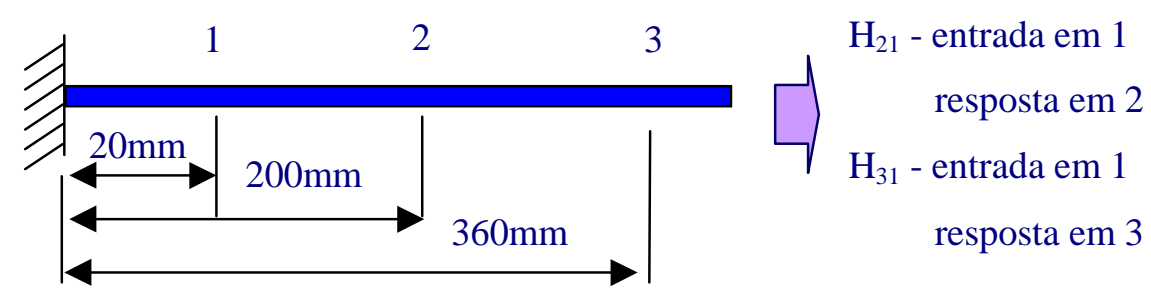

FIGURA (3.2.3-3) - Pontos de obtenção da FRF (Função de Resposta em Frequência)

De acordo com McCONNELL (1995), a localização do transdutor é um fator muito importante que necessita ser monitorado. Caso contrário, o seu movimento sobre a estrutura pode vir alterar não só as frequências naturais e os modos de vibrar bem como as respostas de vibração da estrutura. Nota-se também que pela presença de uma alta flexibilidade nas amostras teve-se que tomar um certo cuidado na escolha do acelerômetro, ou seja, sua massa equivale aproximadamente a $9 \%$ da massa da estrutura analisada, pois segundo o próprio McCONNELL (1995) a massa do transdutor pode influenciar significativamente na aquisição da resposta da estrutura quando esta possui pouca rigidez. Desta forma, a massa modal é alterada, e por sua vez ocorre uma certa mudança nas frequências naturais. Esta mudança no comportamento dinâmico constatada nos ensaios irá depender do modo de vibrar que está sendo analisado, podendo ser maior para alguns modos e no entanto menor 
para outros. Portanto fez-se primeiro a aquisição de $\mathrm{H}_{21}$ para depois então fazer a aquisição de $\mathrm{H}_{31}$, mantendo no máximo um acelerômetro sobre a amostra.

Após a aquisição dos dados, o próximo passo foi traçar as FRFs (gráficos de Módulo e Fase) dos casos a serem analisados. Tal tarefa é realizada através do pacote computacional MATLAB, possibilitando desta forma a visualização de $\mathrm{H}_{21}$ e $\mathrm{H}_{31}$ para o Caso 1 e para o Caso 2. De acordo com EWINS (1984), é possível através da FRF (Módulo e Fase) traçar o círculo modal (Parte Imaginária da FRF contra Parte Real da FRF) e pela formulação apresentada no capítulo 2, pode-se estimar o fator de amortecimento modal para modos do Caso1 e do Caso2. A FIGURA (3.2.3-4) revela como foi possível determinar os valores de $\omega_{\mathrm{a}}, \omega_{\mathrm{b}}, \theta_{\mathrm{a}}$ e $\theta_{\mathrm{b}}$ que estão presentes na equação (3.2.3-1). Vale lembrar, que esta equação estima o fator de perda para estruturas levemente amortecidas, ou seja, estruturas com $\eta_{\mathrm{r}}$ abaixo de $3 \%$.

$$
\eta_{\mathrm{r}} \approx \frac{2\left(\omega_{\mathrm{a}}-\omega_{\mathrm{b}}\right)}{\omega_{\mathrm{r}}\left(\operatorname{tg}\left(\theta_{\mathrm{a}} / 2\right)+\operatorname{tg}\left(\theta_{\mathrm{b}} / 2\right)\right)}
$$

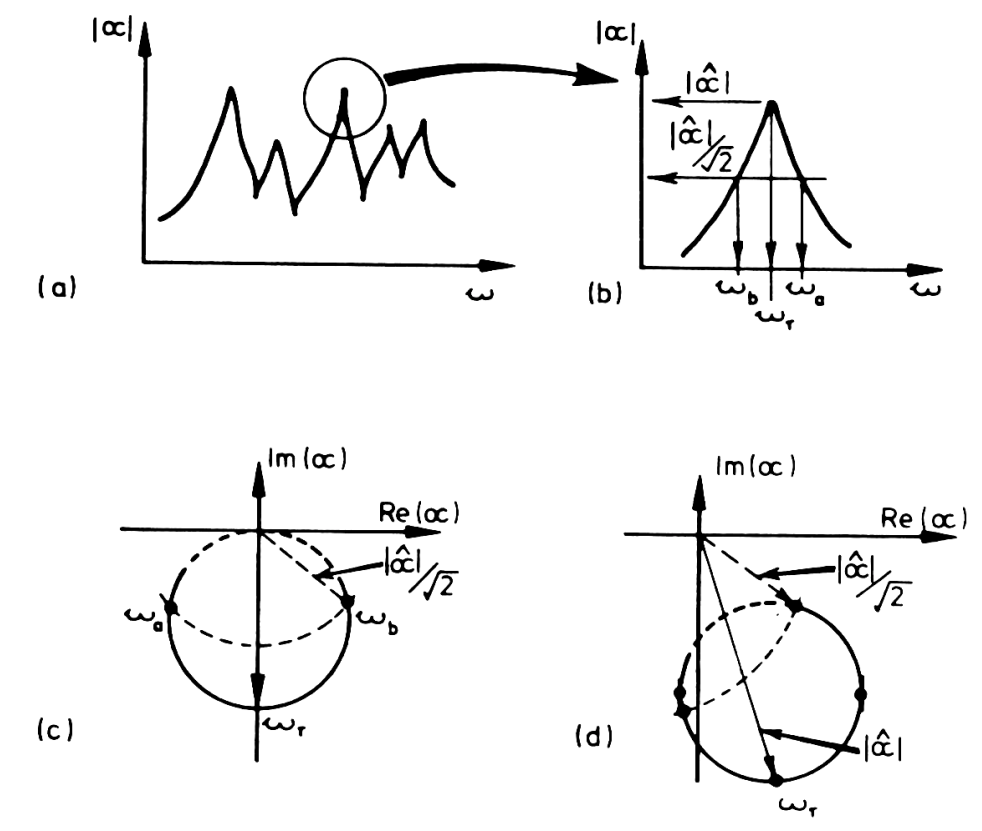

FIGURA (3.2.3-4) - Método da Amplitude do Pico da Análise Modal EWINS (1984) 
A princípio escolhe-se o modo que será analisado (FIGURA (3.2.3-4a)), a partir daí considera-se que os demais modos não interferem sobre este que está sendo analisado, ou seja, tal modo é dominante numa pequena faixa de frequência ao qual está contida a frequência natural. Destaca-se assim esta faixa de frequência, determinando-se através do gráfico do módulo da FRF os valores que correspondem ao valor de amplitude igual a amplitude máxima divida por $\sqrt{2}$ como mostra a FIGURA (3.2.3-4b). Isto implica diretamente numa representação polar dada pela FIGURA (3.2.3-4c) ou pela FIGURA (3.2.3-4d). Por fim, faz-se uso dos valores de $\omega_{\mathrm{a}}$ e $\omega_{\mathrm{b}}$ para determinar os seus respectivos ângulos de fase através do gráfico de fase da FRF. Sabe-se que por propriedades geométricas do círculo modal os valores de $\theta_{\mathrm{a}}$ e $\theta_{\mathrm{b}}$ são dados por:

$$
\begin{aligned}
& \theta_{\mathrm{a}}=2 .\left(\text { Fase de } \omega_{\mathrm{a}}-90^{\circ}\right) \\
& \theta_{\mathrm{b}}=2 .\left(90^{\circ}-\text { Fase de } \omega_{\mathrm{b}}\right)
\end{aligned}
$$

Entretanto, sabe-se que: $\eta_{\mathrm{r}}=2 \zeta_{\mathrm{r}}$. Portanto, o fator de amortecimento modal $\left(\zeta_{\mathrm{r}}\right)$ para uma estrutura levemente amortecida é dado por:

$$
\zeta_{\mathrm{r}} \approx \frac{\left(\omega_{\mathrm{a}}-\omega_{\mathrm{b}}\right)}{\omega_{\mathrm{r}}\left(\operatorname{tg}\left(\theta_{\mathrm{a}} / 2\right)+\operatorname{tg}\left(\theta_{\mathrm{b}} / 2\right)\right)}
$$

Sendo assim, com um ensaio de impacto pode-se determinar as frequências naturais do sistema e os fatores de amortecimento modal tendo a FRF no domínio da frequência. Após a aquisição dos valores de resposta no domínio da frequência, segue a determinação das resposta no domínio do tempo. É importante lembrar que as vibrações transientes possuem sinais de excitação e/ou resposta sem periodicidade, ou seja, eles não são múltiplos de $2 \pi / T$, onde T é o período fundamental. EWINS (1984) descreve que é possível aplicar Transformadas de Fourier nestes sinais desde que haja um período longo de aquisição, pois tais transformadas são apenas aplicáveis à sinais periódicos. Neste trabalho propôs-se um tempo de aquisição de 2 segundos. Assim a Transformada Inversa de Fourier fornecerá x(t):

$$
x(t)=\frac{1}{2 \pi} \int_{-\infty}^{\infty} H(\omega) F(\omega) e^{j \omega t} d \omega
$$

Através da resposta em função do tempo é possível observar o comportamento transiente que as amostras revelam após receber uma entrada impulso. Tanto para o Caso 1 
como para o Caso 2 é possível verificar visualmente quanto tempo cada caso estudado leva para atenuar a resposta.

Os resultados bem como suas análises e a verificação da qualidade do processo de cálculo são apresentados e detalhados no capítulo a seguir. 


\section{CAPÍtulo 4.}

\section{RESULTADOS}

Através dos resultados do presente trabalho buscou-se:

1-Avaliar as Funções de Resposta em Frequência (FRF) investigando a influência da sequência de empilhamento das lâminas no comportamento dinâmico de vigas feitas de material compósito polimérico reforçado para o Caso I ([45/-45/45/-45/45/-45/45/-45/0/90]s) e o $\underline{\text { Caso } 2}\left([0 / 90 / 0 / 90 / 0 / 90 / 0 / 90 / 0 / 90]_{\mathrm{s}}\right)$;

2-Avaliar o amortecimento das amostras do Caso 1 e do Caso 2, verificando a influência da sequência de empilhamento das lâminas;

3-Validar os resultados obtidos pela análise numérica via Método dos Elementos Finitos.

Resultados da Análise Modal via Método dos Elementos Finitos (MEF)

Os resultados obtidos numericamente servem como estimativas que auxiliam durante a análise experimental. A TABELA (4-1a) apresenta as frequências naturais não amortecidas do Caso 1 e do Caso 2 para uma faixa especifica que vai desde $0 \mathrm{~Hz}$ até $400 \mathrm{~Hz}$, sendo captados 8 modos de vibrar. 
TABELA (4-1a) - Resultados obtidos via MEF

\begin{tabular}{|c|c|c|}
\hline Modo & $\begin{array}{c}\text { Caso 1 } \\
\text { ([45/-45/45/-45/45/-45/45/- } \\
45 / 0 / 90]_{\mathrm{s}} \\
\text { Frequência Natural não } \\
\text { amortecida [Hz] }\end{array}$ & $\begin{array}{c}\text { Caso } 2 \\
{[0 / 90 / 0 / 90 / 0 / 90 / 0 / 90 / 0 / 90]_{\mathrm{s}}} \\
\text { Frequência Natural não } \\
\text { amortecida }[\mathrm{Hz}]\end{array}$ \\
\hline 1 & 4,8 & 6,7 \\
\hline 2 & 29,9 & 42,0 \\
\hline 3 & 81,0 & 99,9 \\
\hline 4 & 83,8 & 117,6 \\
\hline 5 & 164,5 & 123,6 \\
\hline 6 & 192,8 & 230,0 \\
\hline 7 & 272,6 & 372,4 \\
\hline 8 & $>400$ & 379,6 \\
\hline
\end{tabular}

A FIGURA (4-1) representa o comportamento das frequências naturais não amortecidas em função dos modos de vibrar para o Caso 1 e o Caso 2.

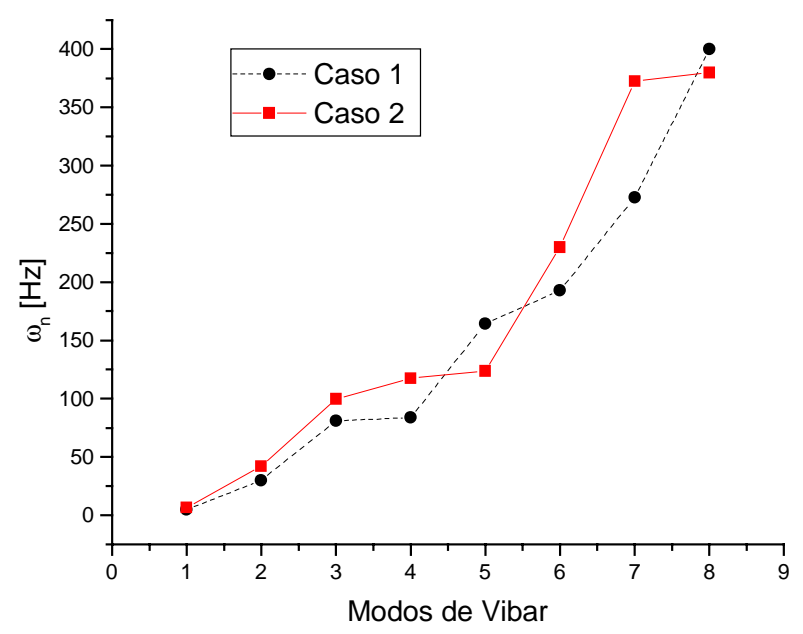

FIGURA (4-1) - Comparação entre as frequências naturais do Caso 1 e do Caso 2 via MEF 
A seguir a FIGURA (4-2) revela alguns modos de vibrar da viga engastada que foram capturados do pós-processador ANSYS52. Estes estão explicitados na TABELA (4-1b).

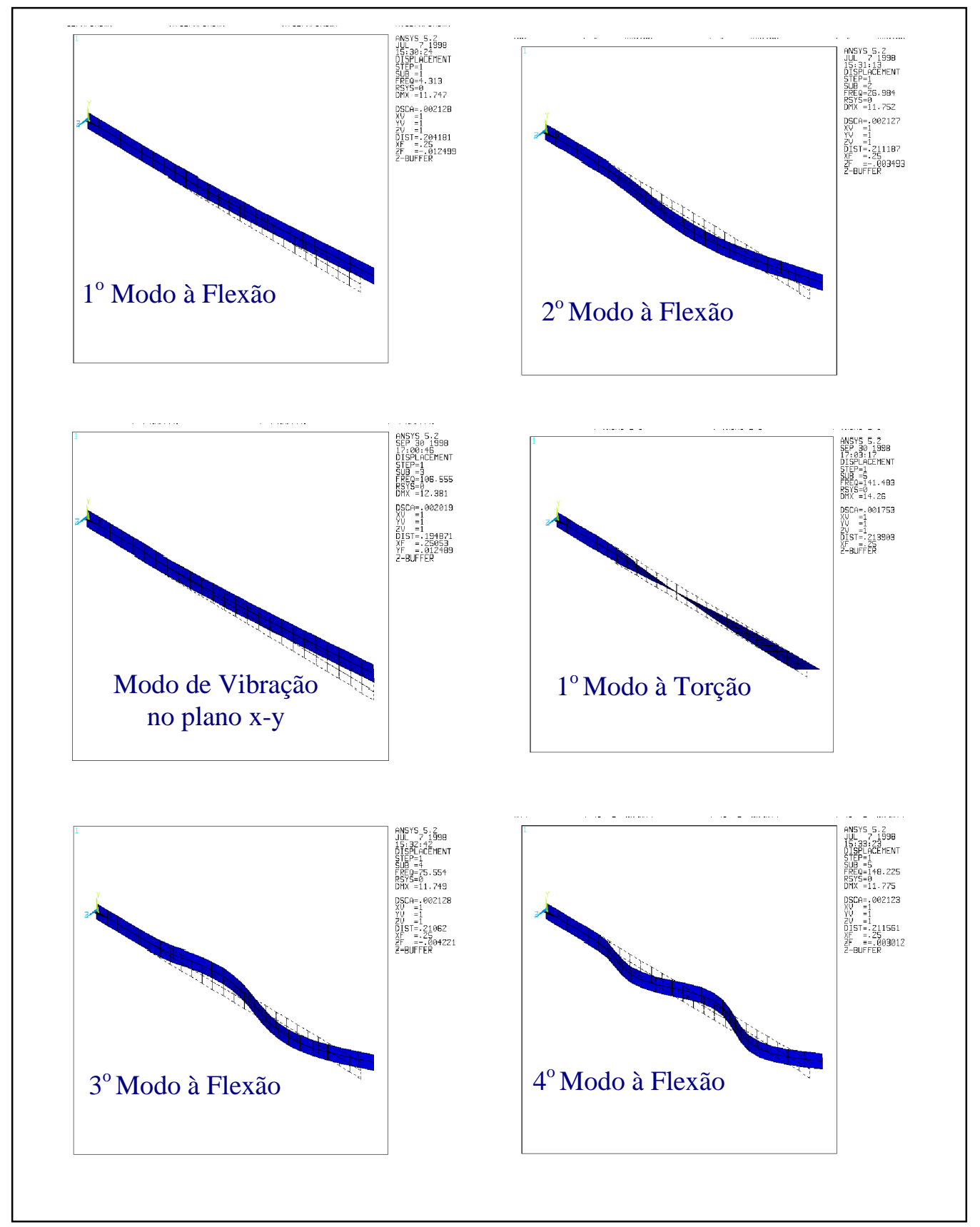

FIGURA (4-2) -Modos de vibrar da viga engastada 
Verifica-se pela FIGURA (4-2) que as formas de vibrar fletem, torcem ou vibram no próprio plano do laminado. Ou seja, através do pós-processamento dos modos de vibrar é possível identificar as formas de vibrar que correspondem a cada frequência natural.(TABELA (4-1b)).

TABELA (4-1b) - Modos de vibrar e suas correspondentes frequências naturais via MEF

\begin{tabular}{|c|c|c|c|}
\hline \multicolumn{2}{|c|}{ Caso 1 } & \multicolumn{2}{c|}{ Caso 2 } \\
\hline Modo & $\omega_{\mathrm{n}}[\mathrm{Hz}]$ & $\omega_{\mathrm{n}}[\mathrm{Hz}]$ \\
\hline $1^{\circ}$ Modo à Flexão & 4,8 & $1^{\circ}$ Modo à Flexão & 6,7 \\
\hline $2^{\circ}$ Modo à Flexão & 29,9 & $2^{\circ}$ Modo à Flexão & 42,0 \\
\hline Vibração no plano & 81,0 & Vibração no plano & 99,9 \\
\hline $3^{\circ}$ Modo à Flexão & 83,8 & $3^{\circ}$ Modo à Flexão & 117,6 \\
\hline $4^{\circ}$ Modo à Flexão & 164,5 & $1^{\circ}$ Modo à Torção & 123,6 \\
\hline $1^{\circ}$ Modo à Torção & 192,8 & $4^{\circ}$ Modo à Flexão & 230,0 \\
\hline $5^{\circ}$ Modo à Flexão & 272,6 & $2^{\circ}$ Modo à Torção & 372,4 \\
\hline $6^{\circ}$ Modo à Flexão & $>400$ & $5^{\circ}$ Modo à Flexão & 379,6 \\
\hline
\end{tabular}

A partir das FIGURAS (4-1 e 4-2) e da TABELA (4-1b) é possível detectar uma influência da sequência de empilhamento das lâminas. Em primeiro lugar o laminado do Caso 1, que possui fibras direcionadas a $+/-45^{\circ}$ nas camadas mais externas, registra frequências naturais menores do que o laminado do Caso 2 , que possui fibras somente a $0^{\circ} \mathrm{e}$ $90^{\circ}$. Entretanto, para o modo de vibrar à torção ocorre uma inversão nos resultados, ou seja, o laminado do Caso 1 possui uma frequência natural para o modo à torção maior do que o laminado do Caso 2. Isto se justifica porque as frequências naturais refletem a rigidez da estrutura, portanto quanto maior for a frequência natural de um determinado modo, mais rígida será a estrutura quando estiver trabalhando neste modo. Nota-se que o laminado do Caso 2 é mais rígido que o laminado do Caso 1 quando a estrutura sofre flexão. Isto ocorre porque $50 \%$ das lâminas do Caso 2 estão orientadas a $0^{\circ}$, fazendo com que o laminado seja bem rígido nesta direção. Já o laminado do Caso 1 possui apenas 2 lâminas direcionadas a $0^{\circ}$, 
sendo a grande maioria direcionada a $+/-45^{\circ}$. Portanto, a influência das fibras nesta direção durante os modos de flexão garante uma menor rigidez do laminado do Caso 1 frente ao laminado do Caso 2. Entretanto, o laminado do Caso 1 torna-se mais rígido que o laminado do Caso 2 quando a estrutura sofre torção. Isto ocorre justamente por causa da grande quantidade de lâminas externas possuírem $+/-45^{\circ}$ de orientação nas suas fibras. É interessante frisar que tal fenômeno pode ser verificado sensivelmente com aplicação manual de carregamentos de flexão e de torção sobre as amostras.

\section{Resultados da Análise Modal Experimental}

Os resultados experimentais são divididos em 2 grandes blocos:

- Funções de Resposta em Frequência (FRF): neste bloco de resultados são apresentadas as Funções de Resposta em Frequência (FRF) do Caso 1 e do Caso 2, avaliando-se a influência da orientação das fibras. Posteriormente, faz-se uma comparação dos resultados numéricos com os resultados experimentais;

- Estimativa dos Fatores de Amortecimento Modal: neste bloco busca-se estimar os fatores de amortecimento modal para o Caso1 e o para o Caso2, avaliando-se a influência da orientação das fibras. Por fim, verifica-se o comportamento da resposta transiente de ambos os casos.

\section{Funções de Resposta em Frequência (FRF)}

São apresentados os resultados experimentais das Funções de Resposta em Frequência, seguindo a convenção adotada na FIGURA (4-3), tem-se:

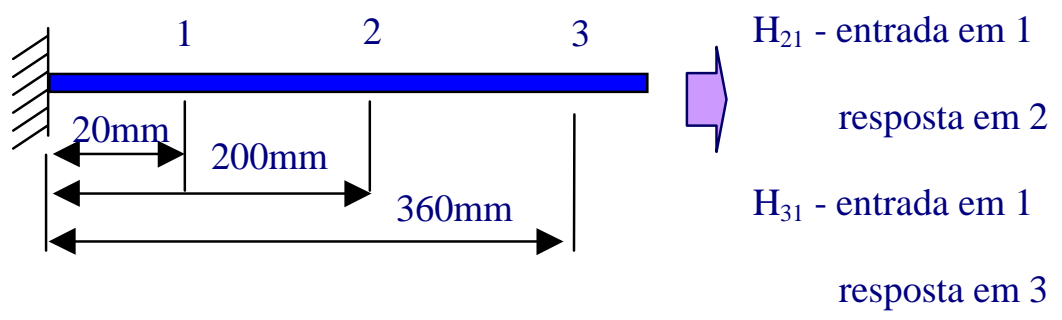

FIGURA (4-3) - Pontos de obtenção da FRF (Função de Resposta em Frequência) 
A)Função de Resposta em Frequência para entrada no ponto 1, saída no ponto 2 do Caso 1 e do Caso 2.
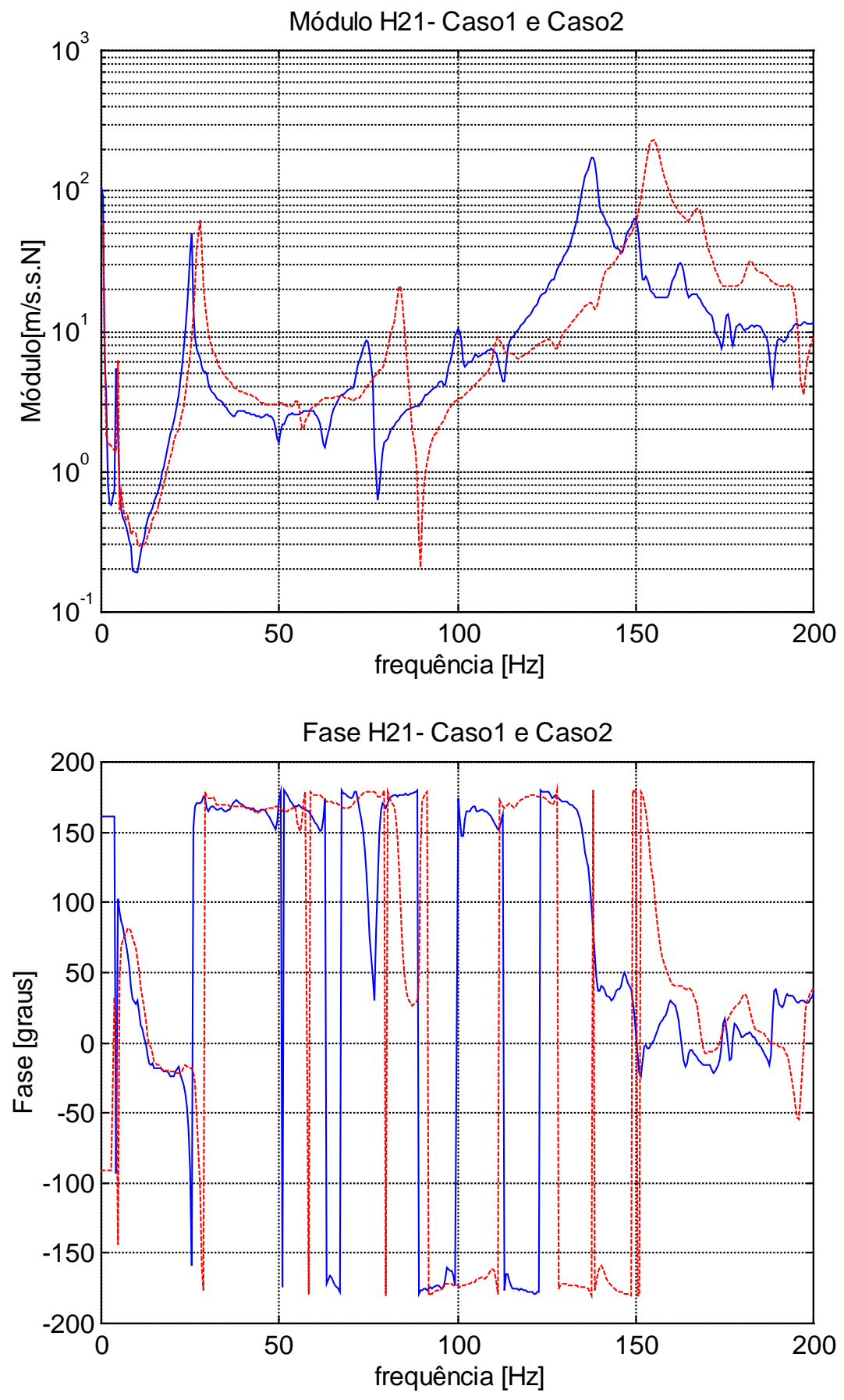

Caso1

Caso2

FIGURA (4-4) - FRFs (H21) do Caso 1 e do Caso 2 
B)Função de Resposta em Frequência para entrada no ponto 1, saída no ponto 3 do Caso 1 e do Caso 2.
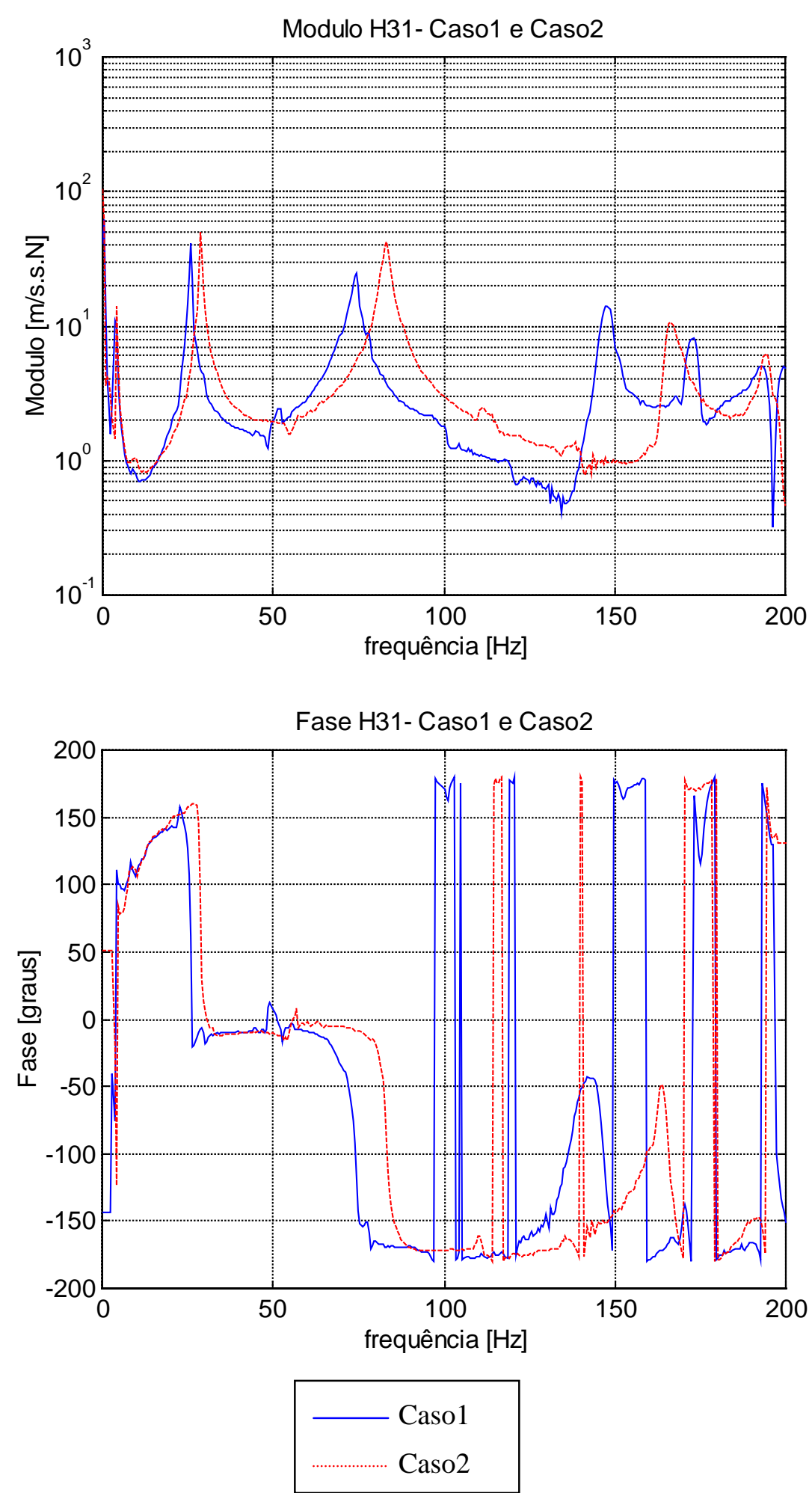

FIGURA (4-5) - FRFs (H31) do Caso 1 e do Caso 2 
C) Função de Resposta em Frequência para entrada no ponto 1, saída no ponto 2 e no ponto 3 para o Caso 1 .
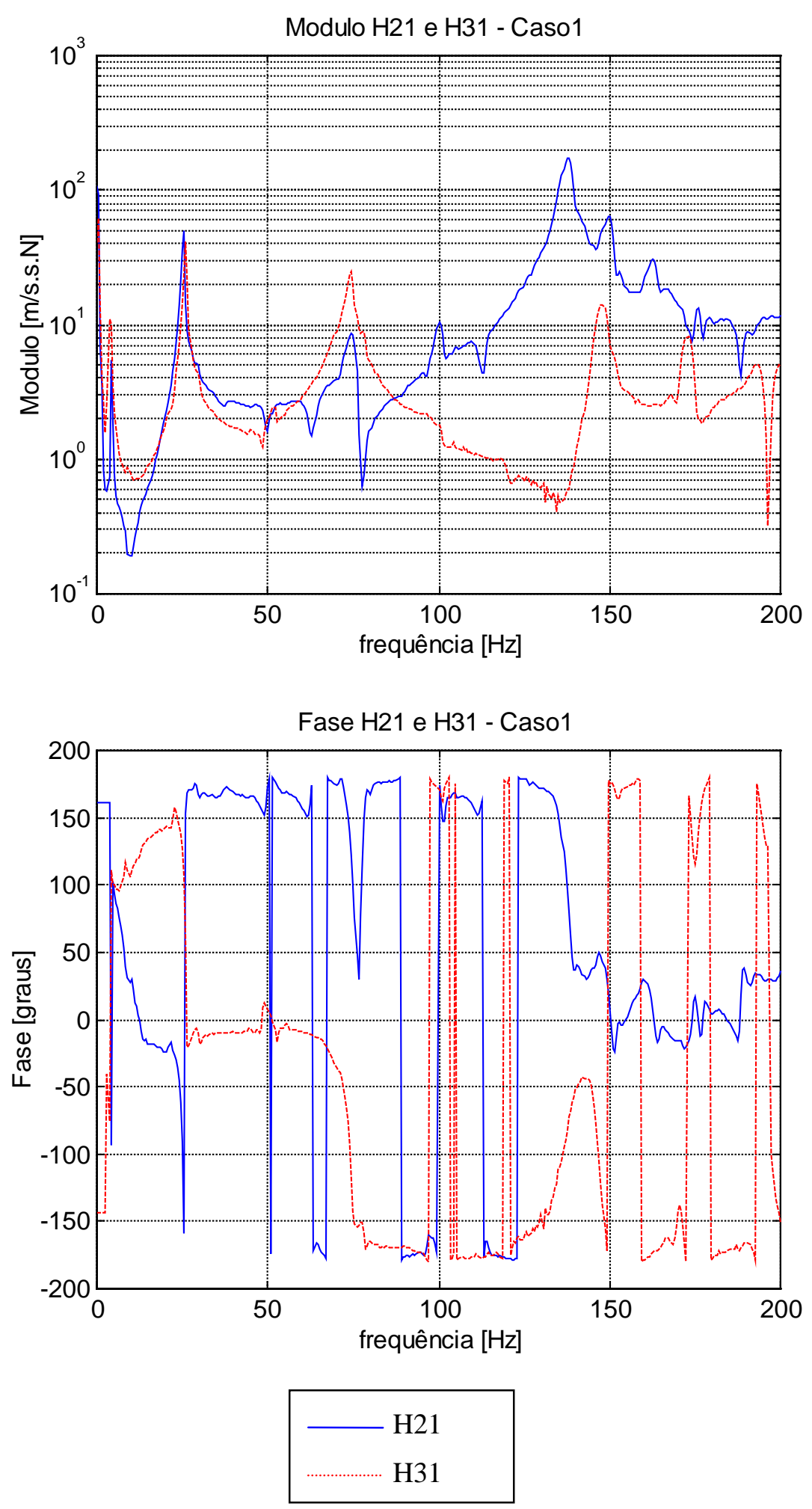

FIGURA (4-6) - FRFs (H21 e H31) do Caso 1 
D) Função de Resposta em Frequência para entrada no ponto 1, saída no ponto $2 \mathrm{e}$ no ponto 3 para o Caso 2 .
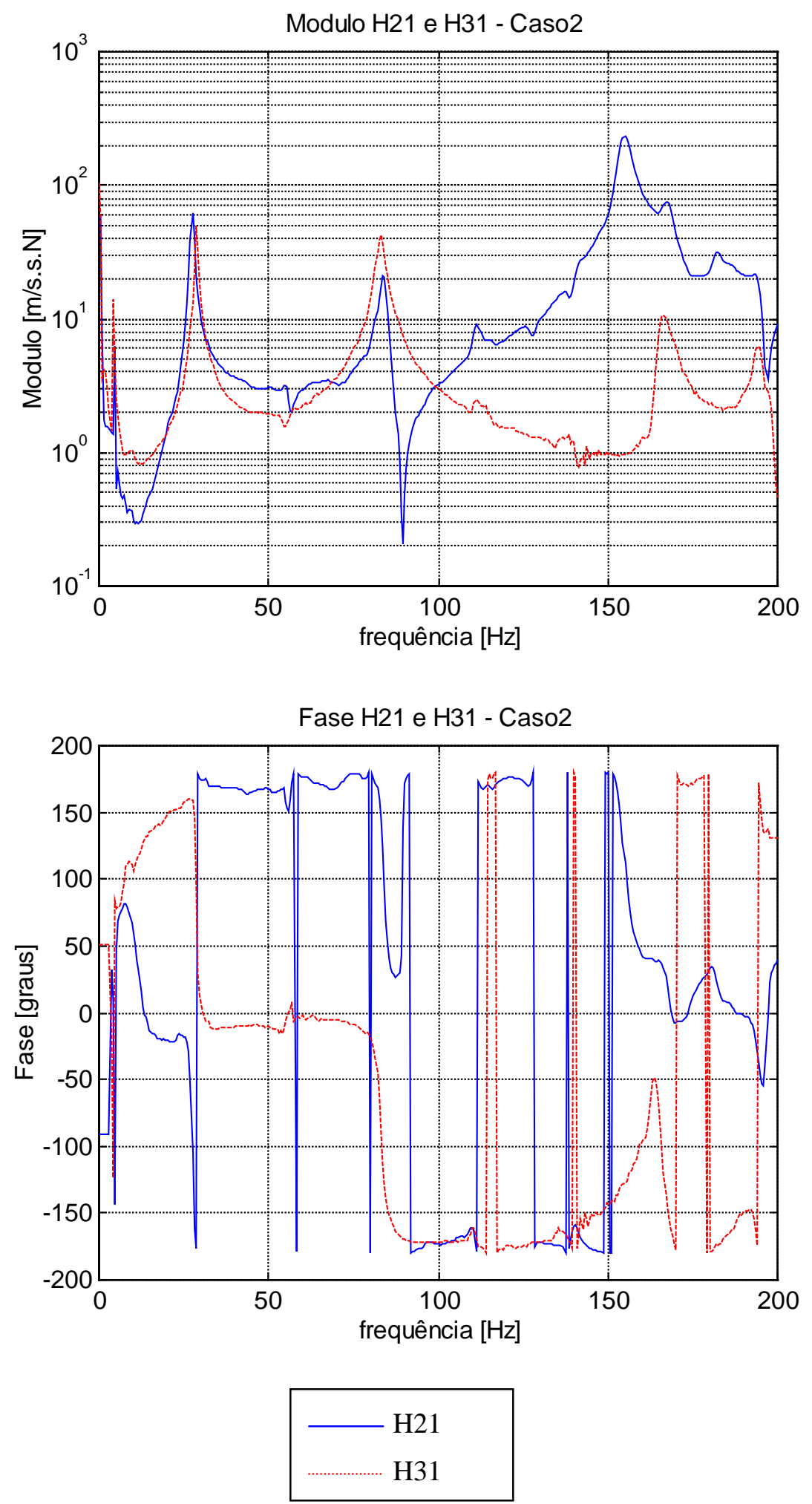

FIGURA (4-7) - FRFs (H21 e H31) do Caso 2 
De acordo com as FIGURAS (4-4 e 4-7) é possível constatar de 4 a 5 picos de frequências na faixa de $0 \mathrm{~Hz}$ a $200 \mathrm{~Hz}$. Detectou-se uma grande presença de ruídos na faixa de $200 \mathrm{~Hz}$ a $400 \mathrm{~Hz}$ nos gráficos de módulo e fase para ambos os casos estudados, não sendo possível a aquisição de algumas frequências naturais. Sabe-se que um ruído é algo intrínseco ao processo de ensaio em laboratório e que provavelmente a massa do acelerômetro tenha contribuído com tal fenômeno. Apesar de tal problema, detecta-se um aspecto importante a ser comentado a partir dos resultados experimentais, ou seja, eles refletiram algo já esperado após a realização da análise numérica, mostrando nitidamente pelas FRFs uma diferença entre as posições dos picos de frequência para os casos estudados. Sendo assim, firma-se através dos resultados experimentais que a sequência de empilhamento das lâminas influenciam diretamente a resposta dinâmica da estrutura. Isto vem concordar com a teoria e a revisão bibliográfica que demonstrava a alteração na rigidez da estrutura com a mudança do ângulo de posicionamento da fibra. As TABELAS (4-2 e 4-3) revelam as frequências naturais amortecidas para os respectivos modos de vibrar obtidas através das FRFs. Constata-se a falta da frequência natural que corresponde ao modo de vibração no plano x-y, pois de acordo com o tipo de ensaio realizado não foi possível captá-la. Isto ocorre porque nesta frequência o laminado vibra no seu próprio plano, como pode ser verificado através da FIGURA (4-2). Com auxílio das respectivas FRFs foi possível levantar as tabelas abaixo:

TABELA (4-2) - Resultados Experimentais de $\mathrm{H}_{21}$ para o Caso 1 e para o Caso 2

\begin{tabular}{|c|c|c|}
\hline \multirow{2}{*}{ Modos } & $\begin{array}{c}\text { Caso 1- } \mathrm{H}_{21} \\
\text { Frequência Natural }[\mathrm{Hz}]\end{array}$ & $\begin{array}{c}\text { Caso 2- } \mathrm{H}_{21} \\
\text { Frequência Natural [Hz] }\end{array}$ \\
\hline 1 & 4,0 & 4,5 \\
\hline 2 & 25,5 & - \\
\hline 3 & - & 84,0 \\
\hline 4 & 74,0 & 111,5 \\
\hline 5 & 139,0 & 155,5 \\
\hline 6 & - & \\
\hline
\end{tabular}


TABELA (4-3) - Resultados Experimentais de $\mathrm{H}_{31}$ para o Caso1 e para o Caso2

\begin{tabular}{|c|c|c|}
\hline \multirow{2}{*}{ Modos } & $\begin{array}{c}\text { Caso1- } \mathrm{H}_{31} \\
\text { Frequência Natural }[\mathrm{Hz}]\end{array}$ & $\begin{array}{c}\text { Caso2- } \mathrm{H}_{31} \\
\text { Frequência Natural [Hz] }\end{array}$ \\
\hline 1 & 3,8 & 4,0 \\
\hline 2 & 26,0 & 29,0 \\
\hline 3 & - & 83,0 \\
\hline 4 & 74,0 & 111,5 \\
\hline 5 & 149,0 & 166,5 \\
\hline 6 & 173,0 & \\
\hline
\end{tabular}

Verifica-se assim a falta de precisão para aquisição de algumas frequências naturais para determinados modos devido aos problemas de ruídos comentados anteriormente (TABELA (4-2)). Isto ocorre, principalmente quando o acelerômetro fica localizado na posição 2, ou seja, ele está justamente localizado próximo a uma linha nodal de alguns modos de vibrar de flexão. Já para o acelerômetro localizado na posição 3, a aquisição da FRF foi de melhor qualidade (TABELA (4-3)), ou seja, o acelerômetro foi posicionado num local estratégico sobre as vigas (longe das linhas nodais) para os modos à flexão. Com relação aos modos de torção, o acelerômetro utilizado não foi o mais adequado, haja visto que não se fez uso de acelerômetros angulares. Portanto, mediu-se apenas uma componente do modo à torção tanto para o Caso 1 como para o Caso 2. Vale ressaltar que devido a grande presença de ruídos na faixa de $150 \mathrm{~Hz}$ a $200 \mathrm{~Hz}$, não foi possível detectar o pico de torção no Caso 1 quando mediu-se $\mathrm{H}_{21}$. Já para o Caso 2, o pico que se refere à torção para $\mathrm{H}_{21}$ e $\mathrm{H}_{31}$ é visivelmente bem menor do que os demais, refletindo novamente a falta de precisão desses dados.

Nota-se também, pelos gráficos a presença de antiressonâncias nas FRFs de transferência, sendo visíveis nas frequências mais altas para os gráficos de $\mathrm{H}_{31}$ e nas frequências mais baixas para os gráficos $\mathrm{H}_{21}$. Isto concorda com EWINS (1984) quando descreve em seu trabalho que as antiressonâncias aparecerão nas frequências mais altas quanto mais distante estiver os pontos de aquisição da resposta em relação ao sinal de entrada. Outro aspecto a se destacar das FRFs é que elas possuem uma amplitude do 
primeiro pico menor do que do segundo, tal fenômeno pode estar ocorrendo graças a excitação realizada próxima a linha nodal do primeiro modo a flexão.

Apesar da escolha da massa do acelerômetro ser cuidadosa, percebe-se pelas FIGURAS (4-6) e (4-7) que houve provavelmente uma certa alteração na massa modal da estrutura quando o acelerômetro foi deslocado da posição 1 para a posição 2 . O que se nota é um desvio nas frequências naturais para alguns modos de vibrar, ou seja, para os modos em que a viga era mais flexível verificou-se a influência da massa do acelerômetro na captação das respostas.(McCONNELL, 1995).

Outro ponto que merece destaque é a constatação de uma superioridade no modo à torção para o Caso 1 em relação ao Caso 2. Ou seja, nos resultados via MEF constatou-se que o laminado do Caso 1 era menos rígido à flexão do que o laminado do Caso 2. Já na torção, o laminado do Caso 1 demonstrou-se mais rígido do que o laminado do Caso 2. Tal fenômeno ocorreu também durante os ensaios experimentais, como pode ser visualizado comparando-se a FIGURA (4-8) com a FIGURA (4-2). Percebe-se assim que os resultados via MEF fornecem uma boa estimativa do comportamento dinâmico real das amostras.

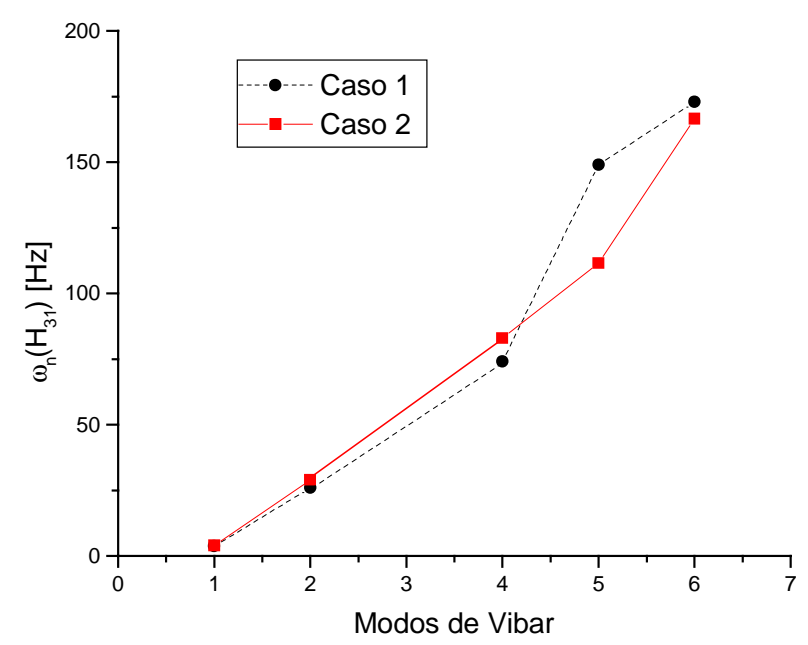

FIGURA (4-8) - Comparação entre as frequências naturais do Caso 1 e do Caso 2

Mesmo com alguns problemas e apesar dos ruídos presentes na experimentação (na instrumentação ou no ambiente de medição), a técnica utilizada é econômica, rápida e nãodestrutiva. Além de ser possível posteriormente estimar o amortecimento estrutural da amostra, levando em consideração influências como de carregamentos e de diferentes tipos 
de vinculações. Isto não seria possível, caso a técnica adotada fosse a de DMTA (Dynamic Mechanical Thermal Analyse) que se propõem a medir o amortecimento apenas do material sob condições bem estabelecidas de vinculação e carregamento (SAHA \& BANERJEE, 1997). HWANG et al (1992) referiu-se à análise modal experimental como uma técnica de boa precisão para estimar propriedades de material.

Sendo assim, a combinação das análises via MEF com as análises experimentais levam a conclusões interessantes sobre a influência da sequência de empilhamento das lâminas no comportamento dinâmico das estruturas. Percebendo-se dessa forma, uma certa coerência entre os resultados numéricos e os resultados experimentais. As tabelas a seguir revelam a porcentagem de erros entre tais resultados.

TABELA (4-4) - Resultados numéricos e experimentais $\left(\mathrm{H}_{21}\right)$ para o $\underline{\text { Caso } 1}$

\begin{tabular}{|c|c|c|c|}
\hline \multirow{2}{*}{ Modos } & $\begin{array}{c}\text { Caso 1 } \\
\text { (experimental) }\end{array}$ & $\begin{array}{c}\text { Caso } 1 \\
\text { MEF }\end{array}$ & $\begin{array}{c}\text { erro } \\
\omega_{\mathrm{n}}[\mathrm{Hz}]\end{array}$ \\
\cline { 2 - 3 } & $\mathrm{H}_{21}[\mathrm{~Hz}]$ & $(*)$ \\
\hline 1 & 4,0 & 4,8 & 17 \\
\hline 2 & 25,5 & 29,9 & 15 \\
\hline 3 & - & 81,0 & - \\
\hline 4 & 74,0 & 83,8 & 12 \\
\hline 5 & 139,0 & 164,5 & 16 \\
\hline 6 & - & 192,8 & - \\
\hline
\end{tabular}

$(*)$ cálculo do erro $=[\mid \mathrm{MEF}-$ Experimental $\mid / \mathrm{MEF}] * 100 \%$

Alguns erros numéricos em relação aos ensaios são relativamente baixos, entretanto, outros valores se afastam muito (TABELAS (4-4 e 4-5)). Vários fatores relacionados aos ensaios fazem com que alguns resultados numéricos se afastem ou se aproximem dos resultados experimentais. Um desses fatores pode ser a presença de ruídos durante as medidas conforme discutido anteriormente. Outros problemas podem estar relacionados diretamente às amostras ou à própria fixação do acelerômetro sobre as mesmas. Vale 
ressaltar que amostras de materiais compósitos possuem um complexo mecanismo de amortecimento interno seguido de problemas que podem ser intrínsecos, tais como, bolhas, falta de uniformidade na espessura, superfície da amostra irregular...Esses fatores não são levados em conta durante a análise numérica, pois a modelagem considera a mesma como inteiramente perfeita, assumindo uma distribuição homogênea das propriedades, o que geralmente não ocorre com as amostras reais. Outro aspecto a se destacar, é que as propriedades do material utilizadas nos cálculos são provenientes da Regra das Misturas e não levam em consideração efeitos da interface fibra-matriz bem como a distribuição irregular de resina sobre as fibras. Vale ressaltar também que o ANSYS52 permite apenas como dados de entrada propriedades de lâminas com fios unidirecionais, e no entanto, as vigas ensaiadas foram feitas a partir de tecidos bidirecionais possuindo um melhor ancoramento bem como uma maior rigidez devido o entrelaçamento dos fios.

TABELA (4-5) - Resultados numéricos e experimentais $\left(\mathrm{H}_{21}\right)$ para o $\underline{\mathrm{Caso} 2}$

\begin{tabular}{|c|c|c|c|}
\hline \multirow{2}{*}{ Modos } & $\begin{array}{c}\text { Caso 2 } \\
\text { (experimental })\end{array}$ & $\begin{array}{c}\text { Caso 2 } \\
\text { MEF }\end{array}$ & $\begin{array}{c}\% \\
\text { erro } \\
\end{array}$ \\
\cline { 2 - 3 } & $\omega_{\mathrm{n}}[\mathrm{Hz}]$ & $\omega_{\mathrm{n}}[\mathrm{Hz}]$ & \\
\hline 1 & 4,5 & 6,7 & 33 \\
\hline 2 & 28,0 & 42,0 & 33 \\
\hline 3 & - & 99,9 & \\
\hline 4 & 84,0 & 117,6 & 29 \\
\hline 5 & 111,5 & 123,6 & 10 \\
\hline 6 & 155,5 & 230,0 & 32 \\
\hline
\end{tabular}

$(*)$ cálculo do erro $=[\mid \mathrm{MEF}-$ Experimental $\mid / \mathrm{MEF}] * 100 \%$

Mesmo com esses problemas abordados, a FIGURAS (4-9a, 4-9b e 4-9c) revelam uma certa coerência entre as respostas do modelo teórico e as análises experimentais principalmente para o Caso1 onde a regressão linear entre a resposta teórica e a experimental está muito próxima da unidade. Além disso, as frequências naturais via MEF são maiores 
que as experimentais por serem frequências não amortecidas. Sendo assim, tal modelo teórico permitiria uma futura previsão de respostas em níveis mais complexos de excitação para alguns modos, tal como choques.(EWINS, 1984). Entretanto vale ressaltar que a modelagem do fenômeno de amortecimento seria interessante, pois as frequências naturais não amortecidas para os modos mais altos tendem a se afastar mais acentuadamente das frequências amortecidas.

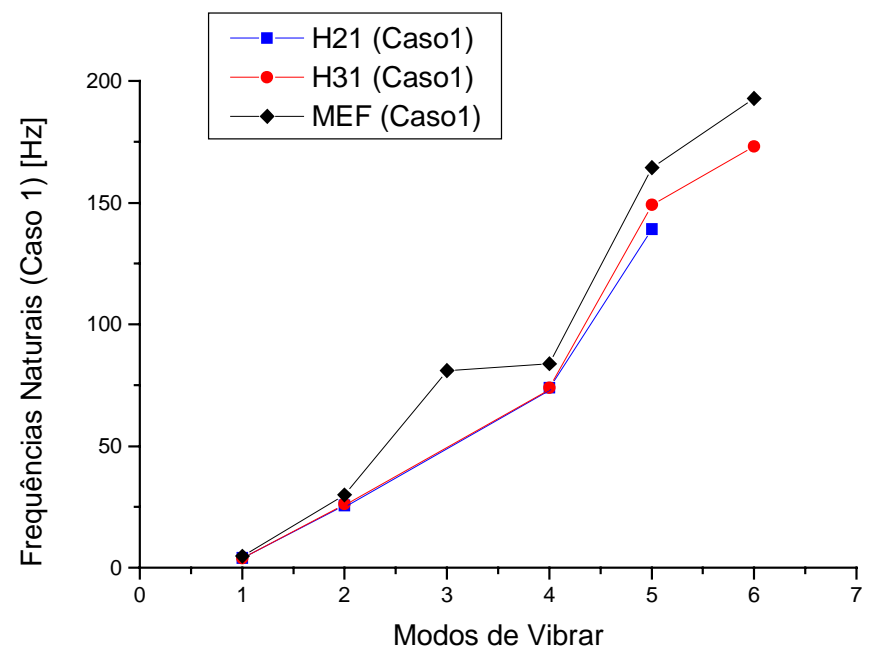

FIGURA (4-9a) - Comparação entre as frequências naturais experimentais e via MEF do Caso 1

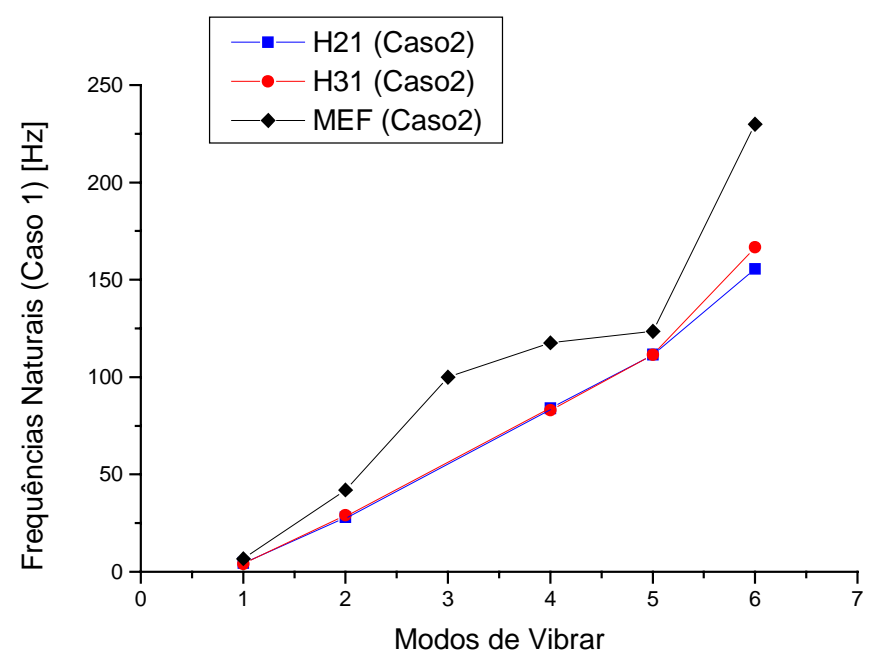

FIGURA (4-9b) - Comparação entre as frequências naturais experimentais e via MEF do Caso 2 


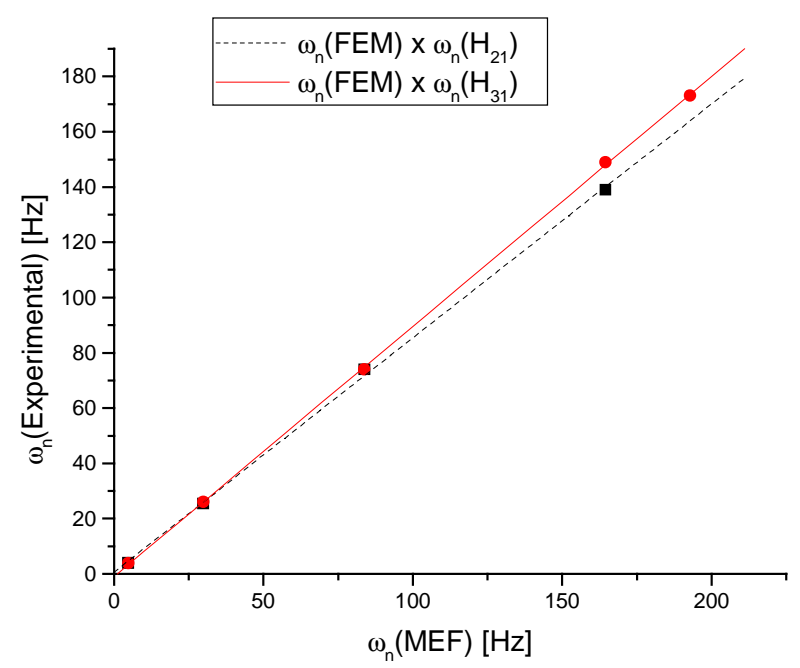

FIGURA (4-9c) - Regressões lineares entre as frequências naturais experimentais e via MEF para o Caso1 e o Caso 2

Ao final das análises teóricas e experimentais verifica-se que a resposta de ambos os casos de estudo (Caso 1 e Caso 2) foram alteradas devido a diferença de orientação das fibras sobre as camadas do laminado, o que mostra portanto que é possível alterar a rigidez da estrutura sem necessitar alterar sua massa ou sua geometria (formas e dimensões). Desta forma, o projetista pode optar pela sequência de empilhamento que melhor lhe convém, ou seja, escolher as orientações das fibras que resultarem em respostas satisfatórias diante do tipo de solicitação que será aplicado na estrutura (flexão, torção ou flexo-torção).

\section{Estimativa dos Fatores de Amortecimento Modal}

Vários programas computacionais já foram desenvolvidos para calcular os fatores de amortecimento modal de uma estrutura com uma certa precisão. Um desses programas é o freq que foi desenvolvido em linguagem PASCAL e tem por objetivo ajustar um círculo ao gráfico polar da resposta..(BAPTISTA, 1995). Entretanto, o presente trabalho visa apenas estudar a influência da sequência de empilhamento das lâminas no comportamento dinâmico da estrutura. Através das análises feitas anteriormente sobre o comportamento à flexão e à torção para ambos os casos estudados, tem-se que apenas 2 modos já seriam suficientes para avaliar a influência da orientação das fibras do compósito no fenômeno de amortecimento. 
A princípio ao analisar as FRFs, nota-se a presença de picos bem agudos para algumas frequências naturais, revelando inicialmente uma baixa capacidade de amortecimento por parte de ambos os casos estudados. Entretanto, para outras faixas de frequência tem-se um gráfico mais ameno, mostrando assim um amortecimento maior. Desta forma, com o objetivo de entender melhor o fenômeno de amortecimento, tomou-se respectivamente os picos que correspondem ao $3^{\circ}$ Modo à Flexão e ao $1^{\circ}$ Modo à Torção para ambos os casos de estudo. A estimativa do fator de perda (loss factor) em cada um desses modos foi realizada com o auxílio do Método da Amplitude do Pico da Análise Modal proposta por EWINS (1984) bem como através da utilização do programa freq (BAPTISTA, 1995) que foi baseado no Método de Kennedy e Pancu. A TABELA (4-6) revela os valores estimados através dos gráficos de FRF.

TABELA (4-6) - Fatores de Amortecimento estimados para o Caso 1 e o Caso 2

\begin{tabular}{|c|c|c|c|c|c|}
\hline \multirow{2}{*}{ Modos } & \multirow{2}{*}{ Método } & \multicolumn{2}{|c|}{ Caso 1} & \multicolumn{2}{|c|}{ Caso 2} \\
\hline & & $\eta_{\mathrm{r}}$ & $\zeta_{\mathrm{r}}$ & $\eta_{\mathrm{r}}$ & $\zeta_{\mathrm{r}}$ \\
\hline $3^{\circ}$ Modo & EWINS & 0,044 & 0,022 & 0,026 & 0,013 \\
\hline à Flexão & freq & - & 0,020 & - & 0,015 \\
\hline$\omega_{\mathrm{r}}[\mathrm{Hz}]$ & & \multicolumn{2}{|c|}{74,0} & \multicolumn{2}{|c|}{83,0} \\
\hline $1^{\circ}$ Modo & EWINS & 0,017 & 0,009 & - & - \\
\hline à Torção & freq & - & 0,007 & - & 0,040 \\
\hline$\omega_{\mathrm{r}}[\mathrm{Hz}]$ & & \multicolumn{2}{|c|}{173,0} & \multicolumn{2}{|c|}{111,5} \\
\hline
\end{tabular}

Para começar a discutir os resultados acima, é preciso inicialmente descrever um pouco sobre o fenômeno do amortecimento em materiais compósitos. O amortecimento em materiais compósitos reforçados por fibras deriva essencialmente da matriz e da interface fibra-matriz. Isto ocorre, porque a principal fonte de amortecimento interno depende da viscoelasticidade associada com o deslizamento relativo na interface entre fibra e matriz. Sendo assim, vários fatores influenciam o mecanismo de amortecimento, tais como: 
- frações volumétricas das fibras e da matriz;

- grau de cura da matriz polimérica;

- comprimento e diâmetro da fibra;

- tratamento superficial da fibra;

- sequência de empilhamento das lâminas.

Este último fator passa então a ser analisado com base nos resultados fornecidos pela TABELA (4-6). É facilmente notado que o fator de amortecimento modal é maior para o modo à flexão do que à torção para o Caso 1 pelos dois métodos. Entretanto, o mesmo não acontece para o Caso 2, onde os resultados à torção divergem. Inicialmente pode-se afirmar que a sequência de laminação do Caso 1 permite uma ação mais eficiente por parte da matriz nos modos à flexão, haja visto que a maioria das camadas possuem orientação de $+/-45^{\circ}$. Desta forma, no caso de flexão, onde as camadas externas apresentam maiores níveis de deformação (e tensão), a ação da matriz é preponderante sobre a ação da fibra, garantindo assim uma maior capacidade de dissipação de energia interna, e consequentemente maior fator de amortecimento. Já para a situação de torção, as fibras dispostas a $+/-45^{\circ}$ tem uma atuação mais efetiva frente aos gradientes de tensão, levando a um menor fator de amortecimento quando comparadas com o Caso 2. O comportamento do laminado do Caso 2 pode ser explicado analogamente. Entretanto, ele apresenta fatores de amortecimento menores quanto à flexão, justamente porque na situação à flexão a ação das fibras a $0^{\circ}$ fazem com que a matriz perca um pouco de sua ação dissipativa. Enquanto na situação à torção, as fibras a $90^{\circ}$ atuam como um reforço rígido mas permitem uma ação mais efetiva por parte da matriz quando comparadas com o alinhamento a $+/-45^{\circ}$, conduzindo a um maior fator de amortecimento.

Apesar do valor obtido pelo Método do Ewins não ser calculado (amplitude do pico muito pequena) na situação de torção para o Caso 2, tem-se uma estimativa feita através do freq. Entretanto, vale lembrar que os amortecimentos no modo de torção foram obtidos através das FRFs que captaram apenas uma parcela desta forma de vibrar da estrutura. Então, o amortecimento estimado é uma parcela do amortecimento total para os modos à torção. De qualquer forma, já é possível visualizar uma certa capacidade dissipativa maior por parte das amostras do Caso 2 em relação ao Caso 1. Entretanto, para uma estimativa mais confiável seria necessário o uso de acelerômetros angulares. 
Nota-se também, que os resultados apresentados são relativamente satisfatórios, haja visto que GREIF \& HEBERT (1992) estimaram valores de loss factor para resina epoxi em torno de 0,1 a 0,01 . Portanto, é esperado que compósitos constituídos por uma certa fração volumétrica de fibras forneçam resultados superiores a 0,01 , pois como já foi comentado anteriormente, o fenômeno de dissipação de energia está fortemente associado ao comportamento viscoelástico da matriz polimérica. E sendo assim, tudo passa a depender da porcentagem de fibra bem como estas estão alinhadas ou posicionadas ao longo da espessura no laminado. Vale ressaltar que o amortecimento é um importante parâmetro para controle de ruído e de vibração em estruturas, podendo-se assim ser otimizado de acordo com requisitos de projeto.

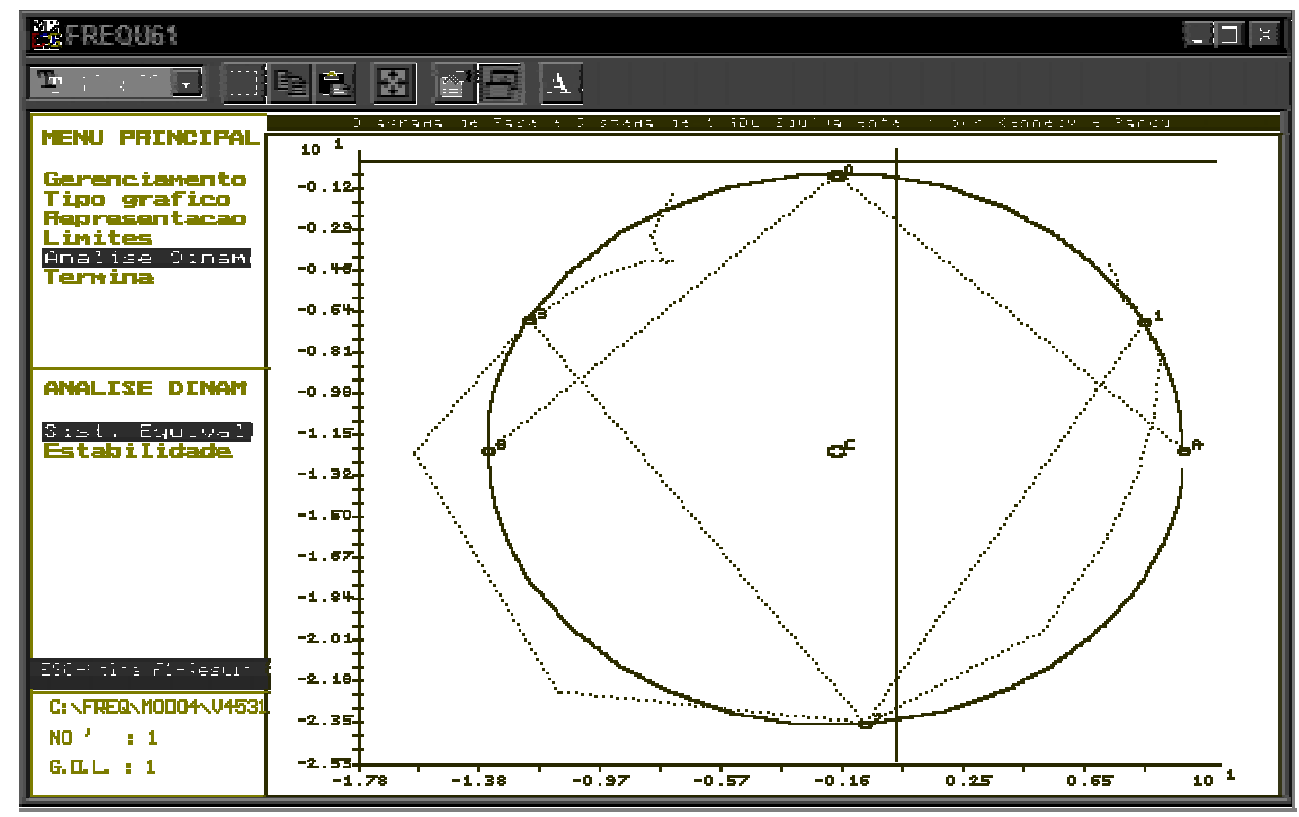

FIGURA (4-10) - Círculo modal ajustado pelo Método de Kennedy e Pancu para estimar o amortecimento à flexão no Caso 1 (sáida do programa freq) 


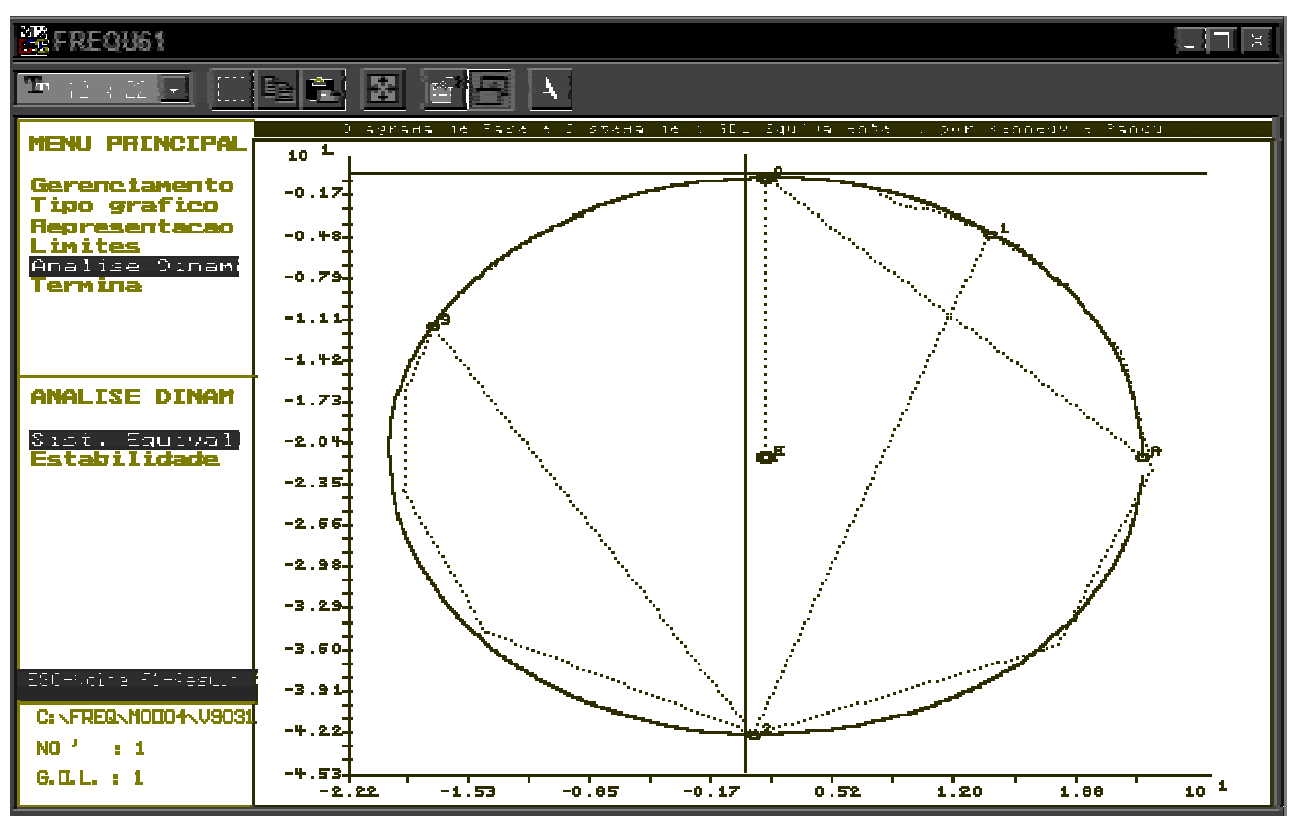

FIGURA (4-11) - Círculo modal ajustado pelo Método de Kennedy e Pancu para estimar o amortecimento à flexão no Caso 2 (sáida do programa freq)

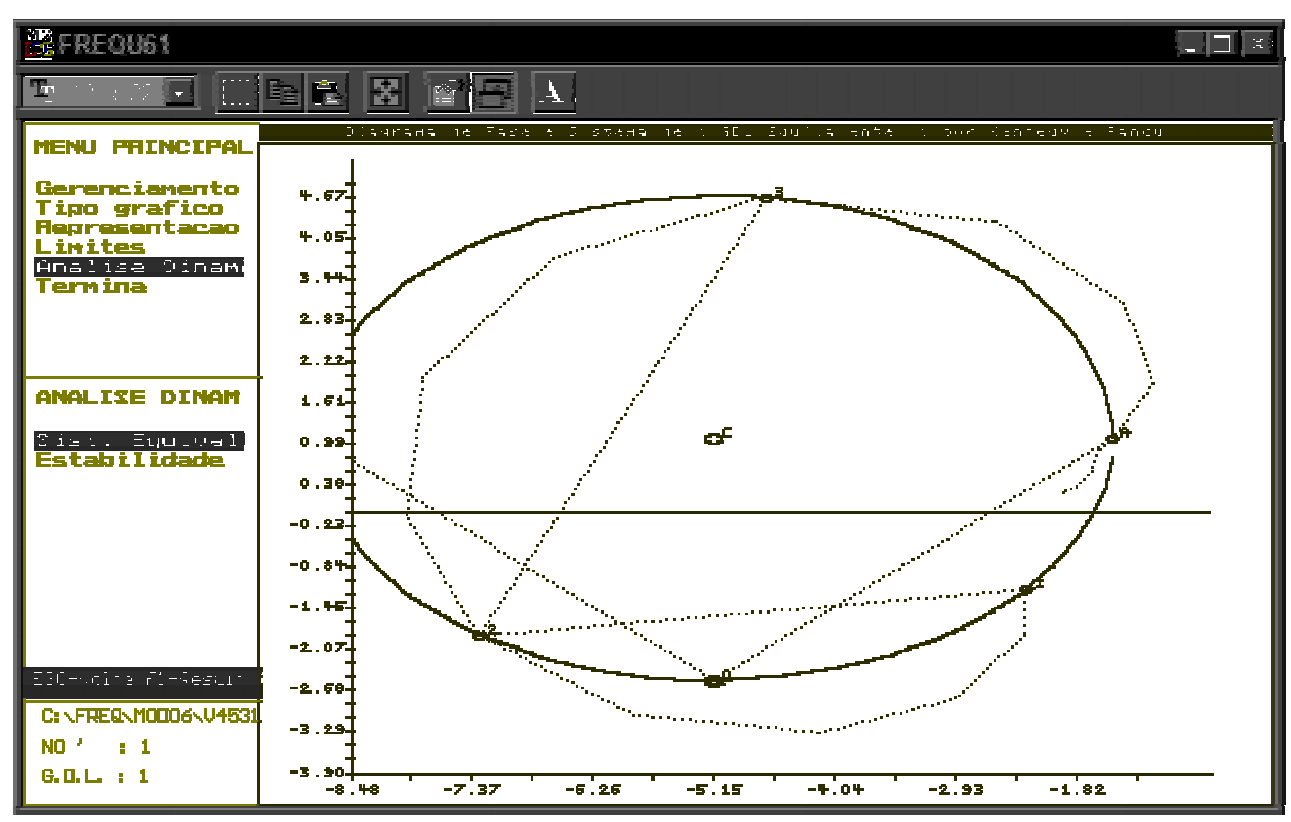

FIGURA (4-12) - Círculo modal ajustado pelo Método de Kennedy e Pancu para estimar o amortecimento à torção no Caso 1 (sáida do programa freq) 


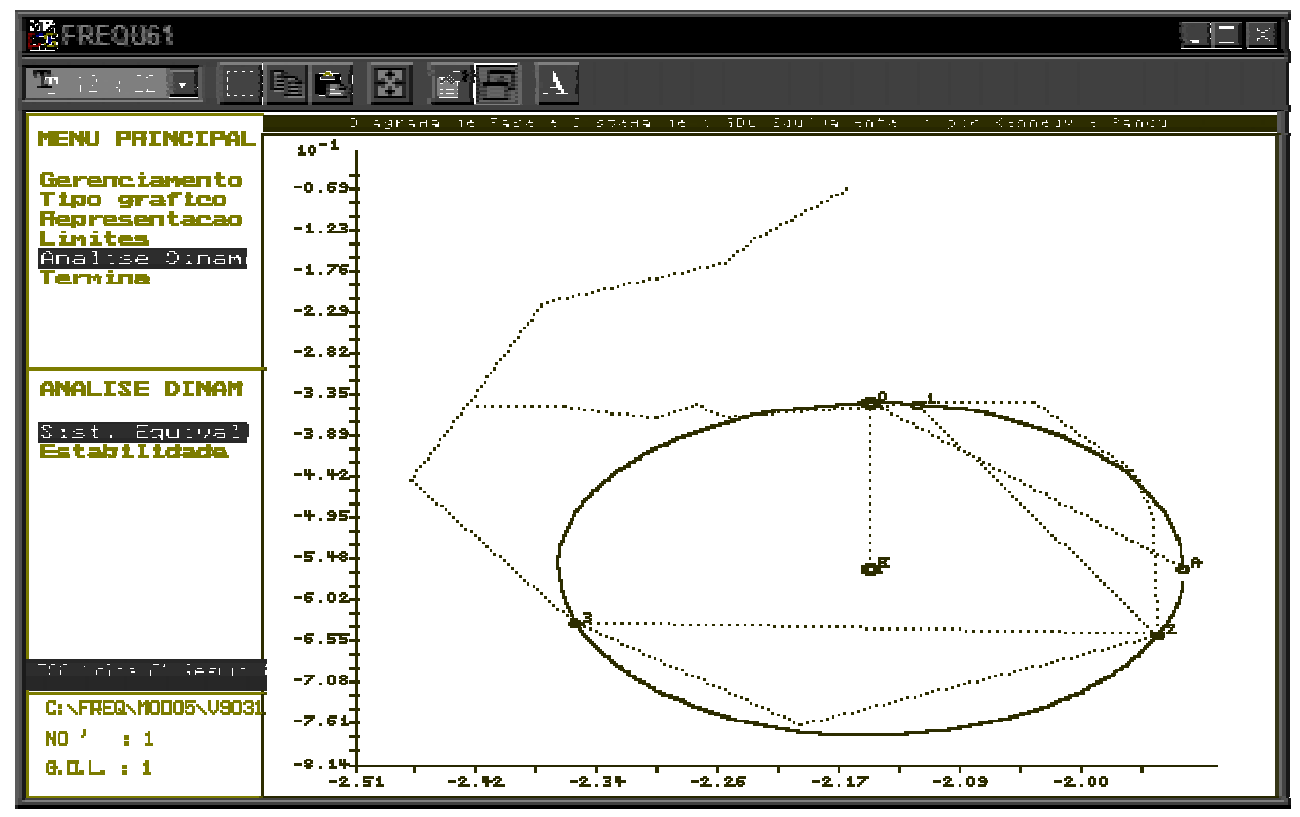

FIGURA (4-13) - Círculo modal ajustado pelo Método de Kennedy e Pancu para estimar o amortecimento à torção no Caso 2 (sáida do programa freq)

Após a verificação dos gráficos no domínio da frequência, levantou-se os gráficos no domínio do tempo para verificar o comportamento transiente de cada caso. Portanto, os gráficos de resposta da estrutura em função do tempo revelam o transiente do sinal de saída logo após o impacto do martelo (convencionados de acordo com a FIGURA (4-4)). 
A)Resposta do sistema em função do tempo para entrada no ponto 1, saída no ponto 2 para o Caso1 e para o Caso2.

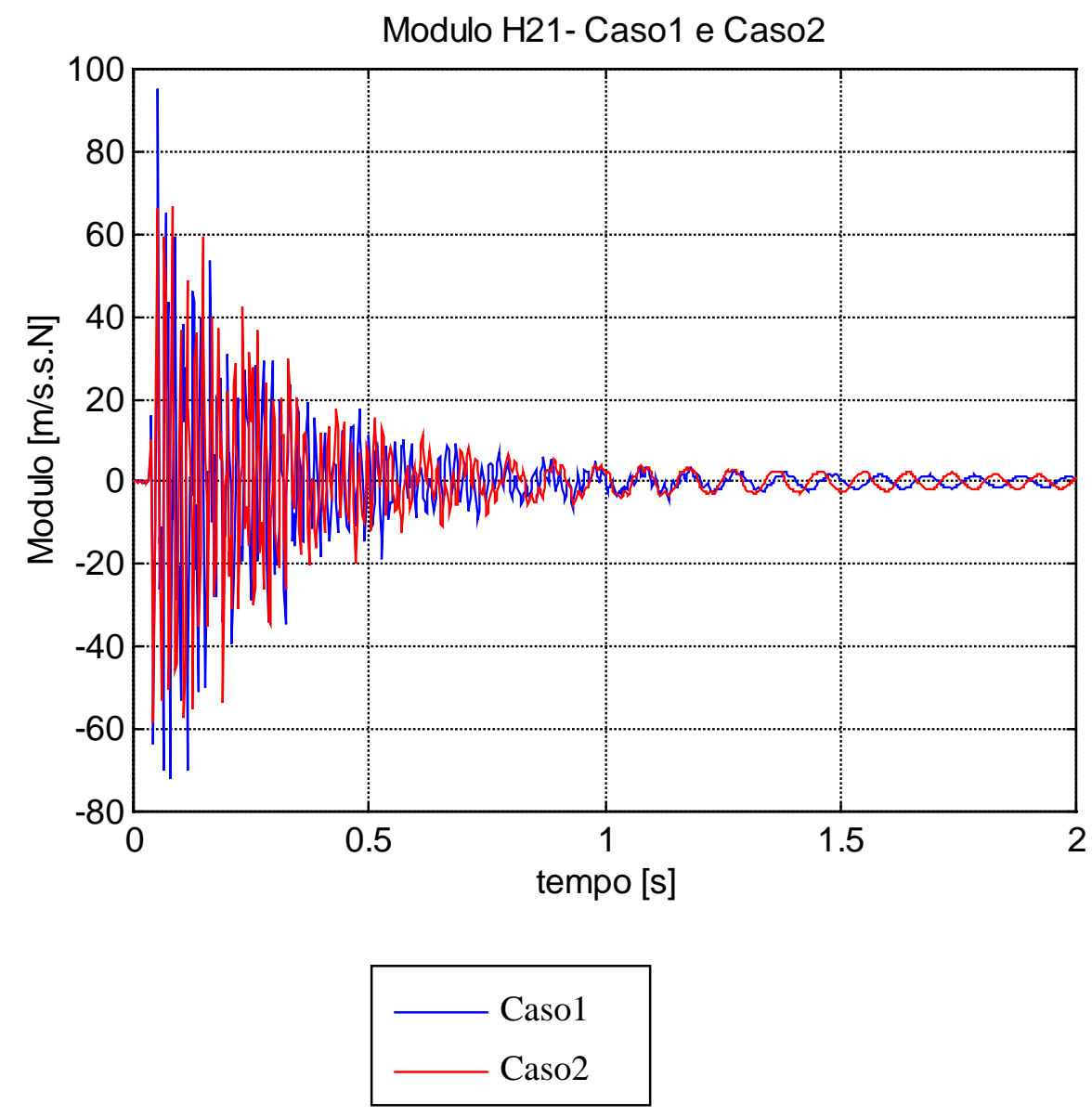

FIGURA (4-14) - Resposta no domínio do tempo (H21)

Através da FIGURA (4-14) percebe-se que quando o acelerômetro está posicionado em 2, ou seja, mais próximo do sinal de entrada, a reposta do laminado do Caso 1 está um pouco adiantada em relação a reposta do laminado do Caso 2, constatando-se a influência do amortecimento para uma atenuação da resposta. Quando o acelerômetro está na posição 3 percebe-se com maior nitidez que o laminado do Caso 2 leva mais tempo para atenuar a resposta como mostra a FIGURA (4-15), dissipando portanto menos energia do que o laminado do Caso 1. 
B)Resposta do sistema em função do tempo para entrada no ponto 1, saída no ponto 3 para o Caso 1 e para o Caso 2.

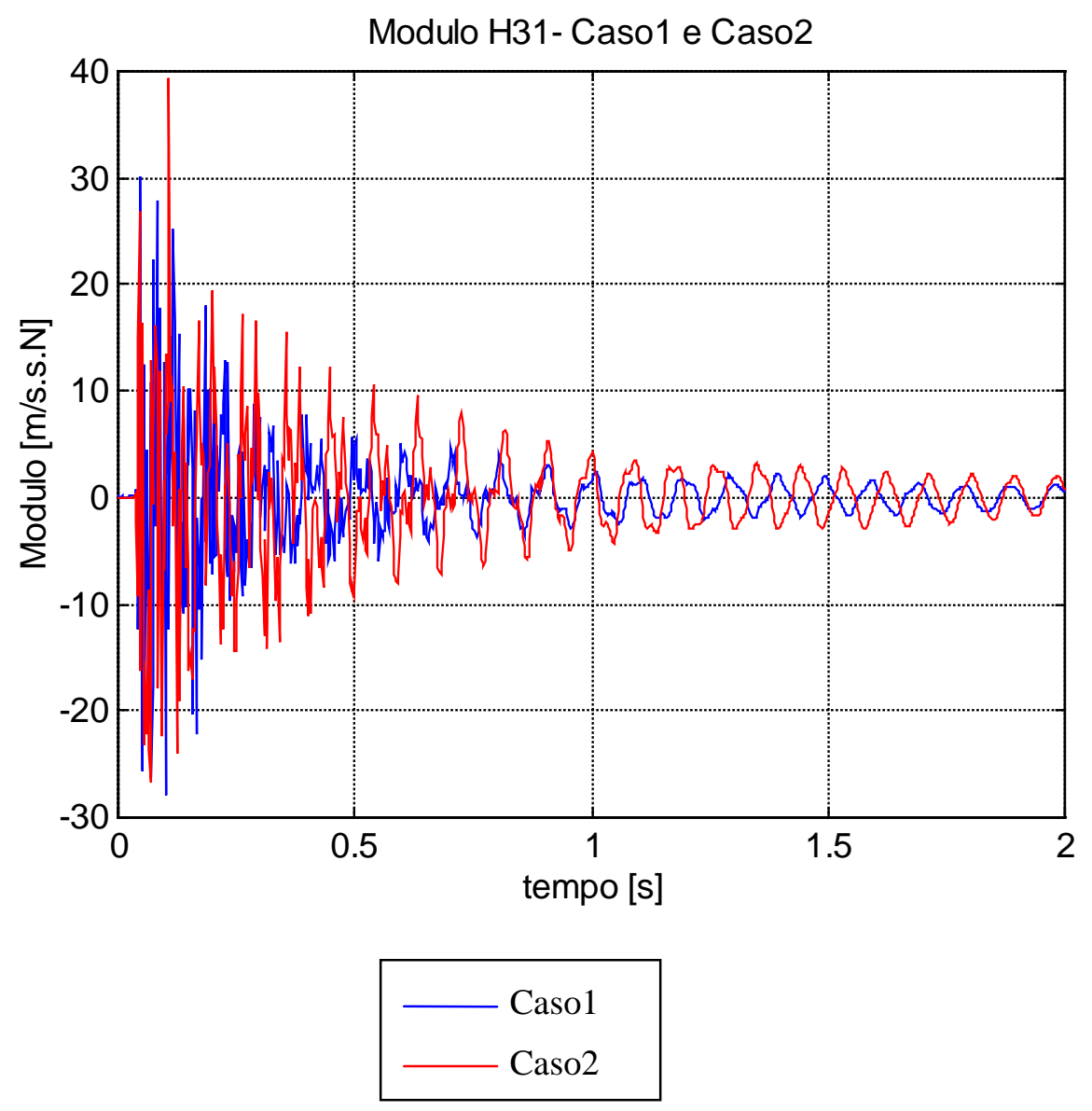

FIGURA (4-15) - Resposta no domínio do tempo (H31)

Vale ressaltar que a FIGURA (4-15) revela um problema de "Leakage" (vazamento), ou seja, o sinal não foi captado totalmente. Portanto, a janela de tempo escolhida não foi suficientemente grande para captar um período inteiro de vibração, ocorrendo um "vazamento" de amplitude do modo principal para os demais modos. Segundo McCONNELL (1995) é possível minimizar o problema de "Leakage" através do uso de janela exponencial de tempo principalmente para estruturas levemente amortecidas que persistem em vibrar por um período de tempo maior do que a janela escolhida. Entretanto, deve-se destacar que o uso da janela exponencial influenciará as medidas dos fatores de amortecimento modal. Haja visto que cada modo será multiplicado por uma função exponencial e terá um amortecimento maior do que o real. McCONNELL (1995) também 
fornece inúmeras maneiras de se ajustar parâmetros da janela de tempo a fim de se ter um melhor desempenho do analisador espectral.

Novamente, após uma análise experimental é possível constatar que a orientação da fibra sobre as lâminas revela uma grande influência na capacidade de amortecimento da estrutura, o que disponibiliza ao projetista mais uma variável para otimizar o desempenho de um produto.

Com base nos resultados e análises desse capítulo, desenvolveu-se no próximo capítulo uma proposta de ciclo de projeto para componentes mecânicos a base de materiais compósitos poliméricos solicitados dinamicamente. 


\section{CAPÍTULO 5}

\section{PROPOSTA DE CICLO DE PROJETO PARA COMPÓSITOS SOLICITADOS DINAMICAMENTE}

O ciclo de projeto proposto na FIGURA (5-1) é constituído de oito etapas sendo duas de checagem para uma possível retroalimentação do processo de desenvolvimento. O ciclo de projeto mostrado está intimamente vinculado ao desempenho dinâmico de componentes feitos a base de materiais compósitos poliméricos reforçados. O seu foco consiste em fornecer uma possibilidade de mudar o comportamento dinâmico da estrutura através da alteração da sequência de empilhamento das lâminas (alteração da orientação da fibra sobre as camadas do compósito), sem promover grandes alterações na geometria (formas e dimensões) ou em outros parâmetros relacionados com o material. A única restrição deverá ser imposta pelo processo de manufatura adotado, ou seja, é necessário verificar se o processo é capaz de executar a laminação desejada. Segue agora uma descrição mais detalhada das etapas e subetapas destacadas no ciclo.

\section{I-Requisitos de Projeto}

Comportamento Dinâmico Desejável: consiste na obtenção de um projeto que satisfaça os requisitos citados abaixo.

1.Frequências naturais exigidas: caso a estrutura seja excitada numa frequência próxima a alguma frequência natural, grandes deslocamentos serão detectados quando o componente estiver em serviço, levando o mesmo à fadiga prematura. Conhecendose tais valores é possível projetá-lo de modo a se obter frequências naturais distantes do valor da frequência de excitação.

2.Amortecimento modal solicitado: em alguns casos torna-se interessante que a estrutura projetada possua um fator de amortecimento modal que seja capaz de atenuar as amplitudes de vibração. Isto torna-se muito atrativo em projetos de veículos que 
transportam passageiros. Sendo assim, pode-se conseguir um maior conforto sem requisitar dispendiosos investimentos no projeto.

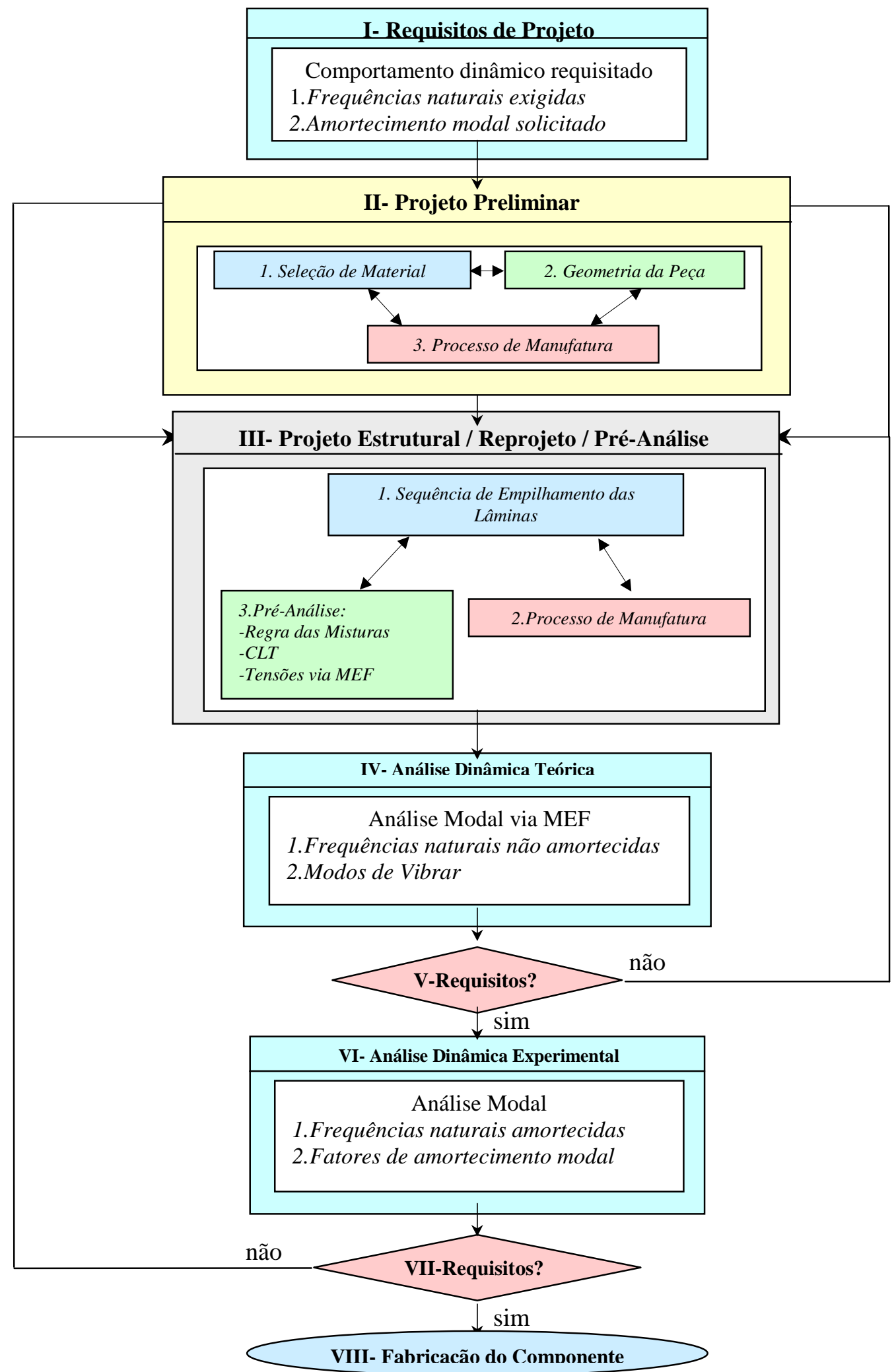

FIGURA (5-1) - Ciclo de projeto para compósitos solicitados dinamicamente 


\section{II-Projeto Preliminar}

O Projeto Preliminar consiste de uma etapa formada por 3 subetapas que ocorrem simultaneamente. Nesta fase, o projetista deve se preocupar apenas em obter um projeto inicial.

1.Seleção do Material: seleciona-se inicialmente o tipo de matriz e o tipo de reforço a ser utilizado, bem como suas respectivas frações volumétricas

2.Geometria da Peça: especifica-se as dimensões do componente que será fabricado

3.Processo de Manufatura: escolhe-se o processo adequado para se fabricar a peça desejada. Vale ressaltar que este processo deve ser compatível com o tipo de material escolhido e com a geometria proposta, ocorrendo uma grande interação entre estas três escolhas.

\section{III-Projeto Estrutural / Reprojeto / Pré-Análise}

O Projeto (ou o Reprojeto) Estrutural é uma estimativa para se atingir os requisitos desejados. Mesmo assim, já é necessário realizar uma Pré-Análise bem como verificar se o processo é capaz de satisfazer as necessidades do projetista.

1.Sequência de Empilhamento das Lâminas: busca-se estimar a melhor laminação possível para o projeto em desenvolvimento.

2.Pré-Análise: faz-se uma pré-análise das tensões que atuam no laminado, verificando inicialmente se a sequência proposta é capaz de suportar o carregamento. Caso não seja, deve-se orientar as fibras de tal modo que o componente resista às tensões que lhe são aplicada. Para isto utiliza-se:

- Regra das Misturas,

- CLT (Classical Laminate Theory)

- MEF (Método dos Elementos Finitos)

3.Processo de Manufatura: o projetista verifica se o processo escolhido inicialmente é capaz de atender a orientação desejada. 


\section{IV-Análise Dinâmica Teórica}

Análise Modal via MEF: constitui-se de uma análise dinâmica com o auxílio de um pacote computacional.

1.Frequências naturais não amortecidas: a partir de um modelo teórico do laminado em elementos finitos obtém-se a solução das equações de movimento negligenciando o fenômeno do amortecimento.

2.Modos de vibrar: a partir das frequências naturais calcula-se as suas respectivas formas de vibrar.

\section{V-Requisitos?}

Checa-se com auxílio do pós-processamento do MEF, se o laminado escolhido é satisfatório para manter as frequências naturais da estrutura distante das frequências que excitam a estrutura. Caso, isto não ocorra, deve-se fazer um Reprojeto Estrutural e novamente checar. Esta fase deve ser persistente, afim de se evitar ao máximo a realização de um novo Projeto Preliminar. Entretanto, caso não seja possível satisfazer os requisitos desejáveis, o projetista terá que selecionar novamente o material.

\section{VI-Análise Dinâmica Experimental}

Análise Modal: constitui-se basicamente de um ensaio de impacto feito com o auxílio de um martelo, um acelerômetro e um analisador espectral.

1.Frequências naturais amortecidas: levanta-se os gráficos de FRF afim de constatar os valores que correspondem às frequências amortecidas, verificando se o modelo em elementos finitos forneceu boas estimativas. E portanto sendo possível validar o modelo para análises mais complexas.

2.Fatores de amortecimento modal: levanta-se os círculos modais ajustados afim de se calcular os respectivos fatores de amortecimento.

\section{VII-Requisitos?}

Checa-se com base nos resultados experimentais se os valores de amortecimento obtidos são satisfatórios. Caso estes não sejam satisfatórios, faz-se um Reprojeto Estrutural ou então um novo Projeto Preliminar. Novamente deve-se persistir para que o Reprojeto 
atinja as necessidades especificadas. Pois, muitas vezes um novo Projeto Preliminar pode acarretar em aumento de custo no produto final.

\section{VIII-Fabricação do componente}

Após a segunda checagem o projeto está pronto, entretanto o projetista ainda dispõe da possibilidade de testar uma gama de sequências de empilhamento (diferentes tipos de laminação). Então, ele poderá escolher a melhor que lhe convém dentre aquelas que satisfazem os requisitos exigidos. Constata-se portanto, que o ciclo de projeto proposto é como um processo de triagem que seleciona de uma maneira rápida as especificações para que a peça final tenha um comportamento dinâmico desejável. Está economia de tempo e principalmente de material faz com que os custos do produto final sejam menores comparados aos custos de um produto desenvolvido aleatoriamente.

Vale ressaltar ainda que o ciclo proposto pode ser melhorado com a presença de rotinas computacionais de otimização, ou seja, a III e IV etapas podem ser fundidas a fim de se estimar a melhor sequência de empilhamento de acordo com as frequências que excitam a estrutura. $\mathrm{O}$ objetivo seria maximizar a diferença absoluta entre as frequências naturais da estrutura e as frequências de excitação através da mudança da orientação das fibras sobre as lâminas. Sendo assim, para a escolha do laminado haveria uma redução ainda maior do tempo de projeto e portanto acarretaria numa maior redução de custo. 


\section{CAPÍTULO 6}

\section{CONCLUSÕES E SUGESTÕES}

Os resultados obtidos experimentalmente e numericamente levam às seguintes conclusões:

-O comportamento dinâmico de vigas feitas de material compósito com diferentes sequências de empilhamento de lâminas leva a obtenção de diferentes FRFs (Função de Resposta em Frequência) conduzindo portanto a diferentes frequências naturais e diferentes fatores de amortecimento modal para estruturas com mesma geometria, massa e condições de contorno especificadas. Desta forma, para se obter uma estrutura mais amortecida não é necessário aumentar a fração volumétrica de matriz; pode-se alterar a orientação das fibras sobre as lâminas bem como o sequenciamento chegando assim a resultados desejáveis. Vale ainda ressaltar que aplicação de compósitos em estruturas mais complexas pode reduzir o número de subestruturas que por consequência leva a uma redução no número de montagens e melhora o desempenho do componente;

-Confrontando valores experimentais com valores numéricos obtidos via Método dos Elementos Finitos, verificou-se que para algumas frequências os valores são coerentes. Entretanto para outros ocorre uma certa divergência. Isto leva a necessidade de aprimorar os dados de entrada de propriedades do material para a análise. Portanto, para um cálculo mais preciso das propriedades da lâmina faz-se necessário o uso de dados dos fabricantes de fibra e de resina, ou então obter tais propriedades através de ensaios normalizados como os refenciados pela ASTM D3039/ D3039M - 95 a(1995). Outra maneira de melhorar a convergência é propor um modelo de amortecimento mais realístico, para o cálculo das frequências naturais amortecidas. Outra fonte de erro reside no fato que a análise numérica considerou lâminas com fios unidirecionais, e as vigas ensaiadas foram feitas a partir de tecidos bidirecionais o que certamente leva a resultados divergentes; 
-Para garantir que os modos de vibrar sejam bem detectados pode-se realizar uma varredura transversal com os acelerômetros ( 2 pontos no mínimo) para assim obter com maior precisão variações de inclinação transversal da amostra, podendo-se também usar acelerômetros angulares para garantir a captação dos modos de torção. Além disso, pode-se fazer uma varredura na direção longitudinal da viga com os acelerômetros, desta forma é possível se ter uma leitura mais precisa das formas de vibrar da estrutura, evitando assim a realização de leituras sobre linhas nodais. Vale ressaltar que a análise numérica via Método dos Elementos Finitos pode fornecer uma boa estimativa para se posicionar os acelerômetros fora dessas linhas nodais;

-Como as amostras são muito flexíveis, verificou-se que em alguns instantes o acelerômetro causou uma pequena deflexão estática na amostra, vindo alterar alguns resultados devido ao acréscimo de massa modal. Uma opção então, seria utilizar um acelerômetro de massa inferior ou produzir amostras mais espessas. Poder-se-ia também concentrar uma massa no modelo simulado na posição correspondente ao acelerômetro;

-Os materiais compósitos possuem características atrativas para projetos, principalmente quando são projetados de maneira otimizada. Uma das grandes vantagens reside no fato de que é possível alterar as frequências naturais e os fatores de amortecimento modal da estrutura sem acrescentar massa, bastando para tal alterar a sua rigidez através da mudança da orientação das fibras e do sequenciamento das lâminas. Isto é visualizado através do ciclo de projeto proposto no capítulo 5 que fornece uma espécie de guia para o projetista desenvolver um produto a base de compósito polimérico reforçado. Entretanto, pode-se melhorar ainda mais tal ciclo, criando rotinas computacionais de otimização e modelando o amortecimento para se obter um projeto otimizado de maneira rápida e que satisfaça aos requisitos de desempenho do componente. Isto torna-se bastante interessante, pois minimiza-se tempo e custos para se chegar ao modelo experimental. Entretanto previsões teóricas geralmente não refletem de maneira totalmente realística as condições reais do problema.

-Desta forma, o ciclo de projeto proposto tem como objetivo reunir aspectos positivos da análise teórica com os da análise experimental, possibilitando assim que os resultados otimizados e confiáveis sejam obtidos de maneira rápida e consistente. 


\section{Referências Bibliográficas}

ADAMS, R. D. (1987). Damping properties analysis of composites. In: ENGINEERED MATERIALS HANDBOOK, v.1, Composites, ASM International. Ohio. Library of Congress Catalogin in Publication Data. p.206217.

AHMADIAN, R.A.; MANTENA, P. R. (1996). Modal investigation of pultruded hybrid composite frame structures using experimental and finite element methods.In: IMAC (INTERNATIONAL MODAL ANALYSIS CONFERENCE), 14.,Dearborn, 1996. Proceedings. Michigan, v.2, p.907-913.

ANSYS USER'S MANUAL (1995). Procedures, v.I.

ANSYS USER'S MANUAL (1995). Theory, v.IV.

AMERICAN SOCIETY OF MECHANICAL ENGINEERING (1986). ASME. Boiler and Pressure Vessel Code. Section I. New York

AMERICAN SOCIETY FOR TESTING AND MATERIALS (1995). ASTM. D3039/D3039M - 95 a. - Standard test method for tensile properties of polymer matrix composite materials.In: Annual book of ASTM standards.

Philadelphia. v.14.02, p.1-10.

BANERJEE, J. R.; WILLIAMS, F. W. (1996). Exact dynamic stiffness matrix for composite Timoshenko beams with applications. Journal of Sound and Vibration, v.194, n.4, p.573-585. 
BAPTISTA, L. H. (1995). Uma contribuição para a análise da estabilidade contra trepidação de máquinas ferramentas. São Carlos. 157p. Dissertação (Mestrado) Escola de Engenharia de São Carlos, Universidade de São Paulo.

BLASS, A. (1985). Processamento de polímeros. Florianópolis, Editora da UFSC.

BRITISH STANDARDS INSTITUTION (1987). BS 4994 - Design and construction of vessels and tanks in reinforced plastics. London. UK.

CALLISTER Jr., W. D. (1985). Materials science and engineering. New York, John Wiley \& Sons.

CARVALHO, J. (1996). Computer integrated design optimisation and manufacturing of filament wound parts. Tese (Doutorado) - Faculty of Applied Sciences, Division PMA, K.U. Leuven .

CLOUGH, R.W.; PENZIEN, J. (1975). Dynamics of structures. New York, McGraw-Hill.

CRAIG, R. R. Jr (1981). Structural dynamics: an introduction to computer methods. New York, John Wiley \& Sons.

CUDNEY, H.H.; INMAN, D.J. (1989). Experimental verification of damping mechanisms in a composite beam. In: IMAC(INTERNATIONAL MODAL ANALYSIS CONFERENCE), 7., Las Vegas, 1989.Proceedings. Nevada, v.1, p.704-710.

DHARAN, C.K.H. (1979). Composite materials design and processes for automotive aplications. Ford Aerospace and Comunications Corporation. Palo Alto. California. p.19-30.

DIRETRIZES PARA ELABORAÇÃO DE DISSERTAÇÕES E TESES NA EESC/USP. (1996). Serviço de Biblioteca. 2.ed., São Carlos, Brasil. 
DU PONT COMPANY TEXTITLE. (1981). number 428 - vibration of kevlar49 (aramid), graphite and fiber glass, fibers and composite reinforced with these fibers. Fibers Department Preliminary Information. Wiligton, Delaware.

ENGINEERED MATERIALS HANDBOOK (1987) ASM International, v.1 Composites. Library of Congress Catalogin in Publication Data.

ESLIMY-ISFAHANY S.H.R.; BANERJEE J.R. (1997). Dynamic response of composite beams with application to aircraft wings. Journal of Aircraft, v.34, n.6, p.785-791

EWINS, D. J. (1984). Modal testing: theory and practice. London, Research Studies Press Ltd.

FRONK, T. H. et al. (1995). Finite element modeling of damping in constrained layer composite structures induced by inplane loads using ADINA. Computers \& Structures, v.56, n.2/3, p.357-363.

GHOSH, P. et al. (1997). Dynamic mechanical analysis of FRP composites based on different fiber reinforcements and epoxy resin as the matrix material. Journal of Applied Polymer Science, v.64, n.12, p.2467-2472.

GREIF, R.; HEBERT, B. (1992). Experimental techniques for dynamic characterization of composite materials. Advances in Experimental Mechanics and Biomimetics (ASME - 1992), AD-v.49/AMD-v.146, p. 83-97.

HANDBOOK of COMPOSITES (1982). London, Van Nostrand Reinhold Company.

HE, L.; WANG, I.; TANG, D. (1993). Dynamic Responses of Aircraft Wing Made of composite materials. In: IMAC (INTERNATIONAL MODAL ANALYSIS CONFERENCE), 11., Kissimme, 1993.Proceedings. Florida, v.2, p.1342-1346. 
HU, B.G.; DOKAINISH, M.A. (1993). Damped vibrations of laminated composite plates - modeling and finite element analysis. Finite Elements in Analysis and Design. n. 25, p.103-124.

HUEBNER, K.H. (1994).The finite element method for engineers. New York, John Wiley \& Sons.

HULL, D. (1981). An introduction to composite materials. London, Cambridge University Press.

HWANG, W.;YANG, M.;WU, Y.; SOONG, K. (1992). An experimental-numerical techinique for study of the dynamic characteristics of composite plates. Journal of the Chinese of Mechanical Engineers, v.13, n.14, p.299-307.

KIM, M.J.; GUPTA, A. (1990). Finite element analysis of free vibrations of laminated composite plates. In: IMAC (INTERNATIONAL MODAL ANALYSIS CONFERENCE),8., Kissimmee, 1990. Proceedings.Florida. v.1, p.522-528.

KHATRI, K. N. (1995). Vibrations os arbitrarily laminated fiber reinforced composite material truncated conical shell. Journal of Reinforced Plastic and Composites. v.14, p.923-948.

KOO, K.N.; LEE, I. (1995) Dynamic behavior of thick composite beams. Journal of Reinforced Plastics and Composites, v. 14, p.196-210, March.

LIRANI, J. (1985). Determinação da estabilidade teórica contra trepidação de máquinas-ferramentas com o auxílio de computador. São Carlos. 219p. Tese (Livre-Docência) - Escola de Engenharia de São Carlos, Universidade de São Paulo.

LOSSIE, M. (1990). Production Oriented Design of Filament Wound Composites. Tese (Doutorado), Faculty of Applied Sciences, Division PMA, K.U.Leuven. 
LUCATO, D. (1991). Contribuição ao projeto e validação de trem de pouso, tipo Wittman, em lâmina ortotrópica transversa de material compósito vidro e epoxi, para aeronaves enquadradas no F.A.R. PART-23. São Carlos. Tese (Doutorado) - Escola de Engenharia de São Carlos, Universidade de São Paulo.

MATLAB User's Guide (1996). The Math Works, USA.

MATTHEUS F.L.; RAWLINGS R.D. (1994). Composite Materials Engineering and Science. London, Chapman \& Hall.

McCONNELL, K. G. (1995). Vibration testing (Theory and Practice). New York, John Wiley \& Sons.

MEIROVITCH,L. (1967). Analytical methods in vibrations. London, CollierMacmillan limited.

NEWLAND, D. E. (1987). On the modal analysis of non-conservative linear sytem. Journal of Sound and Vibration, v.112,n.1, p.69-96.

OWENS-CORNING WORLD (1994) Textile fibers for industry (ficha técnica). Fiber Tower - Toledo - Ohio

QIAN, G.; HOA, S. V. \& XIAO, X. (1997). A vibration method for measuring mechanical properties of composite, theory and experiment. Composite Structures. v.39, n.1-2, p.31-38.

RAO, S. R.; GANESAN, N. (1997). Dynamic response of non-uniform composite beams. Journal of Sound and Vibration. v.200, n.5, p.563-577.

RIKARDS, R.; CHATE, A. \& BARKANOV, E. (1993). Finite element analysis of damping the vibrations of laminated composites. Computers \& Structures, v.47, n.6, p.1005-1015. 
ROSEN, B.W.; DOW, N.F. (1987). Overview of composite materials and design. In: ENGINEERED MATERIALS HANDBOOK, v.1, Composites, ASM International, Ohio. Library of Congress Catalogin in Publication Data. p.175180.

SAHA, N. \& BANERJEE, A. (1998). Dynamic mechanical study on unidirectional polyethylene-carbon fibers: PMMA hybrid composite laminates. Journal of Applied Polymer Science, v.67, p.1631-1637.

SHACKELFORD, J. F. (1996). Introduction to materials science for engineers. New York, John Wiley \& Sons.

THOMSON, W. T. (1973). Teoria da vibração com aplicações. Rio de Janeiro, Interciência.

TSAI, S. W. (1986). Composites design. Dayton. United States Air Force Materials Laboratory. THINK COMPOSITES.

TSAI, S. W. \& HANH, H. T. (1980). Introduction to composite materials. Pennsylvania. Technomic Publishing Company. Inc. Lancaster

UMEKAWA S.; MOMOSHIMA S. (1992). Composites in Japan. Composite Engineering, v.2, n.8, p.677-690.

VAROTO, P. S. (1991). Análise modal no domínio da frequência: um método de identificação de multi-modos. São Carlos. 192p. Dissertação (Mestrado) Escola de Engenharia de São Carlos, Universidade de São Paulo.

VINSON, J.R.; SIERAKOWSKI, R.L. (1986). Behavior of structures composed of composite materials. Dordrecht, Martins Nijhoff.

WANG, A.S.D. (1987). Strength, failure, and fatigue analysis of laminates. In: ENGINEERED MATERIALS HANDBOOK, v.1, Composites, ASM International. Ohio. Library of Congress Catalogin in Publication Data. p.236251. 
WILLING, J.(1993). How to design composite parts. Focus. English Edition.p.11-14

ZABARAS, N.; PERVEZ, T. (1990). Viscous damping aproximation of laminated anisotropic composite plates using the finite element method. Computer Methods in Applied Mechanics and Engineering, n.81, p.291-316.

ZAPFE, J. A.; LESIEUTRE, G. A. (1997). Vibrations analysis of laminated beams using an interative smeared laminate model. Journal of Sound and Vibration. v.199, n.2, p.275-284. 


\section{APÊNDICE A}

\section{ANÁLISE DE MATERIAL COMPÓSITO UTILIZANDO ANSYS 5.2}

O ANSYS é um pacote comercial de Elementos Finitos que permite análises de estruturas através da simulação de um modelo teórico computacional. O seu "solver" é capaz de realizar análises estruturais estáticas e dinâmicas, linear ou não-linear. Ele também inclui análises de transferência de calor, bem como fluídicas e eletromagnéticas. Os prés e pósprocessadores também estão inclusos no pacote, mas podem ser executados através de outros programas, tais como o PRO-ENGINEER (PTC).

Este apêndice trata da análise de material compósito via ANSYS versão 5.2. Porém informações adicionais podem ser encontradas no ANSYS User's Manual (1995).

\section{Elementos}

O ANSYS 5.2 possui 3 elementos específicos para modelagem de componentes feitos de material compósito. O primeiro é denominado SHELL99, ele é um elemento do tipo casca que possui 8 nós e cada um desses nós têm 6 graus de liberdade (deslocamento e rotação em torno dos eixos $\mathrm{x}, \mathrm{y}$ e z) além de permitir a montagem de até 100 camadas o que o torna atrativo para modelos espessos. O segundo é denominado SOLID46, ele é um elemento hexaédrico que possui 8 nós e cada um desses nós tem 3 graus de liberdade (deslocamento nos eixos $\mathrm{x}, \mathrm{y}$ e $\mathrm{z}$ ) e além de permitir a montagem de mais de 100 camadas o que o torna atrativo para modelos tridimensionais. Para finalizar, o terceiro é denominado SHELL91; ele é similar ao SHELL99 porém permite a montagem de apenas 16 camadas que suportam efeitos de plasticidade, isto o torna atrativo para modelos mais finos.

O pacote permite a especificação de cada camada que pode ser analisada como um material ortotrópico, podendo as propriedades assumirem valores diferentes de acordo com a orientação das fibras no laminado. As propriedades que podem ser especificadas são: 
EX = módulo de Young na direção da fibra;

$\mathrm{EY}=$ módulo de Young perpendicular à fibra;

$\mathrm{EZ}=$ módulo de Young perpendicular ao plano do laminado;

GXY = módulo de cisalhamento no plano do laminado;

GYZ = módulo de cisalhamento no plano perpendicular ao laminado;

$\mathrm{GXZ}=$ módulo de cisalhamento no plano perpendicular ao laminado;

NUXY = coficiente de Poisson na direção $\mathrm{x}$;

NUYZ = coficiente de Poisson na direção y;

NUXZ = coficiente de Poisson na direção $\mathrm{z}$;

DAMP $=$ amortecimento;

DENS = densidade do compósito;

THETA = ângulo de orientação das fibras na lâmina;

TK = espessura da lâmina

O elemento SHELL99 foi escolhido para as análises e a FIGURA (A-1) mostra o elemento com mais detalhes:

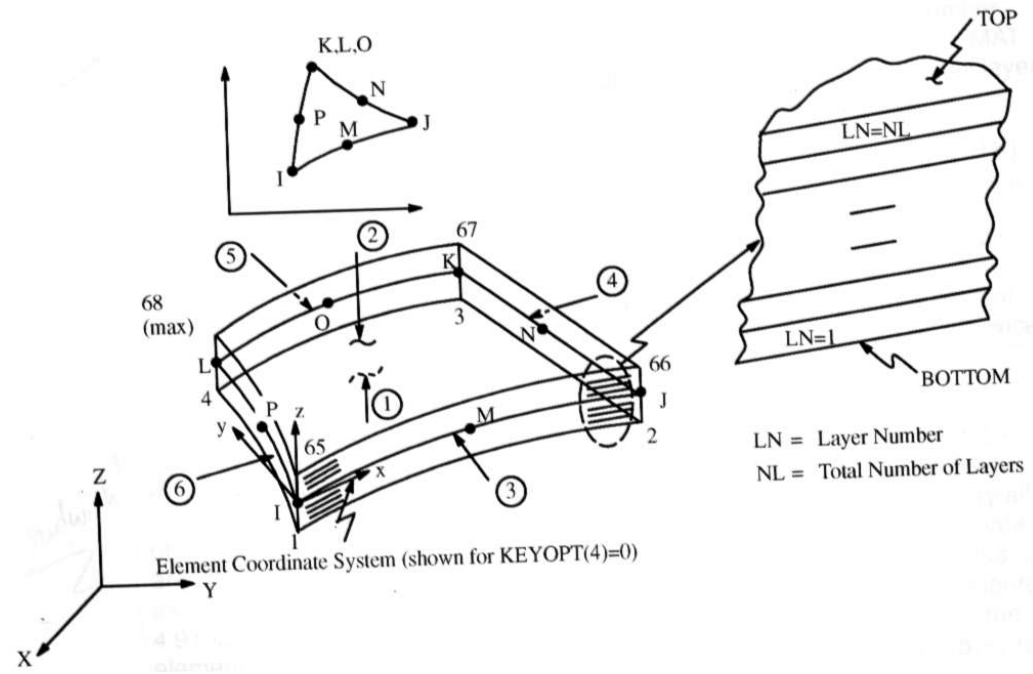

FIGURA (A-1) - Elemento SHELL 99

ANSYS User's Manual (1995) 


\section{Carregamentos e Restriç̃es}

Os carregamentos de força podem ser aplicados nos nós, ou distribuídos sobre as arestas. Os carregamentos de pressão são distribuídos nas superfícies dos elementos bi ou tridimensionais, além disso pode-se colocar efeitos da aceleração da gravidade ou acelerações centrífugas. As restrições podem ser impostas como vinculações em nós ou através da retirada de alguns graus de liberdade. A FIGURA (A-2) mostra que os resultados destes carregamentos são tensões que podem ser obtidas nas diversas lâminas do conjunto.

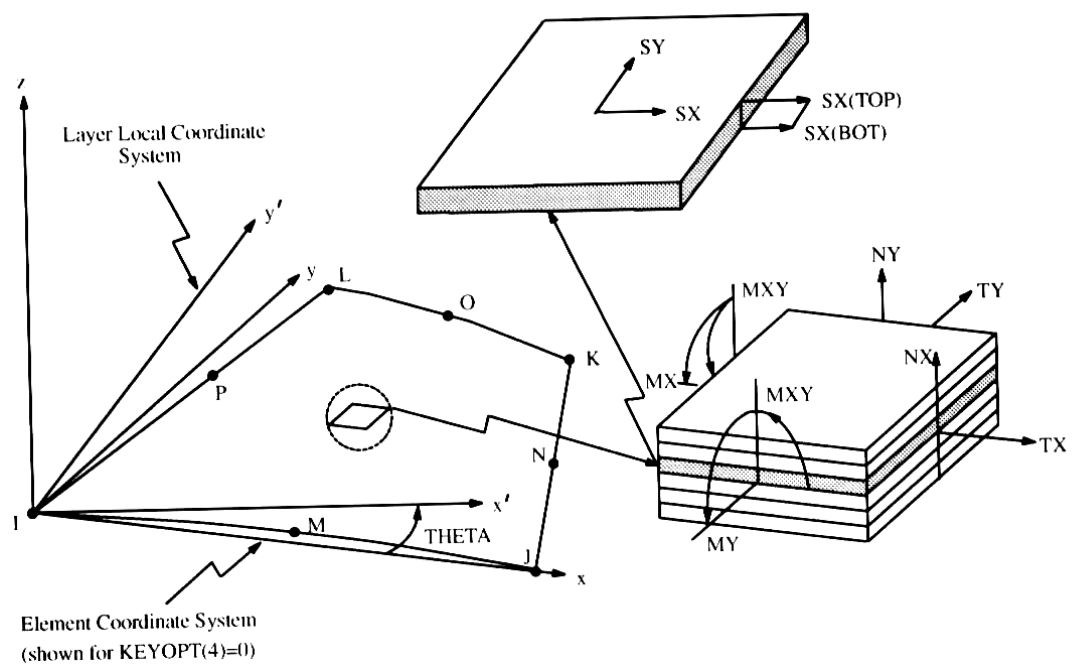

FIGURA (A-2) - Tensões nas lâminas

ANSYS User’s Manual (1995) 


\section{APÊNDICE B}

\section{ANÁLISE MODAL UTILIZANDO ANSYS 5.2}

O ANSYS User's Manual (1995) assume que para a determinação das frequências naturais não amortecidas e modos de vibrar faz-se necessário a solução da seguinte equação de movimento para uma estrutura não amortecida:

$$
[\mathrm{M}]\{\ddot{\mu}\}+[\mathrm{K}]\{\mu\}=\{0\}(\mathrm{B}-1)
$$

Para um sistema linear, as vibrações serão de forma harmônica:

$$
\{\mu\}=\{\phi\}_{\mathrm{i}} \cos \{\phi\}_{\mathrm{i}} \cos \omega_{\mathrm{i}} \mathrm{t}
$$

onde:

$\{\phi\}_{i}=$ representa o autovetor do modo de vibrar da $i^{\text {tn }}$ (i-ésima) frequência natural.

$\omega_{\mathrm{i}}=\mathrm{i}$-ésima frequência natural circular (radianos por unidade de tempo)

$\mathrm{t}=$ tempo

Então, a equação (B-2) torna-se:

$$
\left(-\omega_{\mathrm{i}}^{2}[\mathrm{M}]+[\mathrm{K}]\right)\{\phi\}_{\mathrm{i}}=\{0\}
$$

Esta igualdade é satisfeita se:

$$
\{\phi\}_{\mathrm{i}}=\{0\} \text { ou det }\left([\mathrm{K}]-\omega^{2}[\mathrm{M}]\right)=0
$$

A primeira opção é a trivial, então optando pela segunda tem-se:

$$
\left|[\mathrm{K}]-\omega^{2}[\mathrm{M}]\right|=0
$$


Isto é um problema de autovalor ao qual pode ser resolvido para $n$ valores de $\omega^{2}$ e $n$ autovetores, que satisfazem a equação (B-5) onde n é o número de graus de liberdade. Raramente o resultado é dado em $\omega[\mathrm{rad} / \mathrm{s}]$, mas sim em $\mathrm{f}[\mathrm{Hz}]$ :

$$
\mathrm{f}_{\mathrm{i}}=\frac{\omega_{\mathrm{i}}}{2 \pi} \quad(\mathrm{B}-6)
$$

onde:

$\mathrm{f}_{\mathrm{i}}$ - frequência natural do i-ésimo modo (ciclos por unidades de tempo $=\mathrm{Hz}$ )

Vale ressaltar que o pacote de análise numérica oferece a opção de que cada autovetor $\{\phi\}_{\mathrm{i}}$ seja normalizado tendo como maior componente a unidade. Além disso, ele possibilita a extração de quantas frequências naturais o usuário desejar. 


\section{GLOSSÁRIO}

Tem-se como objetivo mostrar nesta seção alguns termos costumeiramente utilizados em trabalhos que abordam materiais compósitos.

Absorção de umidade: Incorporação da umidade do ar pelo material.

Absorvedor (Bleeder): Todo material utilizado em modelagem a vácuo com a finalidade de absorver o excesso de resina. $\mathrm{O}$ absorvedor é posicionado sobre o laminado e separado por um filme desmoldante poroso ou perfurado.

Acelerador (Promoter; Accelerator): Substância que acelera uma reação química sem sofrer alteração na sua constituição.

Adesão (Adhesion): Estado no qual duas superfícies são mantidas juntas em uma interface.

Adesivo com cura à temperatura ambiente (Room temperature curing adhesives): Resina adesiva sintética capaz de sofrer endurecimento à temperatura ambiente na presença de catalisador.

Aditivo (Additive): Qualquer substância adicionada à outra, visando melhorar as propriedades química, física, mecânica.

Agente de cura (Curing agent): Agente catalítico ou reativo que, quando adicionado à resina, causa a sua cura.

Agente desmoldante (Release agent): Material aplicado na superfície do molde, formando um filme que tem a finalidadede evitar a adesão da resina ao molde.

Aglutinante (Mat Binder): Resina aplicada à fibra de vidro, durante o processo de fabricação, para mantê-las no lugar, conservando a forma de manta.

Ângulo de saída (Draft Angle): Ângulo feito pela tangente à superfície de saída de um molde e a direção de saída.

Anisotrópico (Anisotropic): Material que exibe diferentes propriedades ao longo de eixos em diferentes direções (anisotropia).

Área rica em resina (Resin rich area): Região com um conteúdo de resina acima de um limite estabelecido. 
Área seca (Resin starved area): Área do compósito que possui quantidade insuficiente de resina para umedecer completamente o reforço.

Nota: Esta condição pode ser devida à impregnação não apropriada ou pressão de moldagem excessiva.

Atmosfera-padrão (Standard laboratory atmosphere): Atmosfera tendo umidade relativa de $(50 \pm 2) \%$, à temperatura de $(23 \pm 1)^{0} \mathrm{C}$. Também é padrão nas seguintes condições:

condição média: $40 \%$ U.R. a $25^{\circ} \mathrm{C}$;

condição média: $15 \%$ U.R. a $25^{\circ} \mathrm{C}$;

condição média: $75 \%$ U.R. a $25^{\circ} \mathrm{C}$;

Autoclave (Autoclave): Vaso fechado que permite a aplicação de pressão para a compactação do laminado e de calor para promover a cura da resina.

Bolha de ar (Air-bubble void): Aprisionamento de ar dentro e entre as camadas de reforço não interconectadas e de formato esférico.

Bolhas superficiais (Air Locks): Depressões superficiais sobre uma parte moldada, causada pelo aprisionamento do ar entre a superfície do molde e o material plástico.

Bolsa de vácuo (Vacuum bag): Montagem utilizada na moldagem a vácuo.

Camada de descolamento (Peel ply): Camada externa de um laminado, a qual deve ser removida ou sacrificada para proporcionar melhor adesão de camadas adicionais.

Camada laminada (Lamina; Layer; Plyer): Cada uma das camadas do laminado.

Canalizador (Breather): Todo material utilizado em moldagem a vácuo para assegurar uma distribuição do vácuo sob a bolsa e para facilitar a saída de voláteis.

Carga biaxial (Biaxial load): Condição na qual um laminado é tensionado em duas direções diferentes no plano do laminado.

Casca-de-laranja (Orange peel): Superfície não uniforme que lembra a casca-de-laranja.

Catalisador (Catalyst): Substância que ativa uma reação química.

Ciclo (Cycle): Sequência completa ou repetição de operações em um processo ou parte de um processo.

Ciclo de montagem (Molding cycle): Período de tempo necessário para a realização de uma sequência completa de operações de moldagem que resultem na produção de uma determinada peça.

Coesão (Cohesion): Propensão de uma substância aderir a si mesma, através da atração interna entre partículas a nível molecular.

Colméia (Honeycomb): Estrutura formada de células abertas, normalmente com forma hexagonal. 
Compósito (Composite): Material criado pela combinação adequada ou especial de dois ou mais materiais para obter propriedades e características específicas que podem ser:

laminares: compósitos de camadas de componentes laminares;

particulados: onde a fase dispersa é feita de pequenas partículas;

fibrosos: onde a fase dispersa consiste em fibras;

flocosos: onde a fase dispersa consiste em flocos;

de esqueleto: onde há um esqueleto de matriz contínua, preenchido por um segundo material.

Compósito de moldagem reforçado (Reinforced molding compound): Compósito fornecido pelo produtor de matéria-prima, na forma de materiais prontos para a utilização.

Construção-sanduíche (Sandwich contruction): Compósito constituído por núcleo de material de baixa densidade e laminados relativamente finos nas faces.

Conteúdo de vazios (Void content): Porcentagem de vazios em um laminado, determinada pela seguinte equação:

Porcentagem de vazio $=100-x$

$$
\begin{aligned}
& x=\frac{a d}{c}+\frac{a e}{b}, \text { onde } \\
& \mathrm{x}=\text { volume total calculado para o laminado } \\
& \mathrm{a}=\text { massa específica do laminado } \\
& \mathrm{b}=\text { massa específica da fibra } \\
& \mathrm{c}=\text { massa específica da resina curada } \\
& \mathrm{d}=\text { conteúdo de resina } \\
& \mathrm{e}=\text { conteúdo de fibra }=1-\mathrm{d}
\end{aligned}
$$

Se o laminado contêm uma carga:

$$
x=\frac{a d}{c}+\frac{a e}{b}+\frac{a f}{g} \text {, onde }
$$

e $=$ conteúdo de fibra $=1-\mathrm{d}-\mathrm{f}$

$\mathrm{f}=$ conteúdo de carga

$\mathrm{g}=$ massa específica da carga

Corpo de prova (Specimen): Parte individual ou uma porção de uma amostra usada para um determinado ensaio, possuindo forma e dimensões especificadas.

Cura (Cure): Mudança irreversível das propriedades da resina por reação química. Após a cura, a resina passa ter o comportamento de termofixo. Além disso, a cura é obtida 
normalmente pela adição de um catalisador para dar início ao processo. A ativação deste catalisador pode ser feita por ação do calor ou pela adição de um acelerador.

Deformação plástica (Plastic deformation): Mudança nas dimensões de um material sob carga, que não é recuperada quando esta carga é removida.

Delaminação (Delamination): Separação de um laminado ao longo do plano entre suas camadas, devido à perda de adesão entre estas.

Desmoldagem (Demolding): Processo de remoção da peça moldada do molde por meios mecânicos, manual ou uso de ar comprimido.

Direção longitudinal (Lengthwise direction): Orientação referente às operações de corte ou aplicação de cargas, onde:

-para tarugos, é a direção do eixo mais longo;

-para outros materiais de forma diferentes, com resistências diferentes em cada direção longitudinal, é a direção mais resistente;

-para os materiais igualmente resistentes em todas as direções, a longitudinal pode ser arbitrada com relação à granulação, direção de escoamento na fabricação, direção mais longa, etc.

Direção transversal (Crosswise direction): Orientação referente às operações de corte ou aplicação de cargas, onde:

-para tubos e cabos, é a direção perpendicular ao eixo maior;

-para sistemas que possuam resistência maior em uma direção que em outra, é a direção de menor resistência.

Distância de bordo (Edge distance): distância do centro de um orifício à borda do componente na direção da tensão principal em termos de diâmetros do orifício.

Dobra (Wrinkle): Imperfeição da superfície em plásticos laminados que tem a aparência de um vinco ou dobra em uma ou mais camadas.

Eliminação do recobrimento superficial (Desizing): Processo de retirada do recobrimento superficial de uma fibra.

Endurecedor não tóxico (Safety hardener): Endurecedor de resinas cujos danos à saúde humana são mínimos.

Envelhecimento (Aging): Efeito das condições ambientais nas propriedades e características de um determinado material, em um intervalo de tempo definido.

Estabilidade dimensional (Dimensional stability): Propriedade de um material reter a forma precisa na qual ele é fabricado. 
Estruturas-sanduíche (Sandwich contructions): Painéis compostos por materiais leves de enchimento (colméias, espumas, etc.), aos quais duas faces finas, densas e de alta resistência são aderidas.

Falha catastrófica (Catastrophic failure): Falha mecânica que cessa com a capacidade do componente de resistir aos esforços solicitantes.

Fator de concentração de tensão ou entalhe (Notch factor): Razão entre a resistência determinada na amostra lisa e a resistência determinada na amostra com entalhe.

Fibras moídas (Milled fibers): Fibras contínuas moídas por martelo até um pequeno módulo de vidro filamentado, utilizadas como aditivo antifissuramento aos adesivos.

Fixação de resfriamento (Cooling fixture): Fixação usada para manter a forma ou tolerância dimensional de uma peça moldada ou encapsulada, após esta ser removida do molde, até o material estar frio o bastante para reter sua forma.

Gramatura (Weight per area): Massa por unidade de área.

Intemperismo (Weathering): Exposição de um material ao ambiente externo.

Interface (Interface): Ponto ou superfície de junção entre dois meios diferentes, sendo nas fibras de vidro, a área de contato entre o vidro e o acabamento e, nos laminados, a área de contato entre o reforço e a resina de laminação.

Junção (Joint): Local onde dois materiais são fixados entre si.

Laminação (Lay-up): Nos compósitos, consiste na reposição das camadas de reforço impregnadas com a resina sobre o molde previamente preparado.

Laminado (Laminate): Produto formado pela adesão de duas ou mais camadas de reforço, através da matriz polimérica.

Laminado anisotrópico (Anisotropic laminate): Laminado no qual as propriedades mecânicas são diferentes em direções diferentes.

Laminado balanceado (Balanced laminate): Todos os laminados simétricos que apresentam pares de camadas (não necessariamente adjacentes), orientadas em direções positiva e negativa em relação a um eixo.

Laminado bidirecional (Bi-directional laminate): Laminado de compósito com as fibras orientadas em várias direções no plano do laminado. É também um laminado cruzado.

Laminado cruzado (Cross laminate): Laminado no qual algumas camadas tem as fibras orientadas em ângulos retos com relação às restantes.

Laminado híbrido (Hybrid composite): Laminado constituído por dois ou mais tipos diferentes de fibras.

Laminado isotrópico (Isotropic laminate): Laminado que possui as propriedades mecânicas iguais em todas as direções. 
Laminado paralelo (Parallel laminated): Laminado em que todas as camadas do material são orientadas aproximadamente paralelas com respeito à direção mais resistente à tração.

Laminado simétrico (Symmetric laminate): Laminado no qual as camadas estão dispostas de modo a apresentar um plano de simetria entre elas.

Laminado unidirecional (Unidirecional laminate): Laminado de compósito contituído por fibras, no qual todas as fibras estão orientadas praticamente em uma única direção.

Ligante (Blinder): Resina ou qualquer outro material aglutinante, utilizado na fabricação de mantas, pré-formas e pré-impregnados, que tem como finalidade manter a geometria e o arranjo das fibras até o momento da moldagem de peças.

Manta (Mat): Material fibroso para compósitos que consiste em fibras picadas, orientadas aleatoriamente, ou em fibras nuas emaranhadas, mantidas com um aglutinante, com níveis em lençóis de várias larguras, massas e comprimentos.

Materiais orientados (Oriented materials): Materiais, particularmente polímeros e compósitos amorfos, cujas moléculas e/ou macroconstituintes são alinhados segundo uma orientação específica. Os materiais orientados são anisotrópicos.

Módulo de perda (Loss modulus): Termo de amortecimento que descreve a dissipação de energia na forma de calor, quando um material sofre deformação.

Moldagem (Molding): Conformação de composição plástica dentro do molde, normalmente acompanhada de aquecimento e pressão.

Moldagem a vácuo (Vacuum bag molding): Processo para moldagem de compósitos, no qual um filme de material flexível transparente é posicionado sobre o laminado, onde o vácuo é aplicado entre o filme de material flexível e laminado. $\mathrm{O}$ ar presente nas entranhas é mecanicamente expulso do laminado e removido pelo vácuo.

Moldagem por moldes ajustados (Matched metal molding): Processo para moldar os compósitos, no qual são usados um molde macho e outro fêmea, metálicos como na moldagem por compressão para formar a peça contrariamente à laminação por baixa pressão, ou então, spray-up.

Molde (Mold): Cavidade ou matriz dentro do qual o material plástico é colocado para ser formado, submetido ou não a aquecimento ou pressão

Monofilamento (Monofilament): Fibra isolada ou comprimento indefinido, que serve como fio em operação têxtil normal.

Núcleo (Core): Membro central de uma contrução-sanduíche no qual as faces do sanduíche são fixadas. Normalmente, o núcleo é colméia ou material rígido de células fechadas.

Ondulação da fibra (Crimp): Ondulação natural de um conjunto de filamentos contínuos não tensionados. 
Plástico rígido (Rigid plastic): Plástico que tem módulo de elasticidade em flexão ou tração superior a $70 \mathrm{MPa}$, à temperatura ambiente e $50 \%$ de umidade relativa.

Pós-cura (Post-cure): Cura adicional à temperatura elevada, usualmente sem pressão, para melhorar propriedades finais e/ou completar a cura.

Pot life (Tempo útil de manuseio): Tempo necessário para que o sistema de resina formulado retenha a viscosidade em níveis baixos o suficiente para ser utilizada no processamento.

Prensa automática (Automatic press): Prensa hidráulica para moldagem por compressão, sendo controlada mecânica, elétrica ou hidraulicamente ou por uma combinação de qualquer um destes métodos.

Pressão de moldagem (Molding pressure): Pressão aplicada ao molde ou prensa.

Pré-cura (Precure): Cura total ou parcial de resina sintética ou de adesivo, antes que a pressão seja aplicada, ou em uma junção, antes que a operação de ferramenta seja completada.

Pré-formagem (Preform): Estabelecimento do formato inicial pela distribuição de fibras picadas por ar ou vácuo sobre uma superfície de uma tela perfurada, para o contorno aproximado e espessura desejada na peça acabada.

Pré-gel (Pregel): Camada extra de resina-curada, que parte da superfície do composto não relacionado ao gelcoat.

Pré-impregnação (Preimpregnation): Ato da mistura de resina e reforço, efetuando cura parcial antes da utilização ou embarque para o usuário.

Premix (Premix): Composição de moldagem preparado antes e à parte das operações de moldagem, contendo todos os componentes necessários para a moldagem em si (resina, reforço, cargas, catalisadores, agentes desmoldantes, etc.).

Razão de aspecto (Aspect ratio): Relação do comprimento pelo diâmetro de uma fibra.

Reação irreversível (Irreversible reaction): Reação química que se procede em uma direção, preferencial sem a possibilidade de reversão, como no caso de resinas termofixas.

Reforço (Reinforcement): Material resistente e inerente que, unido ao polímero, melhora suas características de resistência, rigidez e resistência ao impacto.

Resina (Resin): Material orgânico retido semi-sólido ou pseudo-sólido que tem uma massa molecular indefinida (usualmente alta). E que exibe uma tendência a fluir quando sujeito à tensão.

Resistência ao cisalhamento interlaminar (Interlaminar shear strength): Máxima tensão de cisalhamento existente entre as camadas do material laminado. 
Resistência ao descolamento (Peel strength): Resistência à colagem, obtida pelo rasgamento de uma camada (unidades em força / comprimento).

Resistência de adesão (Bond strength): Medida de tensão requerida para separar a camada de material da base.

Roving (Roving): Coleção de mechas de filamentos contínuos.

Roving tecido (Woven roving): Tecido fabricado com rovings.

Saída (Draft): Inclinação em relação à superfície vertical de um molde, destinada a facilitar a remoção das peças moldadas.

Sensibilidade à concentração de tensão ou sensibilidade ao entalhe (Notch sensitivity): Grau de aumento de tendência à fratura, apresentado por um material devido à presença de não homogeneidades, como entalhe, mudança brusca de seção, trinca, arranhão ou defeito de fabricação.

Sequencia de empilhamento (Lay-up): Descrição dos materiais componentes de um laminado, sua disposição e geometria.

Sobrematerial de moldagem (Cull): Excesso de material expelido quando o molde é fechado.

Taxa de impregnação (Wet-out rate): Tempo requerido para uma resina preencher os interstícios de um material de reforço e umedecer a superfície das fibras de reforço, usualmente determinado por meio de transmissão óptica ou luz.

Tecido (Woven fabric): Produto que resulta do entrelaçamento das fibras.

Tecido não-trançado (Non-woven fabric): Material planar para reforço constituído de fios torcidos ou rovings levemente aderidos.

Temperatura de transição vítrea - Tg (Glass transition temperature - Tg): Temperatura ou faixa de temperatura na qual aumenta a mobilidade molecular, resultando em mudanças significativas nas propriedades de um polímero. Por exemplo: queda no módulo de elasticidade.

Temperatura de cura (Curing temperature): Temperatura na qual um determinado componente é submetido à cura.

Tempo de cura (Curing time): Período de tempo durante o qual um componente é submetido ao calor ou à pressão, ou a ambos, para curar a resina.

Tensão específica (fibras)(Specific stress (fibers)): Carga dividida pela massa por unidade de comprimento do corpo-de-prova.

Tensão interna (internal stress): Tensão criada dentro das camadas adesivas, devida ao movimento dos materiais aderidos em diferentes proporções ou pela contração e expansão das camadas de adesivos. 
Tensão longitudinal crítica (Critical longitudinal stress): Tensão longitudinal necessária para causar escorregamento interno e separação em um fio trançado, ou seja, a tensão necessária para superar o atrito entre as fibras, gerando como resultado do entrelaçamento.

Termofixo (Thermoset): Plástico que, quando curado pela aplicação de calor ou métodos químicos, se transforma em um material não fusível e insolúvel.

Tixotropia (Thixotropy): Propriedades referentes a materiais que estão em estado de gel, quando em repouso, mas fluidos, quando agitados, possuindo alta resistência ao cisalhamento estático e baixa resistência ao cisalhamento dinâmico, simultaneamente, ou seja, a viscosidade diminui com o aumento da taxa de cisalhamento.

Tratamento superficial (Surface treatment): Aplicação de material à fibra durante a operação de conformação ou em processos subsequentes, isto é, acabamento.

Vazios (Voids): Bolsões gasosos entranhados e curados no laminado.

Viscosidade (Viscosity): Propriedade de resistência ao escoamento recebida dentro do corpo de um material, expressa em termos da relação entre a tensão de cisalhamento aplicada e a taxa de deformação por cisalhamento resultante.

Voláteis (Volatiles): Materiais que aparecem na formulação de um tratamento superficial ou resina, que podem ser removidos por evaporação à temperatura ambiente ou a uma temperatura ligeiramente elevada. 